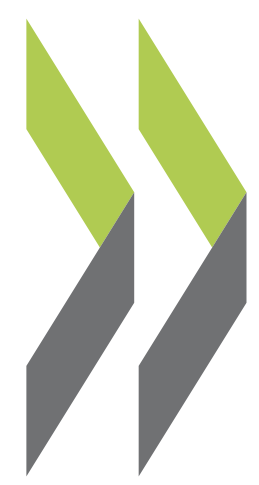

OECD Science, Technology and Industry Working Papers 2016/03

Measuring the Link between Public Procurement and Innovation

\section{Silvia Appelt,}

Fernando Galindo-Rueda 


\section{OECD SCIENCE, TECHNOLOGY AND INDUSTRY WORKING PAPERS}

OECD Working Papers should not be reported as representing the official views of the OECD or of its member countries. The opinions expressed and arguments employed are those of the authors.

This document and any map included herein are without prejudice to the status of or sovereignty over any territory, to the delimitation of international frontiers and boundaries and to the name of any territory, city or area.

Working Papers describe preliminary results or research in progress by the author(s) and are published to stimulate discussion on a broad range of issues on which the OECD works. Comments on Working Papers are welcomed, and may be sent to OECD Directorate for Science, Technology and Innovation, OECD, 2 rue André-Pascal, 75775 Paris Cedex 16, France; e-mail: sti.contact@oecd.org.

The release of this working paper has been authorised by Andrew Wyckoff, OECD Director for Science, Technology and Innovation.

The Statistical data for Israel are supplied by an under the responsibility of the relevant Israeli authorities or third party. The use of such data by the OECD is without prejudice to the status of the Golan Heights, East Jerusalem and Israeli settlements in the West Bank under the terms of international law.

\section{(C) OECD/OCDE 2016}

Applications for permission to reproduce or translate all or part of this material should be made to: OECD Publications, 2 rue André-Pascal, 75775 Paris, Cedex 16, France; e-mail: rights@,oecd.org 


\title{
MEASURING THE LINK BETWEEN PUBLIC PROCUREMENT AND INNOVATION
}

\author{
Silvia Appelt and Fernando Galindo-Rueda \\ OECD Paris
}

\begin{abstract}
This paper presents the findings of a recent OECD project on the measurement of the link between public procurement and innovation. Taking the OECD science and technology measurement frameworks as the starting point, the report highlights what concepts, definitions and measurement approaches can be used, with currently available data or suitably adapted sources, to produce policyrelevant indicators on the use of innovation procurement and carry out empirical analyses on the impact of public procurement on R\&D, innovation and broader economic outcomes. Exploiting recent R\&D and innovation survey data as well as administrative procurement records, the report provides novel multi-country evidence on the incidence of public procurement of innovation by firm size and industry. An exploratory analysis based on linked procurement, company accounts, R\&D, patent and trademark data is employed to showcase the use of combined micro-data sources for analytical applications and points out important links between firm-level procurement activity, R\&D and economic performance. This project has demonstrated:
\end{abstract}

- The relevance of the Oslo Manual framework, subject to potential extensions and complementary guidance, for capturing the role of public demand in driving innovation and the feasibility of asking relevant questions on this subject.

- The case for more widespread available and better-quality procurement records, for accountability and analytical purposes.

- The importance of data-linking as a mechanism for supporting the empirical analysis of the link between public procurement, innovation and business performance.

The conclusions of the project are intended to contribute to the evidence considered in the review and implementation of the OECD measurement frameworks for R\&D and innovation, and may also be of relevance to parallel OECD initiatives aimed at improving the statistical measurement and governance of public procurement policies and practices.

Keywords: public procurement, innovation, $R \& D$, demand-side policies, measurement, statistics 


\section{ACKNOWLEDGEMENTS}

This report has been prepared by Silvia Appelt and Fernando Galindo-Rueda from the Economic Analysis and Statistics Division at the OECD Directorate for Science, Technology and Innovation.

This working paper presents the results of a project on the measurement of the link between R\&D and innovation procurement carried out under the auspices of the Working Party of National Experts on Science and Technology Indicators (NESTI) within the CSTP Programme of Work and Budget for the 2011-12 and 2013-14 biennia and as part of NESTI activities to review the measurement frameworks for $R \& D$ and innovation. The project has benefited from financial support from the European Commission, as part of a collaborative partnership agreement between the OECD and DG Enterprise and Industry (now DG Growth), and the EC-OECD Partnership on Innovation.

The work has benefited from a wide range of contributions from colleagues and experts. NESTI delegates provided valuable inputs throughout various stages of the project, including presentations of the project's results at the NESTI meeting in June 2014. NESTI delegates from Belgium (Jeoffrey Malek Mansour), Portugal (Alexandre Paredes) and Germany (Christian Rammer) kindly shared results from the CIS 2012 survey on the experimental and voluntary questions on public procurement and innovation. Eurostat officials and the participants and consultants engaged in the CIS Task Force were instrumental in helping identify, test and implement these experimental questions in CIS2012. Christian Rammer and his team further volunteered to demonstrate the linking of innovation and administrative procurement data and its use for analytical purposes. Woosung Lee from STEPI prepared a review of the evidence on procurement programmes for Korea. The contribution of expert participants at the two OECD workshops on measuring the link between public procurement and innovation held in Paris in February and December 2013 is gratefully acknowledged, in particular comments received from Elisabeth Pastor and Fred Gault. Colleagues in the OECD Directorate for Public Governance and Territorial Development in charge of measurement and policy analysis of public procurement and in the Science and Technology Policy and the Structural Policy Divisions in DSTI also contributed to these discussions. The authors also wish to thank the project officer at DG ENTR, Bertrand Wert, as well as organisers and participants at events and meetings held in Madrid, Berlin and Brussels where the project was discussed with a view to exchanging new ideas and suggestions. Any errors or omissions are the sole responsibility of the authors. 


\section{TABLE OF CONTENTS}

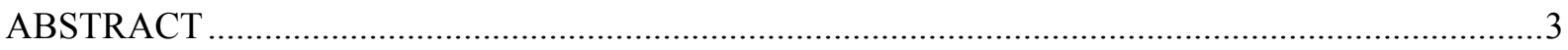

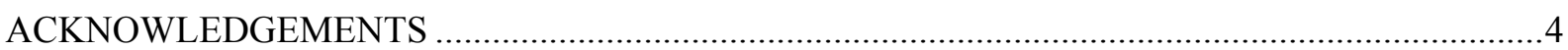

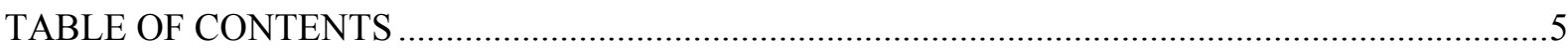

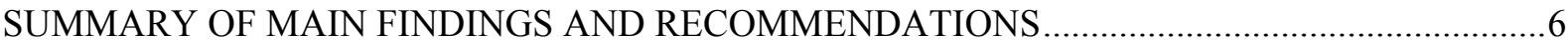

MEASURING THE LINK BETWEEN PUBLIC PROCUREMENT AND INNOVATION ................10

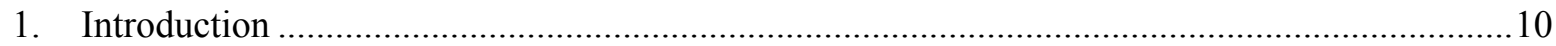

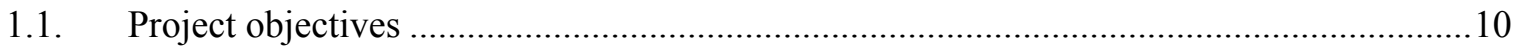

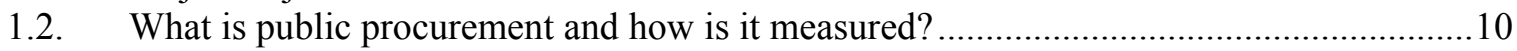

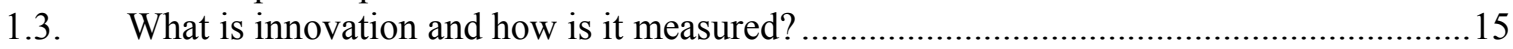

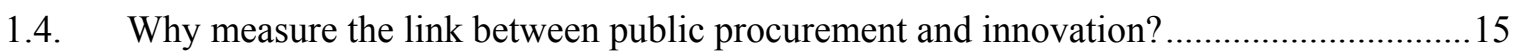

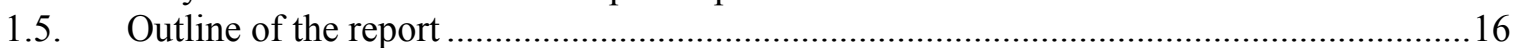

2. The user needs for measuring the link between public procurement and innovation..................16

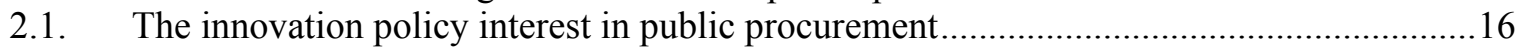

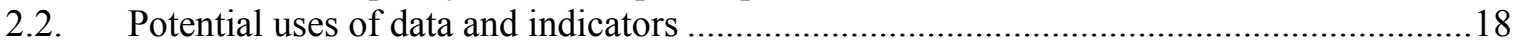

3. Defining and measuring the link between public procurement and innovation .........................21

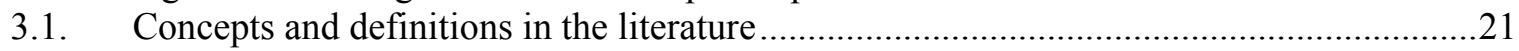

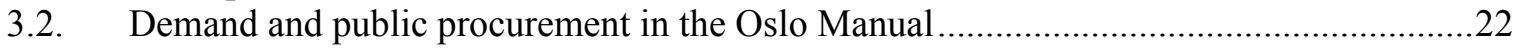

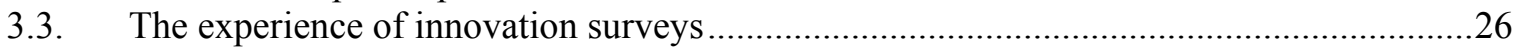

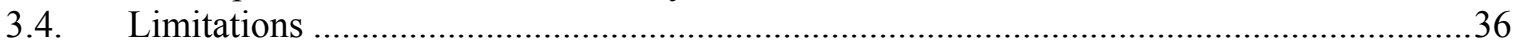

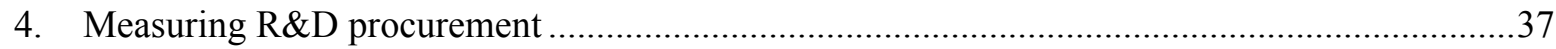

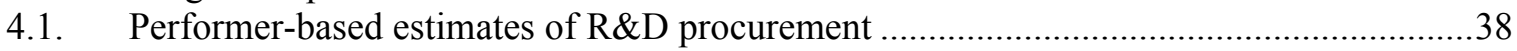

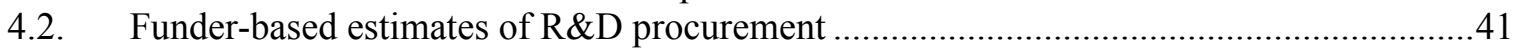

4.3. Comparing performer and funder-based estimates of R\&D procurement .........................42

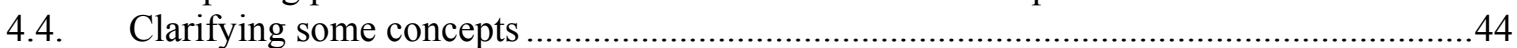

5. Investigating the scope for using administrative procurement sources ...................................46

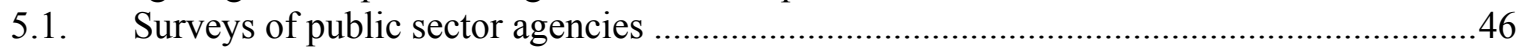

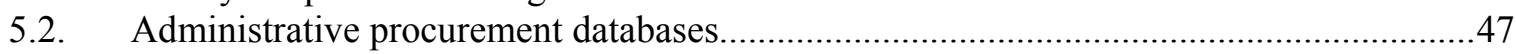

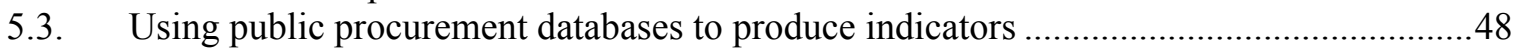

6. Linking data on public procurement and on innovation for analytical purposes........................61

6.1. Recent evidence on the link between procurement, innovation and economic outcomes 61

6.2. Demonstrating the combined use of administrative data, company accounts and IP data .63

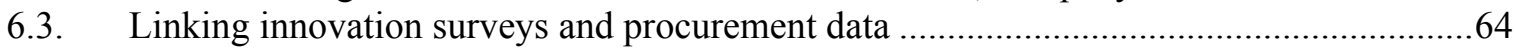

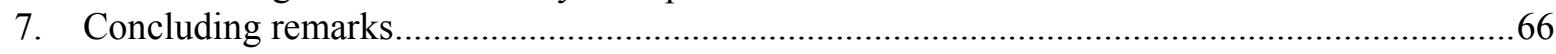

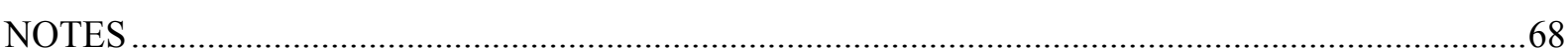

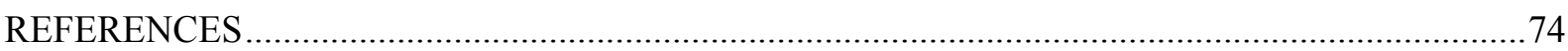

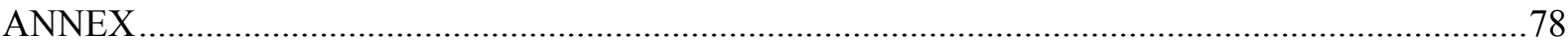

Description and results from the quantitative case study on data liking and analysing administrative

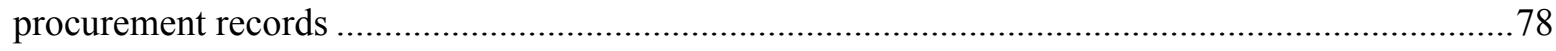




\section{SUMMARY OF MAIN FINDINGS AND RECOMMENDATIONS}

\section{Background and context}

This report attempts to provide a practical perspective on the key concepts, definitions and measurement approaches that can be used, with currently available data or adapted sources, to support and produce new indicators and analysis on the relationship between public procurement and innovation and the use of the former as an innovation policy tool. It does so by taking the OECD S\&T measurement frameworks, particularly the OECD/Eurostat Oslo Manual on innovation and the OECD Frascati on R\&D, as main but not sole departure points.

Public procurement is the purchase by governments and state-owned enterprises of goods and services. It accounts for a significant amount of total general (central and sub-central) government expenditure. In 2013, on average, procurement spending represented $29 \%$ of total general government expenditures (or close to 12\% of GDP) (OECD, 2015a). The economic significance of procurement makes it the object of interest in its potential use as an innovation policy tool. The 2010 OECD Innovation Strategy and subsequent update (OECD, 2015b) indicate that so called demand-side innovation policies - including public procurement of innovation, standardisation and regulation, lead market and user-driven innovation initiatives - are gaining ground in OECD countries and beyond, while the use of other supply/push-driven policy tools are under increased budgetary and regulatory constraints.

Recent OECD work has shown that innovation has become an additional and important strategic objective pursued by public authorities when making public procurement decisions. The number of OECD countries reporting that a strategy or policy is in place to promote the use of procurement to support the delivery of innovative goods or services has gone from 16 in 2012 to 23 in 2014. However, systematic monitoring or analysis of the results of such policies and strategies is far less common.

In spite of growing policy interest, which also recognises the role of procurement in the emergence and growth of new technologies and industries, there is very limited robust statistical evidence on the link between procurement and innovation. This evidence gap is particularly relevant at a time in which several countries are considering the introduction of targets, set asides and complementary policies to promote the use of procurement as an innovation policy tool.

\section{Main empirical findings}

This report provides one of the first available compilations of data on the engagement of firms in public procurement across a wide number of countries and its relation to existing measures of innovation.

- Across a range of EU and some other OECD countries, between 9\% and 34\% of firms delivered goods or services to public authorities in 2010-12, mostly to domestic public organisations only (78\%-94\%). The percentage of firms supplying to public sector organisations increases with firm size, as does the likelihood of supplying to foreign public sector organisations.

- $14 \%$ to $36 \%$ of companies involved in procurement activities over the reference period 2010 2012 reported to have undertaken an innovation activity as part of a public procurement contract. This applies in particular to firms that introduced new products between 2010 and 2012. 
- There is some significant variation as to whether companies which undertook innovation activities as part of procurement engagements are explicitly and formally required to do so in the contracts. In the case of the Netherlands, Italy, Germany and Turkey, between $47 \%$ and $70 \%$ of firms that innovate as part of public contracts indicate that they were required to do so while in Austria, Finland, France, Portugal and Sweden, this requirement tends to be reported as the exception at around $20 \%$ of cases.

- Actual reported innovation rates are significantly larger for companies that are involved in procurement contracts. The gap is more noticeable for product than for process innovation, but differences are also found for other types of innovations that companies serving public authorities may also need to implement, including marketing and organisational innovations.

The robustness and potential causality of these results is yet to be tested with improved access to data and more widespread adoption of these questions. In the case of Germany, where the available data have already been analysed in more detail, the results indicate that differences in product, marketing innovation, organisational innovation, new to market product innovations and in house $\mathrm{R} \& \mathrm{D}$ are significant and robust to controlling for size, age, sector and region.

In order to showcase the use of matched firm-level contract, business performance and IP data, US federal contract award data from FPDS were matched for a subset of US companies to the commercial database ORBIS. ORBIS, developed by Bureau Van Dijk, contains firm-level information on publicly reported R\&D expenses, turnover and employment. The matched data were also linked to information on patent and trademark applications to the USPTO. The exploratory analyses, which control for a number of firm characteristics such as employment and capital stock, as well as firm fixed-effects, find that:

- There is a positive correlation between reporting any $R \& D$ expenses in a given year and having received a contract award from the US government in the previous period. Firms that previously obtained an award are twice as likely to report R\&D expenses compared with firms that were not awarded government contracts. This effect on R\&D mainly stems from non-R\&D related contracts. R\&D service contracts seem to neither induce additional nor crowd out $R \& D$ expenses by the firm.

- The value of government contracts in a year is positively related to the value of a company's volume of R\&D expenses in the following year. The effect, observable for the full sample of contractors, implies that R\&D expenses increase by $0.2 \%$ as the value of past obligations increases by $10 \%$. There is no evidence that changes in the value of government $R \& D$ contracts result in additional R\&D expenses by firms or lead to crowding out.

- The number of patent applications firms filed at USPTO in a given year is positively correlated with past R\&D expenditures and the size of the firm as measured by the number of employees in the previous year. After controlling for past R\&D expenditures and labour and capital inputs, past contract obligations have no effect on firms' patent filing behaviour.

- Contractors that regularly supply to the US federal government increasingly seek trademark protection for goods and services at the USPTO. As the value of past obligations increases by $10 \%$, the number of trademarks firms filed in a given year rises by $0.5 \%$. This effect suggests that firms introduce new goods and services as part of their fulfilment of government contracts. It remains to be investigated whether this is followed by filings in other jurisdictions. 
- Public procurement seems to stimulate demand. Firm turnover is positively correlated with past contract obligations, rising by $0.3-0.4 \%$ as the value of past contract obligations increases by $10 \%$. The results suggest that this effect is attributable to non-R\&D related contracts. This effect also applies for turnover net of government awards in that particular year. Business turnover net of government awards rises by $0.2 \%$ as the value of past contract obligations increases by $10 \%$.

\section{Strategies for improving the data infrastructure for understanding public procurement and its link to innovation}

There is a broad range of possible uses for measures and analyses that capture different dimensions of the relationship between procurement activities and innovation. Irrespective of the innovation dimension, measurement can play an important role in ensuring the transparency and integrity of procurement decisions. There are potential administrative, statistical and policy analysis objectives for developing and reporting measures of innovation procurement, as well as possible tradeoffs between them. Measurement can influence behaviour in both intended and unintended ways, particularly when used as targets at an individual or macro level.

This study has examined the challenges and opportunities of using a range of measurement perspectives, strategies and sources for better understanding the role of public procurement as a driver of innovation. This comprises the innovation and R\&D survey tools laid out in the OECD manuals, procurement administrative data, and hoc studies of public contractors and contracting agencies. All these sources can be highly complementary but a number of obstacles need to be addressed in each case. From this work, a number of recommendations appear to emerge:

- Expand coverage and improve access to administrative procurement data, dedicating some resources to ensuring that data are comprehensive, accurate and fit for purpose for a range of relevant objectives, among which transparency, improved governance and value for money are key considerations. Work towards adopting comparable reporting standards to facilitate cross country analysis.

- Develop infrastructures and competencies that enable public procurement officials and analysts to assess the novelty of procurement specifications and procurement bids by firms and other organisations, exploiting the opportunities of big data analytics and existing repositories.

- Facilitate access to innovation survey microdata in order to allow full exploration of newly emerging data on public procurement within innovation and related surveys. Facilitate the linkage of administrative data, comprising procurement, broader spending (e.g. grants) and IPR-related data, and survey records.

As part of this project's extensive review of the conceptual and practical potential of the Oslo (innovation) and Frascati (R\&D) measurement frameworks to support the analysis of public procurement and its link with innovation, the following conclusions have been reached:

- The existing frameworks promoted by the OECD provide ample coverage for capturing a wide range of user interests, though not all. These frameworks can be suitably adjusted and also more systematically exploited to ensure their full potential can be of benefit to decision makers with an interest in the role of public procurement. The Frascati Manual was revised in 2015 taking into consideration some of the recommendations arising from this project. 
- It is important to promote the collection of information on the key features of markets served by business, not only with attention to the national vs. international dimension, but also regarding the nature of the customers, among which public authorities can play a role. This is of broad interest, as understanding a firm's market is important for contextualising its innovation activity and also the degree of novelty of reported innovations.

- Avoid questions asking respondents to link causes with effects (e.g. as between public demand and innovation activity) as these are subject to significant biases due to the lack of a clear counterfactual. However, recent experience shows is it relevant and possible to identify a firm has introduced an innovation in the context of its delivering of goods and services to public authorities

- Increase attention to the hard-to-make distinction between the development and implementation of innovations and the circumstances in which public authorities bring innovations into practice with development input from companies.

- Questions on sources of information and collaboration deal with users/customers (the largest in terms of responses) and government as if these were two exclusive categories, without noting the potential overlap and its high specificity. It would therefore be desirable to use a revised, more informative taxonomy of partners and sources, without over-extending the available list.

- Questions on public support for innovation currently tend to be constrained to tax incentives and grant funding. Qualitative questions on the relative importance of different instruments, which have been implemented in a few countries, could be extended to include public procurement. It does not seem possible, for the time being, to be able to identify precisely what proportion of innovation expenditures have been paid for by contracts.

It is much less clear to what extent innovation surveys can help identify, through simple questions, whether there is a catalytic role of procurement, whereby the public sector actor is involved in the first-time purchase of innovations which are in ultimate instance bought or used by other private end-users. This requires a long term perspective which typically exceeds the recall periods used in innovation surveys, and carries the added complexity of considering different products and their specific experience. Object-based approaches (i.e. those focused on specific innovations) seem to be more suitable for the study of this dimension of procurement. Longitudinal innovation data can be used as additional evidence to track over time the source of demand for a company's products, particularly young firms for which public procurement might be the first source of revenue. A related recommendation is to consider the role and the processes of public procurement within future experimental efforts to measure innovation within the public sector and to propose measurement guidance in this area, for which there are at present no internationally accepted guidelines.

To conclude, the project underpinning the findings in this report has contributed to the exchange of experiences on the measurement of research and innovation activities and their relationship with procurement, influencing the experimentation among national statistical agencies and academics with an interest in this subject. Procurement has already played a significant role in the new Frascati Manual of 2015 and it is also being considered as part of the ongoing revision of the Oslo Manual. It is indeed through trial and error and analysis of the relevance and validity of the resulting data that specific recommendations may be made in future guidelines, in light of the widespread interest in measuring government engagement in innovation and advancing our understanding of the role of demand in driving innovation and sustainable economic growth. 


\section{MEASURING THE LINK BETWEEN PUBLIC PROCUREMENT AND INNOVATION}

\section{Introduction}

\subsection{Project objectives}

This document sets out the scope, main objectives and main findings of a recent project on the measurement of innovation procurement. The project, which was carried out under the auspices of the Working Party of National Experts on Science and Technology Indicators (NESTI) over the 2012-13 aimed to address the increasing interest among OECD countries and partners economies in the use of demand-side innovation policies and the need for better evidence upon which policy conclusions may be drawn. This project attempted to identify what concepts, definitions and measurement approaches could be used, with currently available data or adapted sources, to produce policy-relevant indicators on the use of innovation procurement and carry out relevant analysis on the impact of procurement decisions and policies on innovation and broader economic outcomes. The conclusions of the project have contributed to the evidence considered in the revision of the OECD Frascati and Oslo Manuals. The project benefited from voluntary contribution support from the European Commission, as part of a collaborative partnership agreement between the OECD and DG Enterprise and Industry, the ECOECD Partnership on Innovation.

This project set out to review existing evidence on the contribution of public procurement to innovation performance and the development of a measurement framework for identifying and measuring the extent, nature and potential impact of public procurement on innovation. In order to achieve these objectives, the project undertook:

- A review of the literature and measurement efforts across OECD countries.

- An assessment of the R\&D and innovation measurement framework to help understand the link between PP and R\&D and innovation.

- An assessment of administrative sources on public procurement for innovation analysis purposes.

- A demonstration of data linking and analysis using public procurement data.

- Two expert workshops held at the OECD, engaging with measurement experts, academics, policy makers and other practitioners with an interest in procurement and its link with innovation.

- A demonstration of the feasibility and potential relevance of data linking across sources (admin and survey) to inform complex "impact" questions.

\subsection{What is public procurement and how is it measured?}

Public procurement is defined by the OECD as the purchase by governments and state-owned enterprises of goods and services (OECD, 2013). ${ }^{1}$ It is important to be able to benchmark any estimates of innovation procurement against agreed economic statistics which provide a framework for measuring the size of public procurement markets. The OECD National Accounts database, based on the System of National Accounts (SNA), is regularly used by the OECD and other organisations to derive overall national procurement market size estimates. ${ }^{2}$ General government procurement is calculated as the sum of: 
- Intermediate consumption (goods and services purchased by government units for their own use, such as accounting or information technology services);

- Gross fixed capital formation (acquisition and development of non-financial assets excluding sales and disposals of fixed assets, such as building new roads); and

- Social transfers in kind via market producers (i.e. goods and services produced by market producers, purchased by government and supplied to households). ${ }^{3}$

Procurement accounts for a significant share of total government (public sector less public corporations) expenditure and GDP. In 2011, on average, general government procurement spending represented $29 \%$ of total general government expenditures, or $12 \%$ of GDP as shown in Figure 1. These figures remain unchained in 2013.

Figure 1. General government procurement, 2013

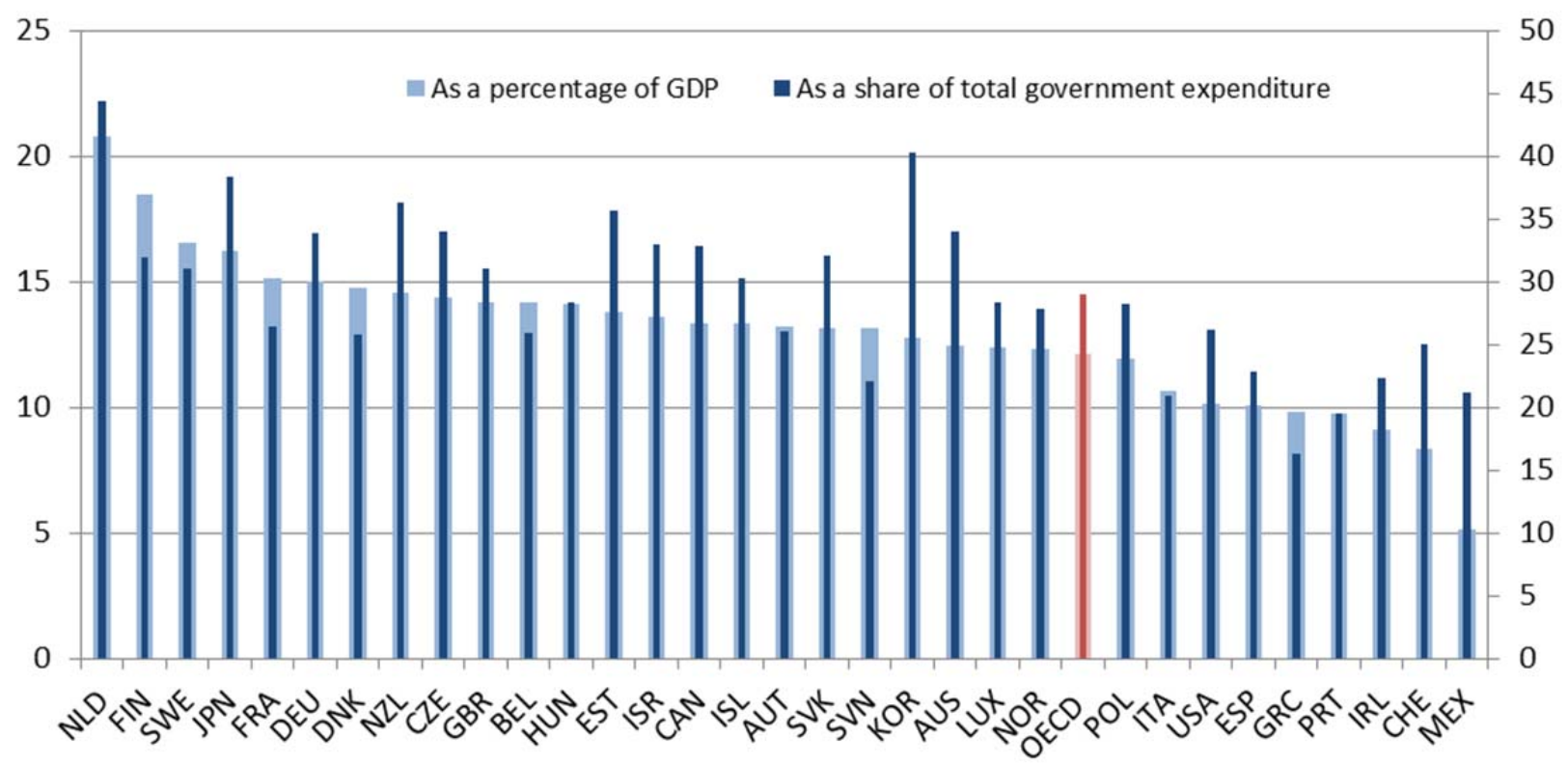

Source: OECD (2015a). Based on OECD National Accounts Statistics (database). Data for Australia are based on a combination of Government Finance Statistics and National Accounts data provided by the Australian Bureau of Statistics. http://dx.doi.org/10.1787/888933249013.

Figure 2 focuses on the intermediate consumption and capital expenditure components of government procurement, as it is not always possible to derive estimates of social transfers in kind via market producers across the entire OECD area. ${ }^{4}$ It shows significant differences across countries, some of which are explained by the extent to which market producers play an important role in the delivery of public services. It is possible to note that with very few exceptions, the purchase of intermediate goods and services dominates that of capital formation.

The general government component of public procurement includes expenditures by central, state and local governments, and social security funds. Sub-central governments should also be included in efforts to improve efficiency in procurement spending, as government procurement spending at state and local levels accounts for $55 \%$ of total general government procurement spending on average across OECD countries. This is of particular importance for federal states (see Figure 3). 
Figure 2. Government expenditures on procurement, by type of use, 2011 Excluding social transfers in kind

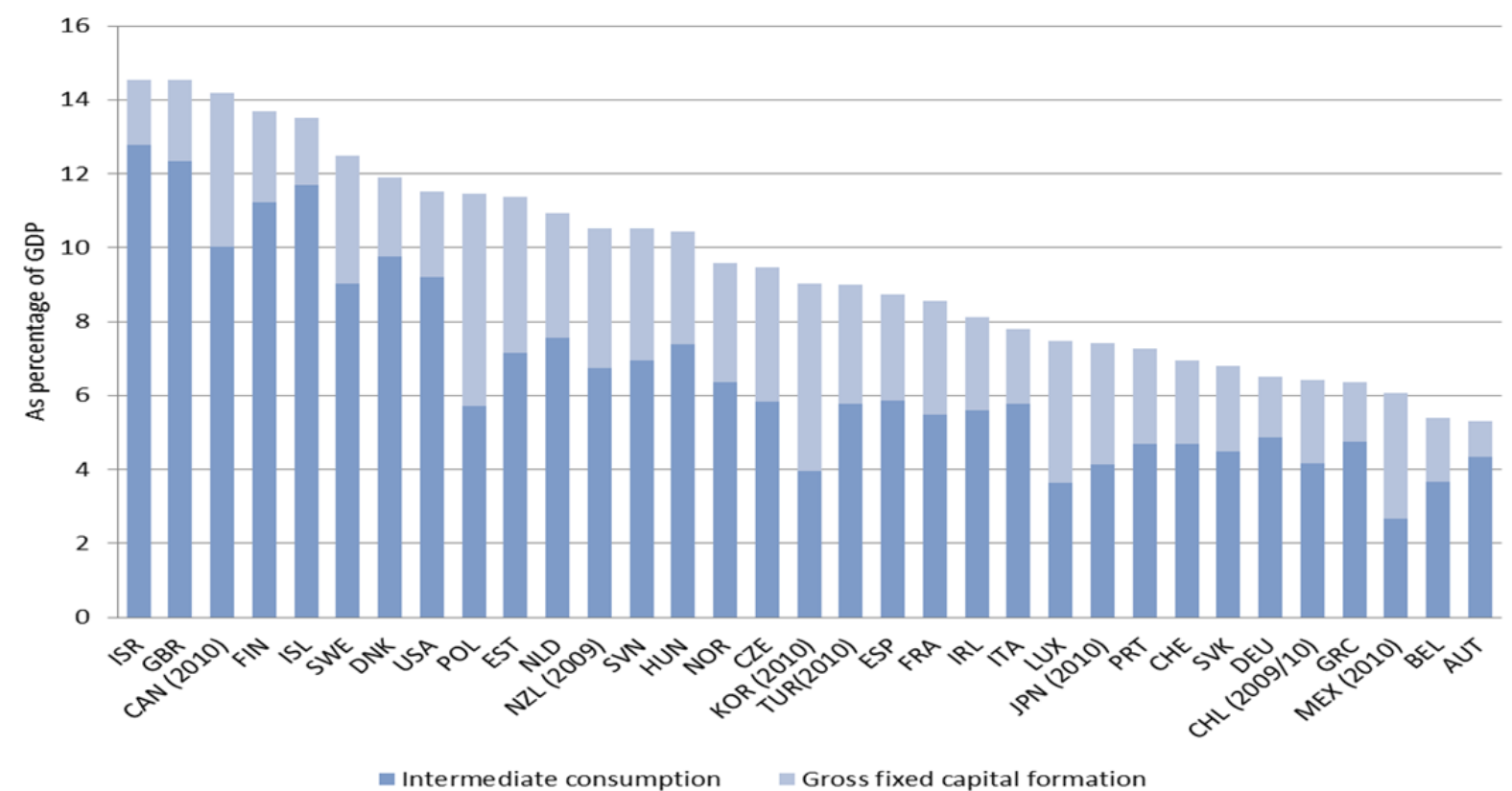

Source: OECD analysis, based on OECD National Accounts at a Glance, 2013.

Figure 3. Share of general government procurement by level of government, 2011

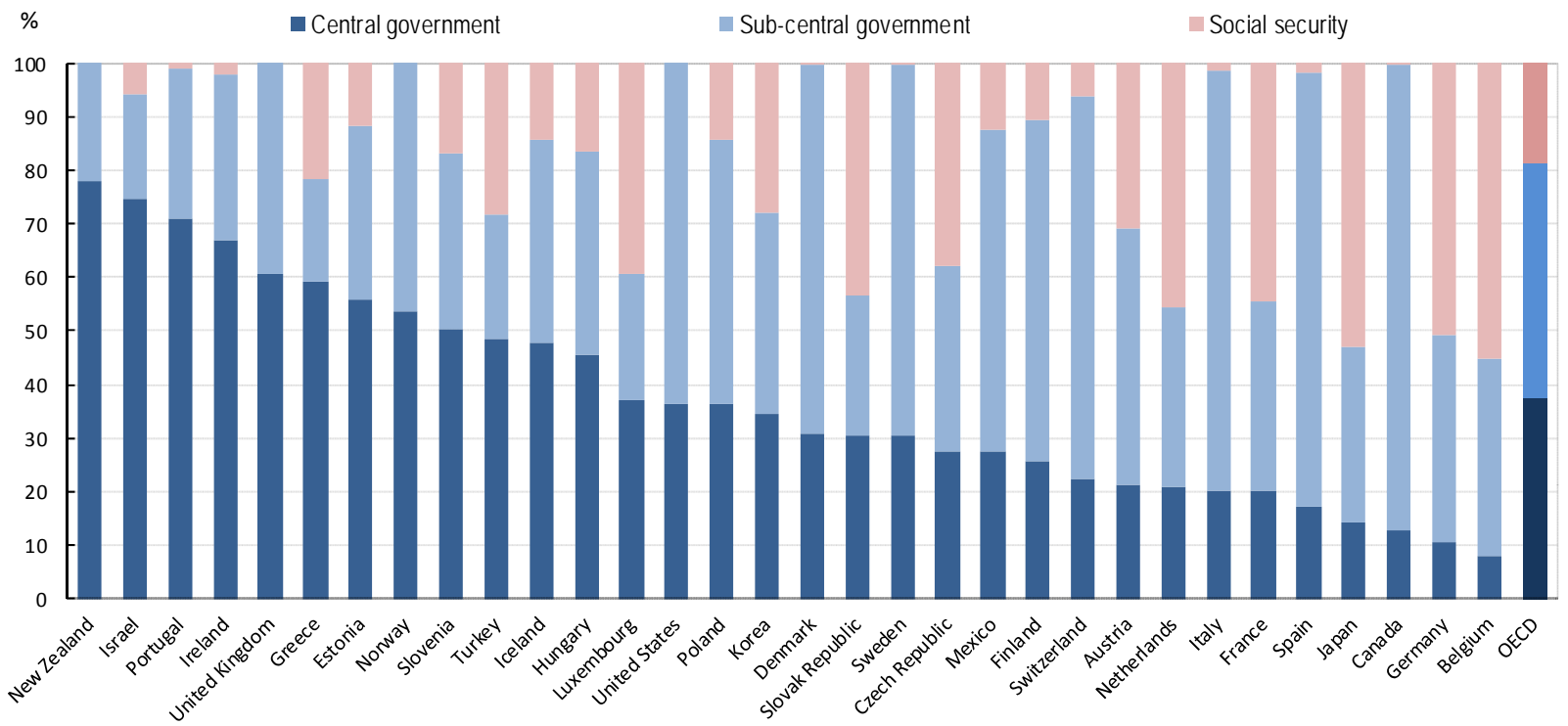

Source: OECD National Accounts Statistics (database). Data for Australia and Chile are not available. Data for Japan at sublevel of government refer to fiscal years. Social security funds are included in central government in New Zealand, Norway, the United Kingdom and the United States.

General government excludes public corporations such as state-owned utilities. The System of National Account's Public Sector definition includes general government and public corporations $(\S 22.15$, SNA2008) as explained in Table 1. General government consists of institutional units that, in addition to fulfilling their political responsibilities and their role of economic regulation, produce services (and possibly goods) for individual or collective consumption mainly on a non-market basis 
and redistribute income and wealth. Within a single economy when there are different levels of government at central, state or local levels, there may be many separate government units. ${ }^{5}$

Table 1. The Public Sector and the Institutional Sectors in the System of National Accounts

\begin{tabular}{|c|c|c|c|c|}
\hline $\begin{array}{c}\text { Non-financial } \\
\text { corporations }\end{array}$ & $\begin{array}{c}\text { Financial } \\
\text { corporations }\end{array}$ & $\begin{array}{c}\text { General } \\
\text { government }\end{array}$ & $\begin{array}{c}\text { Non-profit institutions } \\
\text { serving households } \\
\text { (NPSIH) }\end{array}$ & Households \\
\cline { 1 - 4 } $\begin{array}{c}\text { Public (e.g. publicly } \\
\text { controlled utilities) }\end{array}$ & Public & $\begin{array}{c}\text { Public (including } \\
\text { government } \\
\text { controlled institutes } \\
\text { and non-profit units) }\end{array}$ & $\begin{array}{c}\text { Private (e.g., charities, } \\
\text { universities in some } \\
\text { countries) }\end{array}$ & Private \\
\cline { 1 - 3 } Private & Private & & \\
\hline
\end{tabular}

Source: EC et al (2009), System of National Accounts, 2008.

Corporations produce in the market, i.e. they sell their output at economically meaningful prices. A corporation is a public corporation if a government unit, another public corporation, or some combination of government units and public corporations controls the entity, where control is defined as the ability to determine the general corporate policy of the corporation. In some cases it is possible to derive estimates of the approximate size of state-owned utilities' and other public enterprises' procurement which allow for an adjustment of the General Government SNA-based values.

Aggregate and institutional-sector data from national accounts do not a priori enable a distinction between different types of procurement according to the type of the goods and services bought. Supply-use input-output tables (SUIOTs) provide the best available approximation in official mainstream statistics to what may be defined as a product-based breakdown of government procurement. "Use tables" in particular provide estimates of intermediate consumption by specific industries of different goods and services, allowing for example to identify what is the proportion of intermediate consumption by the "Public administration and defence" sector of a number of high tech goods or knowledge-intensive services.

Figure 4. Governments' intermediate consumption (IC) of R\&D and knowledge-intensive products

Estimates for the "Public administration" sector, selected countries and most recent available data

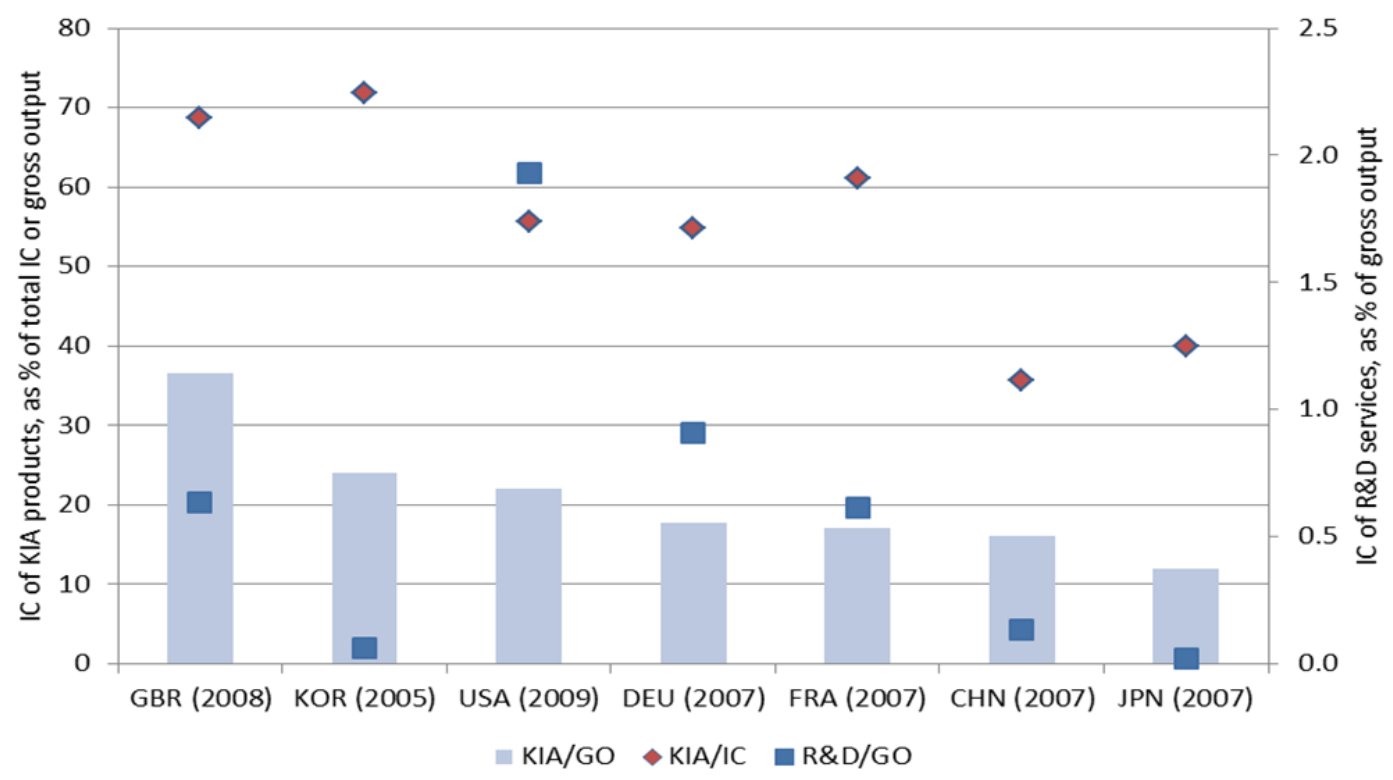

Source: OECD, based on World Input-Output Database (Official national Input files). http://www.wiod.org/publications/source docs/WIOD sources.pdf 
To provide an illustration of the type of indicators that can be constructed based on SUIOT data, Figure 4 represents, for selected countries, the intermediate consumption of R\&D services and products related to knowledge-intensive activity (KIA products) by the "public administration and defence" sector. The results, based on the official national input files used to construct the World's Input Output Database, rank the countries on the basis of KIA intermediate consumption (IC), as a percentage of the sector's total IC and gross output (GO). For the United Kingdom, IC of KIA products (goods and services) is largest, at nearly $40 \%$ of gross output, followed by Korea and the United States. As a proportion of intermediate consumption, Korea is highest at $70 \%$. The United States has the highest ratio of R\&D purchases to gross output, at nearly 2 percent, followed by Germany (1\%), and France and the United Kingdom.

Related evidence for seven European countries (Table 2) shows that government demand is particularly important in sectors such as transport (where government is a large purchaser of equipment), education, office equipment, research and development, as well as construction.

Table 2. Government share of consumption of domestically-produced intermediate goods and services, mid-2000s

Ordered share by industry group in the STAN classification

\begin{tabular}{|c|c|c|c|c|c|c|c|c|c|}
\hline & & Denmark & Finland & France & Germany & Netherlands & Sweden & $\begin{array}{c}\text { United } \\
\text { Kingdom }\end{array}$ & $\begin{array}{c}\text { Unweighted } \\
\text { average }\end{array}$ \\
\hline C35 & Other transport equipment & $18.9 \%$ & $19.4 \%$ & $14.8 \%$ & $22.4 \%$ & $7.3 \%$ & $25.4 \%$ & $38.9 \%$ & $21.0 \%$ \\
\hline C 80 & Education & $16.7 \%$ & $15.0 \%$ & $4.3 \%$ & $6.4 \%$ & $14.2 \%$ & $15.0 \%$ & $23.5 \%$ & $13.6 \%$ \\
\hline C75 & Public admin. and defence; compulsory social security & $7.6 \%$ & $3.4 \%$ & $10.3 \%$ & $11.0 \%$ & $29.1 \%$ & $6.9 \%$ & $2.6 \%$ & $10.1 \%$ \\
\hline C73 & Research and development & $14.1 \%$ & $8.1 \%$ & $4.7 \%$ & $16.4 \%$ & $9.5 \%$ & $4.0 \%$ & $10.5 \%$ & $9.6 \%$ \\
\hline C72 & Computer and related activities & $10.4 \%$ & $10.1 \%$ & $3.5 \%$ & $4.6 \%$ & $11.1 \%$ & $5.6 \%$ & $7.0 \%$ & $7.5 \%$ \\
\hline C45 & Construction & $7.0 \%$ & $3.2 \%$ & $6.9 \%$ & $6.0 \%$ & $12.1 \%$ & $9.8 \%$ & $6.1 \%$ & $7.3 \%$ \\
\hline C85 & Health and social work & $10.9 \%$ & $8.3 \%$ & $1.9 \%$ & $3.9 \%$ & $9.2 \%$ & $9.3 \%$ & $0.8 \%$ & $6.3 \%$ \\
\hline С90T93 & Other community, social and personal services & $3.1 \%$ & $2.9 \%$ & $6.6 \%$ & $4.9 \%$ & $19.3 \%$ & $2.1 \%$ & $10.7 \%$ & $7.1 \%$ \\
\hline C64 & Post and telecommunications & $5.6 \%$ & $5.4 \%$ & $6.0 \%$ & $4.9 \%$ & $5.2 \%$ & $9.1 \%$ & $7.8 \%$ & $6.3 \%$ \\
\hline C55 & Hotels and restaurants & $3.9 \%$ & $7.1 \%$ & $2.7 \%$ & $10.9 \%$ & $6.4 \%$ & $4.3 \%$ & $11.9 \%$ & $6.7 \%$ \\
\hline C70 & Real estate activities & $8.3 \%$ & $7.9 \%$ & $3.6 \%$ & $3.1 \%$ & $1.8 \%$ & $9.2 \%$ & $6.0 \%$ & $5.7 \%$ \\
\hline $\mathrm{C} 29$ & Machinery and equipment n.e.c & $2.4 \%$ & $2.9 \%$ & $7.1 \%$ & $3.2 \%$ & $6.5 \%$ & $2.9 \%$ & $13.8 \%$ & $5.5 \%$ \\
\hline С $36 T 37$ & Manufacturing n.e.c; recycling & $7.8 \%$ & $4.3 \%$ & $3.2 \%$ & $0.4 \%$ & $5.5 \%$ & $3.2 \%$ & $7.9 \%$ & $4.6 \%$ \\
\hline C30 & Office, accounting and computing machinery & $3.8 \%$ & $0.8 \%$ & $5.5 \%$ & $5.7 \%$ & $3.7 \%$ & $3.3 \%$ & $47.1 \%$ & $10.0 \%$ \\
\hline C74 & Other Business Activities & $2.9 \%$ & $4.5 \%$ & $4.1 \%$ & $2.2 \%$ & $4.7 \%$ & & $5.3 \%$ & $4.0 \%$ \\
\hline C33 & Medical, precision and optical instruments & $3.3 \%$ & $6.3 \%$ & $0.3 \%$ & $1.5 \%$ & $4.4 \%$ & $6.3 \%$ & $19.5 \%$ & $5.9 \%$ \\
\hline C17T19 & Textiles, textile products, leather and footwear & $3.5 \%$ & $4.3 \%$ & $2.3 \%$ & $1.2 \%$ & $3.7 \%$ & $4.8 \%$ & $4.6 \%$ & $3.5 \%$ \\
\hline C40t41 & Electricity, gas and water supply & $2.2 \%$ & $2.8 \%$ & $4.5 \%$ & $2.6 \%$ & $3.0 \%$ & $4.0 \%$ & $3.5 \%$ & $3.2 \%$ \\
\hline C65T67 & Finance and insurance & $1.9 \%$ & $4.5 \%$ & $2.4 \%$ & $4.1 \%$ & $2.2 \%$ & $3.2 \%$ & $5.6 \%$ & $3.4 \%$ \\
\hline $\mathrm{C} 21 \mathrm{~T} 22$ & Pulp, paper, paper products, printing and publishing & $1.9 \%$ & $2.6 \%$ & $4.3 \%$ & $2.5 \%$ & $4.6 \%$ & $1.6 \%$ & $5.3 \%$ & $3.3 \%$ \\
\hline C71 & Renting of machinery and equipment & $2.8 \%$ & $3.1 \%$ & $3.2 \%$ & $1.4 \%$ & $1.0 \%$ & $2.6 \%$ & $1.0 \%$ & $2.2 \%$ \\
\hline C50T52 & Wholesale and retail trade; repairs & $1.7 \%$ & $3.4 \%$ & $1.4 \%$ & $2.4 \%$ & $1.9 \%$ & $1.9 \%$ & $4.1 \%$ & $2.4 \%$ \\
\hline C32 & Radio, television and communication equipment & $3.3 \%$ & $3.1 \%$ & $1.2 \%$ & $1.4 \%$ & $0.9 \%$ & & $6.1 \%$ & $2.7 \%$ \\
\hline C60T63 & Transport and storage & $1.2 \%$ & $2.0 \%$ & $2.4 \%$ & $1.5 \%$ & $2.6 \%$ & $1.5 \%$ & $2.5 \%$ & $2.0 \%$ \\
\hline C23 & Coke, refined petroleum products and nuclear fuel & $1.5 \%$ & $1.5 \%$ & $2.0 \%$ & $2.0 \%$ & $1.6 \%$ & $1.5 \%$ & $4.8 \%$ & $2.1 \%$ \\
\hline C15T16 & Food products, beverages and tobacco & $0.6 \%$ & $4.3 \%$ & $0.6 \%$ & $2.1 \%$ & $0.7 \%$ & $1.6 \%$ & $0.6 \%$ & $1.5 \%$ \\
\hline C28 & Fabric.d metal products except mach.y and equipment & $1.5 \%$ & $0.9 \%$ & $0.1 \%$ & $0.7 \%$ & $2.3 \%$ & $1.2 \%$ & $0.6 \%$ & $1.0 \%$ \\
\hline C31 & Electrical machinery and apparatus n.e.c & $1.3 \%$ & $1.4 \%$ & $0.4 \%$ & $0.4 \%$ & $1.8 \%$ & $1.4 \%$ & $3.1 \%$ & $1.4 \%$ \\
\hline $\mathrm{C} 25$ & Rubber and plastics products & $2.0 \%$ & $1.8 \%$ & $0.0 \%$ & $0.8 \%$ & $0.5 \%$ & $1.5 \%$ & $0.9 \%$ & $1.1 \%$ \\
\hline C01T05 & Agriculture, hunting, forestry and fishing & $1.1 \%$ & $0.6 \%$ & $0.8 \%$ & $2.0 \%$ & $1.2 \%$ & $0.7 \%$ & $0.3 \%$ & $1.0 \%$ \\
\hline C34 & Motor vehicles, trailers and semi-trailers & $2.4 \%$ & $0.1 \%$ & $0.3 \%$ & $0.5 \%$ & $0.9 \%$ & $0.6 \%$ & $2.5 \%$ & $1.0 \%$ \\
\hline $\mathrm{C} 24$ & Chemicals and chemical products & $1.2 \%$ & $0.6 \%$ & $0.4 \%$ & $0.5 \%$ & $0.5 \%$ & $1.0 \%$ & $1.4 \%$ & $0.8 \%$ \\
\hline
\end{tabular}

Notes: Intermediate demand by the "public administration" sector C75 in total intermediate demand. The table illustrates government consumption of domestically produced intermediates, providing a concordance between STAN Input-Output and two-digit ISIC Rev. 3 codes, e.g. "C01T05" (C01 to C05) corresponds to ISIC Rev. 3 codes 01-05 (Agriculture, hunting, forestry and fishing). Data are not available on government consumption of final products such as capital formation. The category "Other transport equipment" covers: building and repairing of ships and boats; manufacture of railway and tramway locomotives and rolling stock; manufacture of aircraft and spacecraft; and manufacture of transport equipment not elsewhere classified. The category "Transport and storage" covers: road transport; transport via pipelines; water transport; air transport; supporting and auxiliary transport activities; and activities of travel agencies. The category "education" includes public as well as private education services of all types, provided by institutions as well as by private teachers. Differences among countries in this category most likely reflect variation in outsourcing practices across education systems (with the level of outsourcing being high, for instance, in the United Kingdom). See http://unstats.un.org/unsd/cr/registry/regcst.asp? Cl=2

Source: OECD, STAN Input-Output Tables, February 2012. 
There are some limitations in using these tables for mapping government purchases:

- They are explicitly designed to provide a coherent and balanced description of the supply and demand for products and industries in an economy. They are subject to a diverse set of estimation techniques which need not rely on timely and accurate data.

- They do not allow for a separate identification of public and private units within each "industry". The Public Administration and Defence sector is easy to identify with public sector, but that is not necessarily the case for activities such as education, health and social care in which the state plays a key but variable role as a direct service provider in different countries.

- The detailed breakdown by products and industry is generally only available from public sources for intermediate consumption. Statistics on product purchases by sector basis for gross capital formation (i.e. net additions to capital assets) ${ }^{6}$ are not systematically available.

\subsection{What is innovation and how is it measured?}

The third and latest edition of the Oslo Manual defines innovation as the implementation of a new or significantly improved product (good or service), or process, a new marketing method, or a new organisational method in business practices, workplace organisation or external relations (OECD and Eurostat, 2005). This definition has been originally devised for measurement purposes, ${ }^{7}$ but is increasingly used in a wider range of settings. Innovation activities vary greatly in their nature from firm to firm. Some firms engage in well-defined innovation projects, such as the development and introduction of a new product, whereas others primarily make continuous improvements to their products, processes and operations. Both types of firms can be innovative: an innovation can consist of the implementation of a single significant change or of a series of smaller incremental changes that together constitute a significant change. By definition, all innovation must contain a degree of novelty, either only to the firm or also to the market in which it operates (OECD, 2010).

Innovation is often a continuous process rather than a discrete, static activity. The appreciation of what is new of significantly improved can be to some extent subjective. This makes it difficult to measure. Firms constantly make changes to products and processes and collect new knowledge. In order to capture this process, the Oslo Manual (OECD and Eurostat, 2005) focuses on measurable indicators such as expenditures, linkages and factors that influence innovation activities.

As noted in the OECD Innovation Strategy, innovation, thus defined, is clearly a much broader notion than R\&D and is influenced by a wide range of factors, some of which can be affected by policy. Innovation can occur in any sector of the economy, including government services such as health or education. The current measurement framework applies only to business innovation, where there exists a longer tradition of innovation measurement, even though innovation is also important for the public sector. Consideration is being given to extending the methodology to public sector innovation and innovation in other sectors, so as to correspond to the reality of innovation today. Fostering innovation requires not only consideration of a wide range of innovation activities but also of the many actors engaged in innovation (OECD, 2010).

\subsection{Why measure the link between public procurement and innovation?}

The mechanisms by which public procurement supports innovation include signalling acceptance of innovations as early or lead users and creating new markets (OECD, 2010). However, regulatory and institutional frameworks under which procurement agencies operate may not encourage the 
procurement of innovative goods, services or works. ${ }^{8}$ A tension arises between public procurement and innovation because procurement is often positioned as a transactional rather than strategic activity in public agencies. General public procurement can often be given a greater focus on performance metrics, rather than on specific features of the procured items (defined a priori), thus creating more scope for innovation (OECD, 2014b). Adequate availability of expertise, with staff having knowledge for instance of regulations, technologies and markets, becomes key for innovation procurement.

On the other hand, there is a risk that public procurement of innovation may be at odds with good governance, impacting on transparency, competition and related international standards and obligations (e.g. OECD Council Recommendation for Enhancing Integrity in Public Procurement, the World Trade Organization's Government Procurement Agreement, the EC Directive on public procurement for procurement within the EU, etc.). ${ }^{9}$ Given the large extent of possible trade-offs, measurement becomes particularly relevant as a necessary step for evaluating the scope for procurement policy to drive innovation and its potential impact.

\subsection{Outline of the report}

This project aims to contribute to the clarification of concepts, definitions and possible measurement approaches that have been used in academic studies as well as political debates to assure that statistical and policy analysis objectives are optimally addressed. A number of strategies are pursued, as detailed in the remainder of this document which is structured as follows. Section 2 seeks to lay out the main potential user needs for indicators and analysis of the link between public procurement and innovation. Section 3 considers a working definition of "innovation procurement" and provides some of the main elements that could approximate this concept within the existing framework developed jointly by the OECD and Eurostat. It also provides some examples of recent initiatives to mainstream the measurement of innovation procurement through business innovation surveys. Section 4 deals with the measurement of R\&D procurement. While R\&D is just one type of innovation activity, there is considerable interest, from a number of statistical and policy perspectives, in understanding to what extent and how governments promote $R \& D$ through direct procurement of R\&D services. Section 5 focuses on the use of administrative data sources and other information from public authorities for constructing measures of procurement and its link with innovation. It highlights some potential approaches for producing relevant indicators and analysis using existing administrative sources, documenting some of the pitfalls of these databases. Section 6 demonstrates potential analytical application based on a match of administrative procurement data to company R\&D, IP, business performance data as well as innovation survey data, to assess the impact of public procurement on R\&D, innovation and broader economic outcomes. Section 7 concludes.

\section{The user needs for measuring the link between public procurement and innovation}

\subsection{The innovation policy interest in public procurement}

Recent OECD work shows that demand-side innovation policies - including public procurement of innovation, standardisation and regulation, lead markets and user-driven innovation initiatives - are gaining ground in OECD countries (OECD, 2012). They reflect the trend in innovation policy to address the full extent of the innovation system and cycle (OECD, 2012). As acknowledged by the OECD (2011a), the notion of fostering innovation through procurement is not new. Many countries have pursued active technology procurement policies for decades. It is well recognised, for example, that public procurement has been a key driver of the emergence of a number of high-technology sectors. 
Traditional explanations for the role of procurement as an innovation policy tool emphasise the potential of government's purchasing power to drive and shape innovation both directly and indirectly (Edler, 2007), highlighting the funding, demonstration and risk-sharing attributes of demand-based procurement approaches which may explicitly search for innovative solutions or implicitly encourage them. In the current economic and financial climate, governments' budgetary constraints highlight the importance of identifying innovative solutions to maintain and improve the delivery of public services using less resources, while addressing new societal challenges and public goals. Furthermore, given that policy instruments such as grants, subsidies and tax incentives increase government deficits in the short term, policy makers are increasingly interested in finding out how to use their sizeable procurement budgets to address multiple objectives, amongst which one would include meeting core user needs (e.g. safe and efficient energy consumption) and promoting innovation, using a single policy instrument.

\section{Box 1. Examples of policy initiatives to promote public procurement of innovation}

- Countries like Australia, the United States, the United Kingdom and the Netherlands operate Small Business Innovation Research (SBIR)-type of programmes to fund R\&D in the early stages of product development (OECD, 2011a)

- $\quad$ Austria included public procurement of innovation as priority in its federal strategy for research, technology and innovation in 2011, and proposed a concept for "Innovation Promoting Public Procurement". http://cordis.europa.eu/fp7/ict/pcp/docs/pcp-austria-casev0.pdf

- In the Netherlands, the public procurement expertise centre PIANOo was established in 2005 to professionalise public procurement and to pool knowledge and experience by offering guidelines and trainings to governmental bodies. http://www.pianoo.nl/about-pianoo

- $\quad$ Endorsed by the Demand and user-driven innovation policy framework and action plan TEKES has provided since 2009 financial incentives for public procurers in Finland to undertake innovative procurements ("Innovations in public procurements" programme) and to speed up the introduction of innovations and improve market access for goods and services developed by SMEs (Smart procurement programme). http://www.tekes.fi/en/programmes-and-services/tekes-programmes/smart-procurement/

- Recent legislative measures to support innovation procurement in France (measure 32 of the "Pacte de compétitivité" 2012) foresees measures to promote an increased exchange of information between public buyers and innovative SMEs and enterprises (conference on "l'achat public innovant") and dedicated budgets for public purchases by this set of firms: http://competitivite.gouv.fr/documents/commun/transversal/Dossier-presse-competitivite.pdf

- Six federal German ministries agreed in 2007 to promote "innovation oriented public procurement", encouraging market analysis and continuous dialogue between public procurers and industry among other efforts. A dedicated budget of EUR 2.8 million was most recently set aside by the German Federal Ministry for Economic Affairs and Energy (BMWi) in 2012 to start co-financing the R\&D procurement cost of German public procurers. See OECD(2014b) and http://cordis.europa.eu/fp7/ict/pcp/docs/pcp-germany-v1.pdf

- To promote public procurement of innovation and ensure SME access, Korea operates a New Technology Purchasing Assurance and procurement-conditioned SME R\&D programme (OECD, 2011a/2014a).

- $\quad$ The United Kingdom operates a Forward Commitment Procurement programme in which public agencies commit to buy non-existing products or services at a specified future date, performance level and cost. Early user need communication and supplier engagement are central features of the scheme. http://ec.europa.eu/enterprise/policies/innovation/policy/lead-marketinitiative/files/conference/230316 en.pdf

- Spain's E2I State Innovation Strategy, published in 2010, also foresees a financial incentives scheme for procurers in the area of pre-commercial procurement as well as innovation procurement. http://www.idi.mineco.gob.es/stfls/MICINN/Innovacion/FICHEROS/Spanish Innovation Strategy.pdf

- The 2012 Horizontal Action Plan by the European Commission in 2012 sought to spur demand-led innovation by developing and implementing strategic roadmaps for demand-side actions with stakeholders. In parallel, calling for a monitoring system to measure the implementation of the strategic roadmaps for demand-side policies. http://eur-lex.europa.eu/LexUriServ/LexUriServ.do?uri=COM:2012:0582:FIN:EN:PDF

Source: OECD, based on various sources. 
Box 1 provides an indicative, non-exhaustive overview of policy initiatives adopted by a number of OECD countries and the European Union $^{10}$ to unleash the potential of public procurement in stimulating innovation across industry sectors. ${ }^{11}$ In general, procurement promotion policies are often geared towards pre-commercial procurement (PCP) of innovation, directing support to the R\&D phase prior to commercialisation. Recent innovation procurement policies also support the establishment of platforms for information exchange, special support for authorities, and the adoption of legal reforms allowing for the preferential treatment of SMEs, the use of forward commitment mechanisms and the establishment of public-private partnerships.

In order to ensure the effectiveness of these demand-side policy initiatives and to support administrative, statistical and policy analysis objectives more generally, the measurement of public procurement of innovation is a clear pre-requisite for evidence-based policy making in this area. It is worth considering in some detail what purposes a measurement system has to fulfil in order to develop appropriate and relevant sources and tools to address the existing evidence gaps.

OECD work shows that innovation has become an additional and important strategic objective pursued by public authorities when making public procurement decisions. OECD member countries are no longer considering value for money in the strict sense of price and quality as the sole objective of public procurement. They are gradually including more strategic objectives such as support to small and medium-sized enterprises (SMEs), innovation, and environmental considerations. According to the results of a survey first conducted by the OECD for the Government at a Glance publication of 2013, 16 out of 34 OECD countries report having a strategy or policy to promote the use of procurement to support the delivery of innovative goods or services. ${ }^{12}$ In contrast, only 6 out of those 16 countries report monitoring or measuring the results of such policies/strategies on a regular basis (OECD, 2013). In a similar survey carried out two years later, the numbers reported had increased to 23 and 11 respectively.

The lack of adequate capability, both in terms of shortage of procurement officials and the insufficient specialised knowledge of available technologies, innovations or market developments is noted as a major barrier at a time in which procurement officials are expected to comply with increasingly complex rules and pursue value-for-money objectives, while taking into account strategic considerations such as innovation. In 2015, the OECD recommended countries to evaluate the use of public procurement as one method of pursuing secondary policy objectives in accordance with clear national priorities, balancing the potential benefits against the need to achieve value for money (OECD, 2015d).

\subsection{Potential uses of data and indicators}

A measurement system driven by administrative needs seeks to maintain records of individual procurement actions for monitoring and accountability purposes. The data can be made publicly available through data repositories to ensure competition, transparency and openness of procurement processes, and comply with the prevailing procurement requirements set by policy and national and international legislation. In the case of countries aiming to ensure that a given percentage of procurement actions or values are allocated to procuring innovation, monitoring needs would have to be met by an adequate recording and reporting system. Box 2 presents a non-exhaustive list of innovation procurement targets. 


\section{Box 2. Innovation procurement targets}

The adoption of targets for innovation procurement has been suggested and considered across a number of countries as a possible mechanism for encouraging contracting authorities to promote innovation in the economy while pursuing their primary goals. These targets are in most cases indicative and non-binding. To date, there is no unambiguous measure of innovation procurement that would allow policymakers to identify to what extent governments provide support for innovation through public procurement alongside other innovation policy instruments (e.g. grants and tax incentives). It is therefore important to note that discussion of targets has often preceded a discussion of whether there are robust measurement systems in place to support this type of use of indicators. This, and the possibility that the targets may have unintended effects, may explain why only very few countries have already specified precise innovation procurement targets on a formal basis.

- $\quad$ Austria identified a 2-5\% potential for innovation procurement but has not adopted a specific target. http://cordis.europa.eu/fp7/ict/pcp/docs/pcp-austria-casev0.pdf

- The 2013 Action Plan for Research and Innovation Policy in Finland proposed a 2-3\% target for public procurement enhancing R\&D and innovation activities and a 1\% target for public purchases of new solutions in clean technologies. http://www.tem.fi/files/36112/Action plan for research and innovation policy.pdf

- $\quad$ Legislation to promote innovation procurement in France (measure 32 of the "Pacte de compétitivité" 2012) proposed a $2 \%$ target for public authorities to spend on purchases from innovative SMEs and enterprises by 2020; http://competitivite.gouv.fr/documents/commun/transversal/Dossier-presse-competitivite.pdf

- The Korean government introduced public procurement policies in 2006 for innovation-oriented SMEs and has sought to increase procurement of innovative goods and services through a "New Technology Purchasing Assurance" scheme (NTPA), prioritising products with technology certifications such as NEP (New Excellent Product), NET (New Excellent Technology), GS (Good Software), and EPC (Excellent Performance Certification). The current target is to set aside at least $10 \%$ of the annual public procurement budget for the purchase of NTPA products. In addition to the purchase assurance, SMEs benefit from NTPA R\&D grants provided by the Small \& Medium Business Administration to support technological development (see OECD (2014a) and Lee (2013b)).

- In the Netherlands, the Innovation Platform Initiative proposed a $2.5 \%$ target of total procurement budget reserved for goods or services not yet available on the market, the monitoring of which was noted to be challenging. $\quad$ http://topsectoren.nl/documenten/topsectoren/Progress-Report-on-Enterprise-Policy2013 2014-01-23 85.pdf

- The Spanish government adopted in 2011, as part of its "e2i State Innovation Strategy", the objective of allocating $3 \%$ of new investment contracts to the procurement of technological innovations. http://www.idi.mineco.gob.es/stfls/MICINN/Innovacion/FICHEROS/Politicas Fomento Innv./Acuerdo Consej o Ministros 8-7-11 CPI.pdf

- $\quad$ The Swedish agency VINNOVA put forward in 2007 a proposal that the Swedish government set a target for public authorities to spend at least $1 \%$ of the total procurement volume on innovation. http://www.vinnova.se/upload/EPiStorePDF/vp-07-03.pdf

- The Advisory body for the European Research Area called for a 2\% target for public procurement budget dedicated to innovation. The Europe 2020 Flagship Initiative "Innovation Union" called in 2011 for €10 billion a year to be dedicated to innovations that improve the efficiency and quality of public services. http://cordis.europa.eu/fp7/ict/pcp/main-outcomes-innovation-in-public-procurement-conference-23-24-04brussels.pdf

Source: OECD, based on national sources.

A measurement system driven by statistical needs can assist with the preparation and interpretation of basic government expenditure figures and help address questions on how much support governments provide for R\&D and innovation activities. Aggregate statistics can be used for the purpose of international benchmarking as long as they are produced on a comparable basis, and are sufficiently integrated in the existing frameworks for measuring economic activity, R\&D and innovation.

Policy makers may wish to support the development of an analytical evidence base for policy evaluation and policy setting purposes. In this case, the measurement system supports and informs the 
assessment of procurement and innovation policies, providing the basis upon which competing hypotheses can be formulated and empirically tested. This policy learning can then contribute to the formulation of procurement and innovation policy and programmes, reducing the existing reliance on selected case studies which may not be representative of the population of interest or support the identification of policy impacts. The distinction across these rationales can be important because meeting different purposes entails varying levels of ambition, potential trade-offs and may require different approaches which can be used in isolation or in a complementary way. Take for example the notion of an "innovation procurement" target for contracting authorities. Such targets have been proposed and in some cases adopted without a specific measurement system in place. A measurement system that relies on public databases intended for securing the accountability of individual procurement actions may embed strategic reporting biases that could undermine their potential statistical use and international comparability, for example if there is a direct benefit in being tagged as procuring innovation. For policy makers interested in the validity of a given policy target and the "value for money" of specific innovation procurement programmes, micro-data on procurement decisions and careful research designs can help provide better evidence that takes into account behavioural responses and other confounding effects.

In conclusion, there is a broad range of possible uses for measures and analyses that capture different dimensions of the relationship between procurement activities and innovation. Irrespective of the innovation dimension, measurement can play an important role in ensuring the transparency and integrity of procurement decisions. There are potential administrative, statistical and policy analysis objectives for developing and reporting measures of innovation procurement, as well as possible tradeoffs. Measurement can influence behaviour in both intended and unintended ways, particularly when used as targets at an individual or macro level. This report focuses on the roles of statistical measurement and analysis for informing policy, rather than operational monitoring purposes. Policy questions of interest may include:

- How does innovation procurement compare with other forms of public support for innovation, such as tax relief and grant measures?

- What are the implications of modifying national and international procurement rules?

- What is the role of standards in public procurement and do they impact on innovation?

- What is the impact of public accreditation or certification mechanisms for innovative goods and services and innovation quotas? Can innovation targets be applied to procurement as an incentive mechanism?

- What is the catalytic or demonstration role of public demand in driving innovation diffusion?

- What is the impact of supply-side measures in the context of potential, future procurement actions, such as the award of grants for R\&D in areas of potential public demand? 


\section{Defining and measuring the link between public procurement and innovation}

\subsection{Concepts and definitions in the literature}

Concepts and definitions play a key role in identifying and clarifying the phenomena of interest for measurement. Such concepts and definitions must serve some well-defined purpose, as noted in the earlier section, and must support and also reflect the development of instruments that can be brought into actual measurement practice. Classifications and taxonomies help categorise different, interconnected dimensions of a common phenomenon.

Developing a conceptual framework for measuring the link between procurement and innovation in firms is greatly assisted by considering the general notion of "solution" as comprising the new and improved products and processes that may be the object of procurement decisions by public authorities contracting with firms or other possible providers, to meet a range of economic and social objectives among the former (the public authorities). The notion of "solution", as opposed to good or service, can be considered useful because procurement can be open enough to specify a "need" which can be fully or partially addressed in a different way (as a good or as a service). Solutions may be considered in their ideation or conceptual stage, or as fully implemented, i.e. brought into use.

Measurement needs to take into account which party in this relationship is best suited to provide accurate and reliable information and data. For example, there is abundant experience showing that information on the ultimate economic and social objectives underpinning the solicitation of solutions and their ultimate use would be best provided by the users (the authorities and potentially the users of the services provided by public authorities). Information on the attributes and the processes leading to the development of innovations are probably most effectively reported by the firms and organisations contracted to do so and can be readily linked to measures of economic performance within them.

Despite the growing interest in demand-side policies, and public procurement in particular, few public authorities (e.g. Korea) have attempted to classify public procurement actions so as to distinguish between "off-the-shelf" and innovation-oriented procurement. In the academic literature, various definitions (e.g. Edquist and Hommen, 2000; Edquist and Zabala-Iturriagagoitia, 2012) and taxonomies of innovation procurement have been proposed (e.g. Edquist and Hommen, 2000; Edler and Georghiou, 2007; Hommen and Rolfstam, 2009; Uyarra and Flanagan, 2010; Edquist and ZabalaIturriagagoitia, 2012; Edquist, 2015; Uyarra, 2015).

According to the definition proposed by Edquist and Zabala-Iturriagagoitia (2012), public procurement of innovation occurs "when a public organization places an order for the fulfilment of certain functions within a reasonable period of time (through a new product)", implying that the public entity buys a new product in order to target functions that satisfy human needs or solve societal problems. A new product could be a good or a service or a combination of the two (a system). Definitions of innovation procurement have become more inclusive of innovation activities other than R\&D (Edler and Georghiou, 2007). References to public technology procurement defined as the act of a public agency (Edquist and Hommen, 2000) "to purchase, or place and order for, a product - service, good, or system - that does not yet exist, but which could probably be developed within a reasonable period of time, based on additional or new development work - e.g. R\&D - by the organization(s) undertaking to produce, supply, and sell the product", are rarely found nowadays.

Uyarra and Flanagan (2010) have highlighted the inadequate coverage of various dimensions of innovation (e.g. the recombination of existing goods or services and process innovations) within commonly-used definitions of innovation procurement. Various taxonomies that refer to the type of innovation or stage of technology life-cycle (Edquist and Hommen, 2000; Edler and Georghiou, 2007; 
Hommen and Rolfstam, 2009), the end user of the product (Edler and Georghiou, 2007; Hommen and Rolfstam, 2009) or the nature of the actual goods and services procured (Uyarra and Flanagan, 2010) have been proposed to help clarify these conceptual issues.

Edquist and Zabala-Iturriagagoitia (2012), for instance, classify public procurement of innovation according to three dimensions: (i) the end-user of the purchased good (public authority vs. society as a whole), (ii) the character of the result of procurement process (pre-commercial, adaptive and developmental procurement), and (iii) the cooperative or non-cooperative nature of the procurement process. ${ }^{13}$ In this framework, the so-called pre-commercial procurement is presented as mainly a supply-side policy tool with common but distinct elements to those that define the public procurement of innovation. In this view, the use of a contractual purchase of R\&D or other development services as opposed to a grant does not justify its description as a demand-side tool because there is no guarantee of effective demand for a new product or solution based on the results of the work. The subject of $\mathrm{R} \& \mathrm{D}$ funding through contracts versus grants will be reviewed in section 4 .

\subsection{Demand and public procurement in the Oslo Manual}

There are two main relevant definitions in the OECD/Eurostat Oslo Manual (OM) which can be applied to the study of innovation procurement:

\section{Box 3. Definitions of innovation and innovation activities}

INNOVATION: “...the implementation of a new or significantly improved product (good or service), or process, a new marketing method, or a new organisation method in business practices, workplace organisation or external relations". [Para 146] A common feature of an innovation is that it must have been implemented. A new or improved product is implemented when it is introduced on the market. New processes, marketing methods or organisational methods are implemented when they are brought into actual use in the firm's operations. [Para 150]

INNOVATION ACTIVITIES: "all [...] steps which actually, or intended to, lead to the implementation of innovations". [Para 149]

Source : OECD/Eurostat (2005)

According to the Oslo Manual, a common feature of an innovation is that it must have been implemented in the marketplace. For products (goods and services), this is identified with a market launch. For processes and methods, this means actual use within the firm. This definition of innovation has a number of implications for considering a possible definition of innovation procurement and its relationship with the Oslo Manual:

- A new or improved product is implemented when it is introduced to the market. This constrains the identity of the innovator to units that operate in the marketplace and excludes units like government institutions and non-profit organisations that do not systematically engage in providing goods and services at economically significant prices. ${ }^{14}$ New processes, marketing methods or organisational methods are implemented when they are brought into actual use in the firm's operations. The introduction of innovations by other types of organisations such as public authorities ${ }^{15}$ and non-profit organisations is not currently contemplated for measurement guidance purposes in the Oslo Manual but is the subject of separate OECD analysis - a NESTI project on measuring public sector innovation. The case of public procurement highlights the importance of developing methodological guidelines for dealing systematically with innovation activities that cut across sectoral boundaries. It also has implications for the study of innovation within the government sector. 
- There is no formal requirement that the introduction of a product or the adoption of process or methods is economically successful, because such an assessment requires additional evidence which may not be forthcoming at the point of reporting. An expectation of value creation is implicit in that a firm has dedicated resources to put it into the market or use internally. This perspective, which is principally justified by the need for contemporary measurement of innovation, is somewhat less appealing to policy makers and their focus on solutions delivery and value creation.

- According to the $\mathrm{OM}$, the minimum requirement for an innovation is that the product, process, marketing method or organisational method must be new (or significantly improved) to the firm. This includes products, processes and methods that firms are the first to develop as well as those that have been developed elsewhere and adopted from other firms or organisations. In this way, the Oslo Manual captures diffusion processes. In the case of procurement, this presents the challenge of how to deal with public sector organisations that implement solutions that have been developed by firms or have been already adopted by other public sector organisations.

Table 3. Innovation procurement and its relationship with the Oslo Manual framework: a taxonomy and some- examples

\begin{tabular}{|l|c|c|}
\hline New to public authority & Not new to public authority \\
\hline New to firm & $\begin{array}{c}\text { Order for a solution that does not exist. } \\
\text { Requires product (good or service) } \\
\text { innovation by firm. } \\
\text { [Included in Oslo Manual] }\end{array}$ & $\begin{array}{c}\text { Firm upgrades its processes and wins } \\
\text { contract to deliver a solution to public } \\
\text { authority which the latter previously procured } \\
\text { from another firm or sourced internally. } \\
\text { [Included in Oslo Manual, potential } \\
\text { organizational or process innovation for the } \\
\text { public sector] }\end{array}$ \\
\hline Not new to firm & $\begin{array}{c}\text { First time use by public authority of } \\
\text { innovation developed and brought to the } \\
\text { market by firm in the past. } \\
\text { [In principle not a business innovation but } \\
\text { delivery could be interpreted by firm as a } \\
\text { new product= new use of existing product } \\
\text { [It is a possible innovation by public } \\
\text { authority in an extended framework] }\end{array}$ & Not an innovation \\
\hline
\end{tabular}

* OM§159. The development of a new use for a product with only minor changes to its technical specifications is a product innovation.

As a result, within the current framework, information is collected solely from the perspective of the firm that may deliver goods and services to authorities. This implies that:

- The current innovation measures include innovations introduced by firms in the context of or in anticipation of procurement activities, for example the delivery of a new military aircraft, new instruments for use in hospitals, or state of the art protective equipment for use by fire brigades. However, they do not provide a method for identifying these innovations separately from others.

- The scope of the Oslo definition is focused on innovations that are introduced by firms and thus excludes innovations that are introduced by public authorities, including those with 
procurement activities. ${ }^{16}$ For example, public authorities procuring blueprints, consultancy services or rights to use existing knowledge to allow them to improve the efficiency of their operations or the quality of their services provided to the public may not be reported as innovations by firms, unless the deliverable itself qualifies as an innovation. This reflects the difficulty of separating development and implementation in practice. Questions on procurement for public sector innovation as well as changes in the procurement processes might in the future become the object of future separate, dedicated surveys addressed to public authorities. Such is the object of separate OECD methodological development efforts.

- In between these two extremes, partnerships between companies and the public sector may split responsibilities among their contributors for the risk and outcomes associated with the development and implementation of innovations. These are likely to be reported by both firms and public authorities if asked about them. Those partnerships may also be entities in their own right. When set up as companies, they may be within the scope of standard innovation surveys.

Each one of the cases illustrated in Table 3 is interesting in its own right, with measurement potentially useful for addressing a range of different policy-relevant questions. The Oslo Manual currently combines novelty in development and implementation but is strictly focused on companies as far as the identity of the party implementing the innovation is concerned. ${ }^{17}$ The examples above highlight that the framework is relatively well equipped to capture most instances of what is typically described as innovation procurement. However, for practical reasons, it currently precludes the inclusion of public authorities as innovators. This results in relevant examples being potentially excluded from measurement, in particular when a solution available in the market sector is first procured by the public sector to meet a rather specific need.

The Oslo Manual adopts a "subject" approach which looks at the innovative behaviour and activities of the firm as a whole. The aim is to explore the factors influencing the innovative behaviour of the firm (strategies, incentives and barriers to innovation) and the scope of various innovation activities, and above all to examine the outputs and effects of innovation. These surveys are designed to be representative of most if not all market sector activities so that the results can be grossed up and comparisons can be made between industries and countries. This does not preclude however the investigation of a major innovation or innovation project within a surveyed firm. In that context, it may be possible for respondents to report on the extent and role of government procurement in a rather concise fashion, prompted by specific questions.

The role of procurement within the framework of the Oslo Manual has to be considered from the perspective of demand factors and how they shape innovation activity. ${ }^{18}$ Demand affects the development of new products, as firms modify and differentiate products to increase sales and market share, or create new markets. Demand factors can force firms to improve their production and supply processes in order to reduce costs and lower prices. In many cases, they are also the main driver of innovation. Firms often dedicate resources on researching demand and can adopt marketing measures to influence or create demand for their products. Market factors determine the commercial success of specific technologies or products and affect the path of technological change. They may also determine whether or not firms innovate. If firms do not believe that there is sufficient demand for new products in their market, they may decide either not to innovate or to delay innovation activities, redirecting efforts to other priorities. Several companies look at small segments of the market for evidence to assess the acceptance of prototypes and redesign their innovations before fully committing financially to mass launches, blurring the separation between supply and demand. 
The Oslo Manual notes that both the measurement and analysis of the role of demand in innovation are problematic. It is very difficult to isolate demand effects from supply, and little is known about how to measure demand effects in surveys. Nevertheless, some aspects of demand may be covered through a survey instrument, such as the extent to which innovations in products and services, and the way in which they are provided, are driven through articulated customer requirements, or are supply-driven. The nature of customers and users is also a demand factor that the innovating firm takes into account. Some information can be obtained through innovation surveys in terms of the importance of market-related factors (both positive and negative) on innovation activity.

While the subject approach proposed by the Oslo Manual limits the scope for object-oriented measurement activities, it is possible to adapt questions that are relevant for the study of innovation procurement within existing surveys. The importance of public procurement to innovation is recognised in the manual. Paragraph 376 for example points out that "To evaluate the role of government procurement in innovation processes, it is useful to know whether or not a firm participates in government procurement of innovative products and processes at regional, national or international levels". It does not prescribe specific approaches noting survey space limitations and a lack of relevant and tested examples upon which to draw specific recommendations.

A review of the Oslo framework can be carried out by examining the wide range of roles that the public sector plays, as a procurer, in relation to the company that is in charge of developing and/or implementing the innovation. For example, the following categories fit within the existing manual:

- The public authority as a source of information for innovation, by indicating the willingness to place a new order, formulating the needs and key specifications, engaging in dialogue and providing feedback at key milestones and following delivery. ${ }^{19}$

- As a source of funds for innovation activities that take place in the firm, and the activities that the firm (potentially a services integrator) subcontracts to other firms and organisations.

- As an active collaborator, sharing efforts, not only financial but also in-kind, risks, and the potential upside.

- As the customer for the firm's products, in its own right and as a demonstrator vis-à-vis other public and private markets.

From this review it is possible to suggest a number of potential methodological developments and improvements to better capture the role of public procurement and strengthen the innovation measurement framework:

- It is important to aim to collection information on the markets served by business, not only on its geographical dimension, but also on the nature of the customers, including public authorities. Understanding the market helps put in context the firm's innovation activity and the degree of novelty. Among those with an interest in public procurement, this should be a first priority for surveys to incorporate.

- Well-designed surveys avoid questions that ask respondents to link causes with effects (e.g. as between public demand and innovation activity) as these are subject to significant biases. ${ }^{20}$. However, it is potentially meaningful to ask whether a firm has introduced an innovation in the context of its delivering of goods and services to public authorities, if a clear and unambiguous formulation can be found for such a question. 
- Increased attention to the distinction between development and implementation of innovations and the circumstances in which it is public authorities that bring innovations into practice with development input from companies. One aspect worth considering in more detail is the extent of novelty of innovations from the perspective of the producer vis-à-vis that of the user, while noting it will be difficult in practice for the former to report on the latter. This may be particularly important for the analysis of innovation in professional and creative service firms, whose products often take the form of implementable ideas.

- Questions on sources of information and collaboration deal with users/customers (the largest in terms of responses) and government as if these were two exclusive categories, without noting the potential overlap and its high specificity. It would be therefore desirable to use a revised, more informative taxonomy of partners and sources, without overextending the available list.

- Questions on public support for innovation currently tend to be constrained to tax incentives and grant funding. Qualitative questions on the relative importance of different instruments, which have been implemented in a few countries, could be extended to include public procurement. It does not seem possible, for the time being, to be able to identify precisely what proportion of innovation expenditures have been paid for by contracts.

\subsection{The experience of innovation surveys}

\section{Previous efforts}

Having identified a number of potential developments within innovation survey guidelines, it is relevant to assess what has been the experience of a number of countries that have already implemented questions relating to public procurement in previous innovation surveys. Most countries using innovation surveys include questions on the markets served by respondents. Typically the focus of this question is solely on the geographic location of markets, but not the type of customer served. Exceptions are the United Kingdom and Australian Innovation Surveys, the former of which collected information on whether the company principally services government, business or individual customers. The 2008-2009 innovation survey of Australia in turn asked enterprises whether or not government organisations had been the main source of income from sales of goods and services.

The importance of innovation procurement policies for companies has been addressed in the innovation surveys of the People's Republic of China (hereafter "China") and Korea. The 2012 Korean Innovation survey provides recent evidence on the degree of importance of public procurement (government/public sector purchasing) for firms' innovation activities in Korea, as rated by manufacturing and service firms with more than 10 employees. Overall $32.3 \%$ of firms in manufacturing and $27.7 \%$ of firms in services receiving public support for innovation stated that public procurement was highly important for their innovation activities, behind the importance assigned to support for commercialisation and tax exemptions. A similar type of question was used in China's 2006 innovation survey leading to similar results (CNBS 2007).

The 2003 German innovation survey (Mannheim Innovation Panel) is among the few official innovation surveys that, prior to this project, has drawn an explicit link between innovation and public procurement. Respondents were asked to state which industry the customer that triggered innovation belongs to (Aschoff and Sofka, 2009). The data were used to test the efficacy of public procurement in promoting innovation relative to regulations, $\mathrm{R} \& \mathrm{D}$ subsidies and basic research at universities. Innovation, more precisely innovation success, was measured as the share of turnover achieved with products possessing market novelty. Customer relationships with public administration, defence or 
compulsory social security serve as a proxy for public procurement. Their estimates indicate that public procurement has a positive and statistically significant impact on innovation success, which is attributable to non-defence related procurement. The effect is particularly marked for small firms in regions under economic stress. In contrast, measures of regulation and R\&D subsidies did not appear to show a significant effect on innovation.

\section{Introducing new approaches in innovation surveys - evidence from selected OECD countries}

In 2011/12, the Eurostat Task Force on the Community Innovation Survey, in which the OECD participates as an invitee, considered the content of the CIS2012 survey "model questionnaire", discussing and evaluating proposals for including questions relevant to the involvement in procurement activities of firms. A dedicated new section containing the following optional questions was ultimately included in the model 2012 Community Innovation Survey, with the new questions having a voluntary status. After a process of cognitive testing involving a consultant working for Eurostat and a number of participating countries, it was decided to use the formulation provided in Box 4. This entails a very simple statement about whether a company is involved in procurement contracts for goods or services, distinguishing between contracts with domestic or foreign authorities. This was followed by a separate question aimed only at firms that responded that they had been involved in procurement activities during the reference period. Such companies were also asked whether they had undertaken any innovation activities as part of the contract, with a set of possible answers that attempted to distinguish whether firms did innovate as part of the contract and whether it was a formal requirement to do so.

\section{Box 4. Main questions on public procurement in the 2012 Community Innovation Survey}

10.1 "During 2010-2012, did your enterprise have any procurement contracts to provide goods or services for:

(a) Domestic public sector organisations;

(b) Foreign public sector organisations.

10.2 "Did your enterprise undertake any innovation activities as part of a procurement contract to provide goods or services to a public sector organisation?

- Yes, and innovation required as part of the contract

- Yes, but innovation not required as part of the contract

- No"

Source: Eurostat, 2013

The use of the term "as part of" attempts to proxy the general concept of innovation procurement by providing a simple mechanism for firms to identify and self-report a link between its innovation and procurement activities. The options on contract requirements on the other hand provide an implicit means for the firm to consider whether the authorities were explicitly pursuing the procurement of an innovation. This avoids having to provide a potentially complex definition and presents the concepts in a way that firms may be prepared to respond to. Countries have slightly tweaked the questions to ensure they work in national languages, probably clarifying what is meant by "as part of" and "required". ${ }^{21}$ As of November 2014, the final headline results from these questions have become available for all European countries that introduced the question in the form of tables and charts included in national reports and the Eurostat database on innovation indicators. National statistical agencies providing their agreement to data sharing will likely deposit the micro-data at the Eurostat Safe Centre in the following year when they become available for detailed micro-econometric analysis for approved research organisations. 
The CIS2012 results on those two questions, combined with data for a few non-EU OECD countries, and some detailed but preliminary evidence shared by delegates from Belgium, Germany and Portugal at the project's final workshop held at the OECD in December 2013, indicate that these questions not only passed the initial testing phase but also produced relatively plausible and informative results. Figure 5 shows that between $9 \%$ and $34 \%$ of firms in countries for which data are available delivered goods or services to public authorities in 2010-12, mostly to domestic public organisations only $(78 \%-94 \%)$.

Figure 5. Firms engaged in public procurement contracts, 2010-12 As percentage of all firms

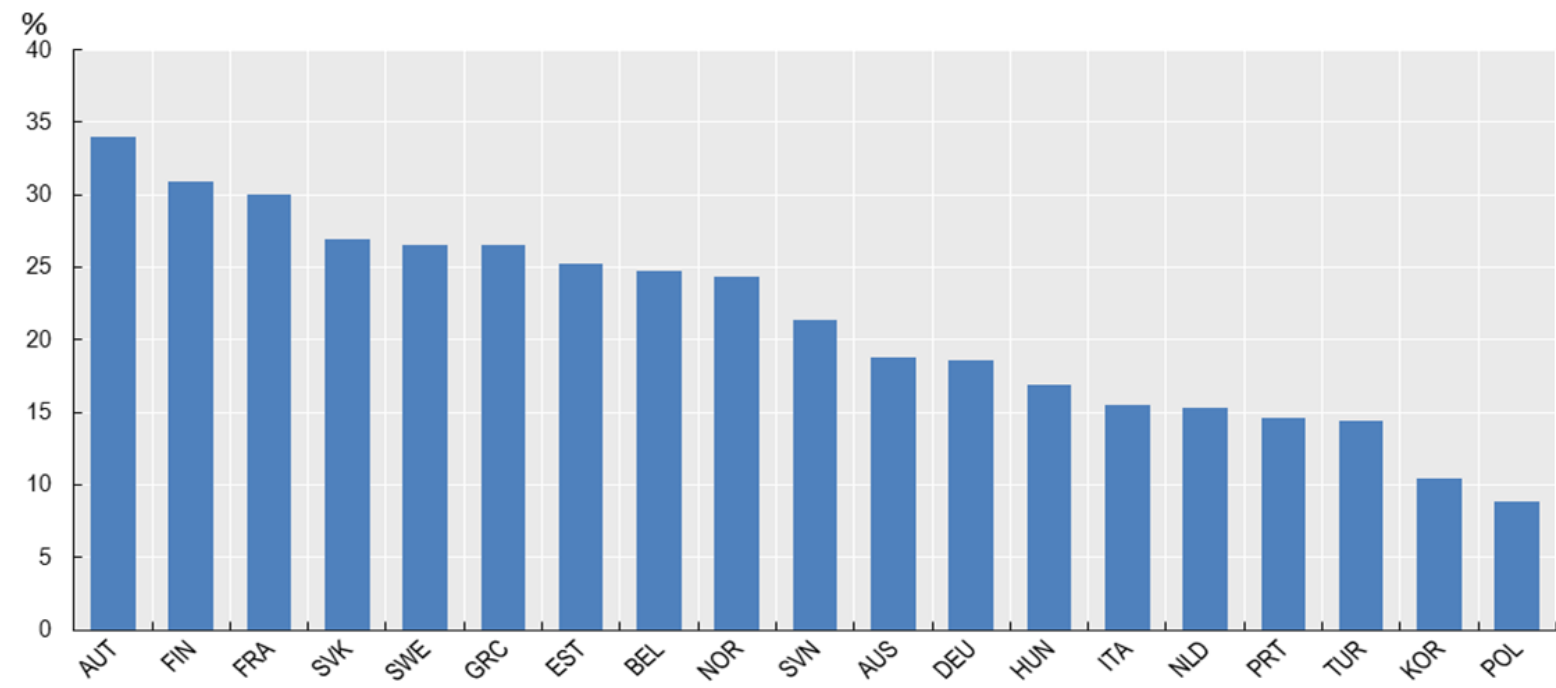

Source: OECD(2015e), based on Eurostat Community Innovation Survey (CIS-2012) and national data sources, June 2015

These results are seemingly consistent, in terms of orders of magnitude, with the only available statistics in Europe on procurement engagement, namely those relating to use of e-procurement systems (Figure 6).

Figure 6. Percentage of enterprises using electronic procurement systems, 2012

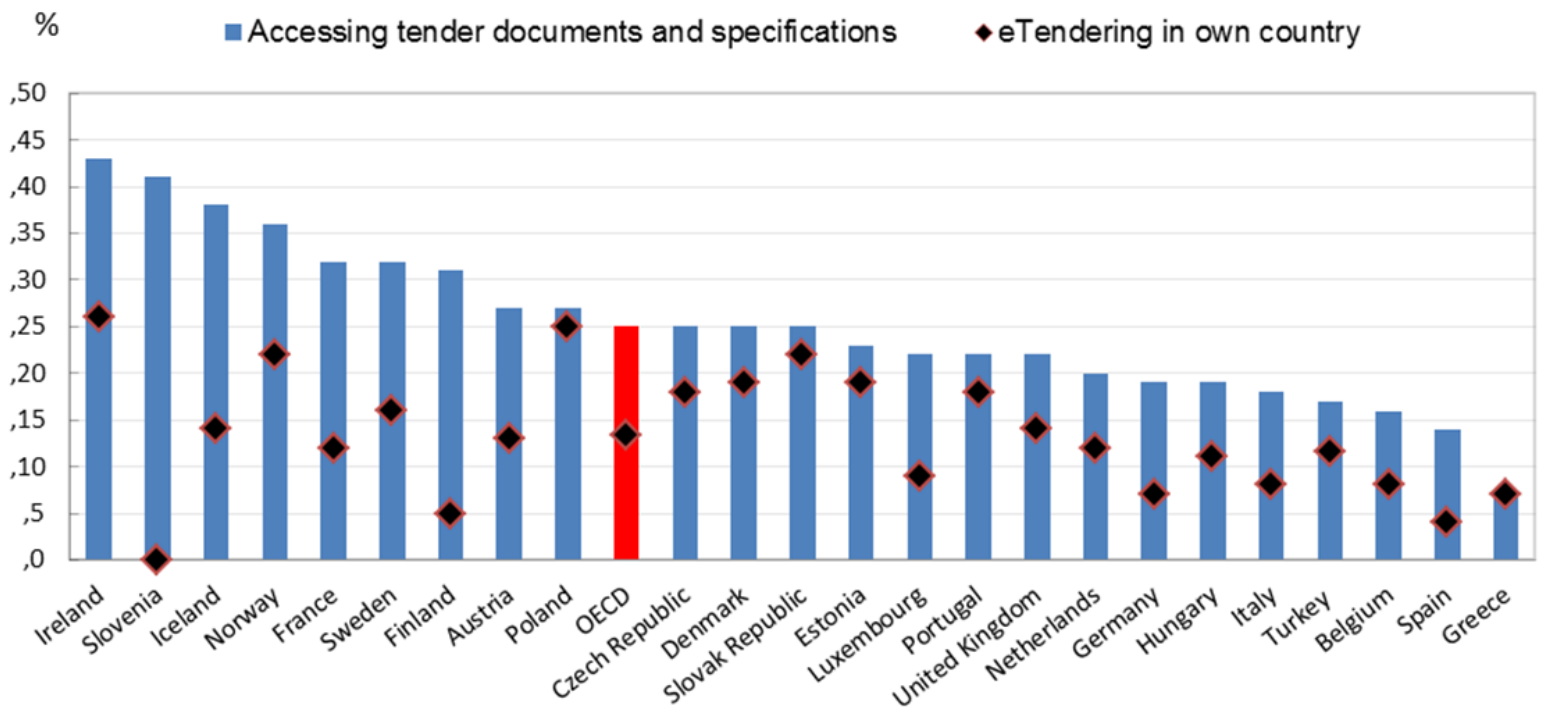

Source: Eurostat. Data for all enterprises employ 10 persons or more (excluding the financial sector). Data for Turkey are for 2011 rather than 2012. Retrieved from OECD (2013), Government at a Glance. DOI: 10.1787/gov_glance-2013-table101-en 
The percentage of firms supplying to both international and domestic public sector organisations increases with firm size, as could be expected. ${ }^{22}$ Figure 7 illustrates this pattern in the case of Portugal, contrasting the full population of firms with those enterprises that report having introduced a product innovation in the reference period 2010-12. The size gradient is less pronounced when considering firms that have been active in innovation over the reference period, indicating that size differences are partly reflected in the likelihood of being innovation active.

Figure 7. Firms with procurement contracts by type of public sector organisation, Portugal 2010-12 As percentage of contracting firms in the relevant firm size category

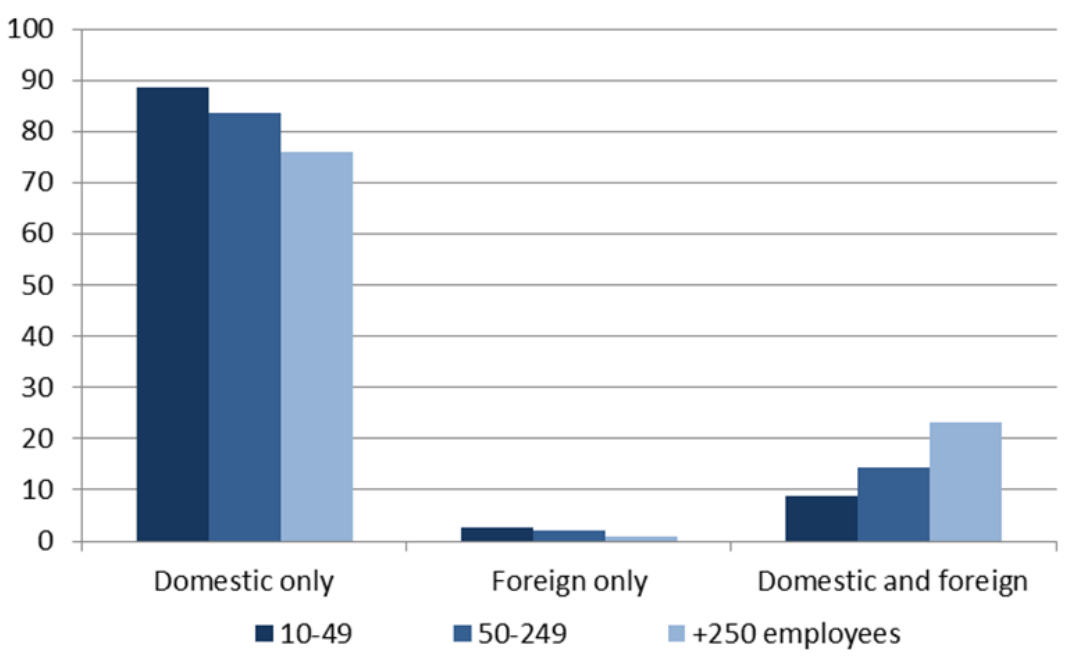

As percentage of contracting firms with product (good or service) innovations in the relevant firm size category

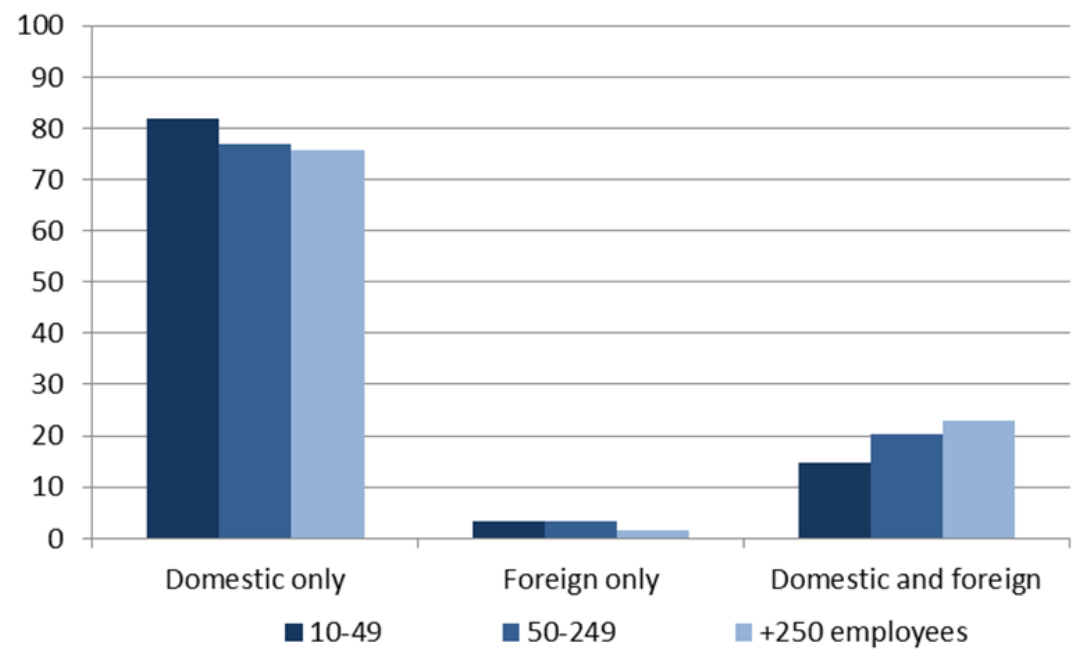

Source: OECD analysis, based on preliminary results from CIS2012 Portugal.

The link between public procurement and innovation can be first assessed by comparing the innovation patterns of firms according to whether they are involved in public contracts. In the case of Germany (Figure 8) ${ }^{23}$ reported innovation rates are indeed significantly larger for companies that are involved in procurement contracts than those that are not. Companies that report being required to innovate by their procurement contracts report an $85 \%$ product innovation rate and particularly high process, organisational and marketing innovation rates. 
Figure 8. Innovation activity and engagement with public sector organisations, Germany, 2010-12 Probability of innovation by procurement status and type of innovation

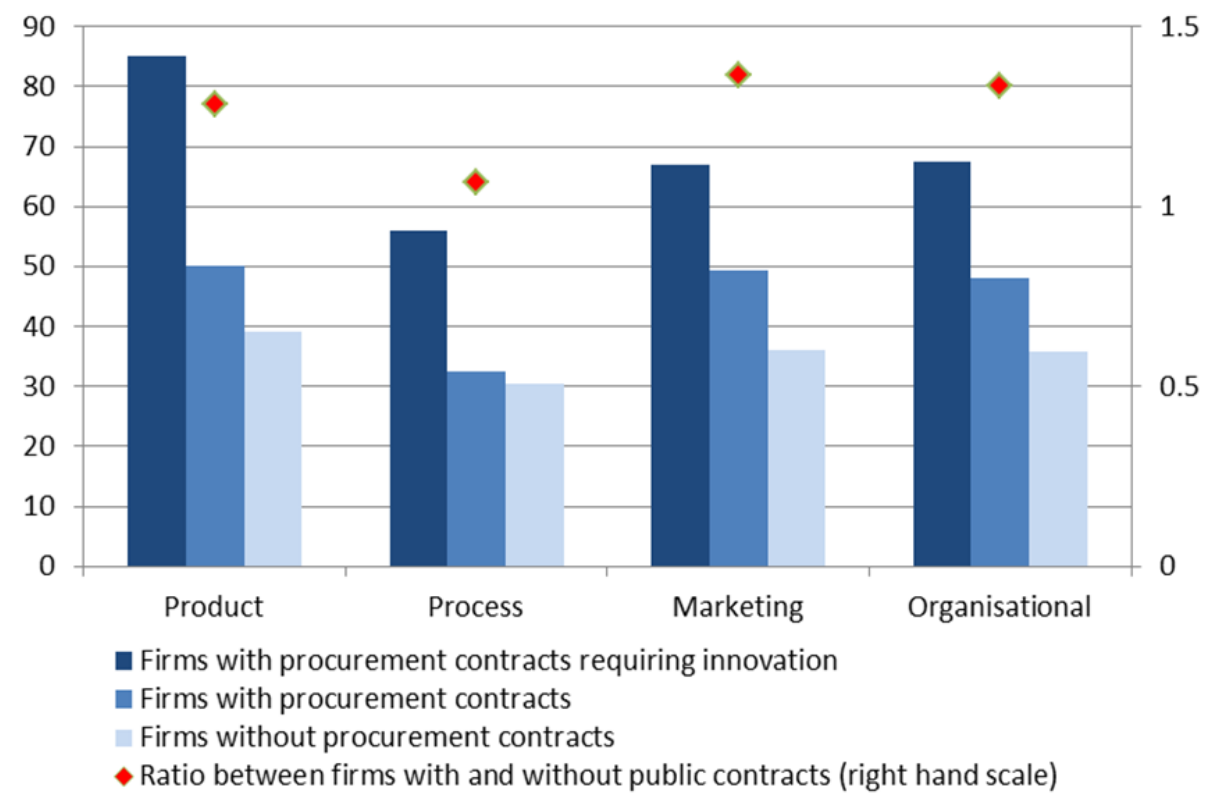

Source: OECD analysis, based on preliminary (unweighted) results from CIS2012 for Germany.

This finding applies more broadly across countries for which data are available. Figure 9a shows that the innovation gap is more noticeable for product than for process innovation, but differences are also found for other types of innovations that companies serving public authorities may also need to implement, including marketing and organisational innovations.

Figure 9. a. Difference in innovation rates for public contractors relative to other firms, by type of innovation

Absolute percentage difference

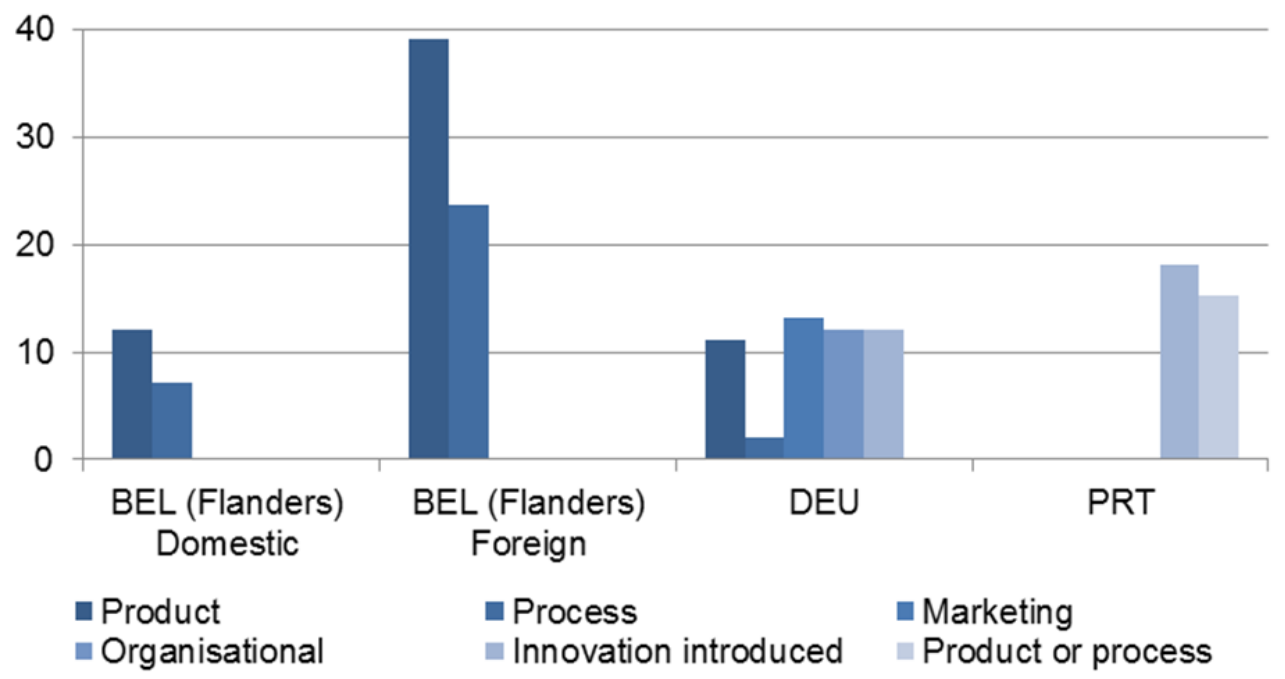

Source: OECD analysis, based on preliminary results from CIS2012 for Germany, Portugal and Flanders region of Belgium (contracts to foreign and domestic authorities compared separately with non-contractors). 
Figure 9. b. Participation in public sector markets, by firm size and innovation status, 2010-12

As a percentage of firms in the relevant group

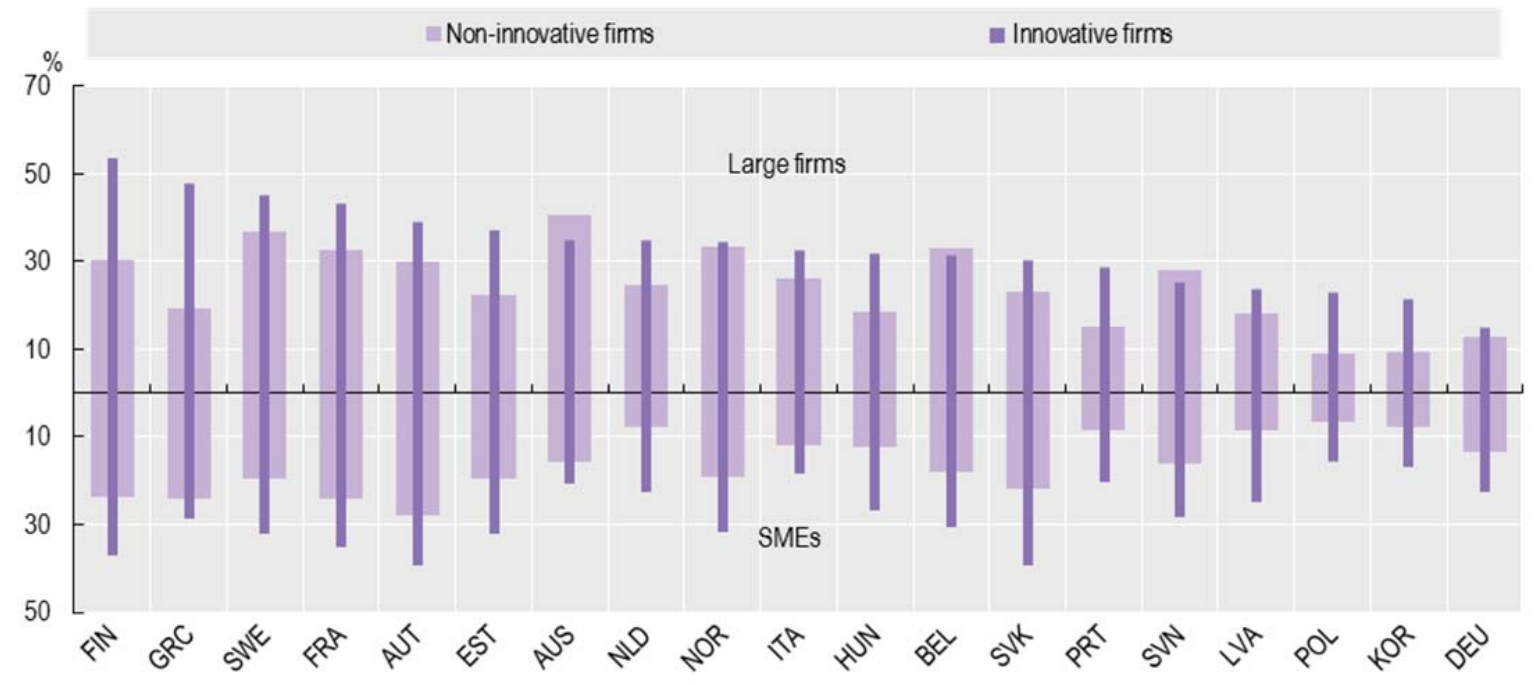

Source: OECD, based on Eurostat Community Innovation Survey (CIS-2012) and national data sources, June 2015.

Participation in public procurement markets is more common among large firms than among SMEs, and, with remarkably few exceptions, is far more likely among innovative than non-innovative firms (Figure 9b). This is even more clearly the case for SMEs.

It remains to be fully tested to what extent these differences are statistically significant once other factors and business characteristics are controlled for and whether similar results are obtained for other countries. This type of analysis should become feasible as more detailed indicators are produced after the initial release in November 2014. In the case of Germany, the results presented at the OECD expert workshop indicate that differences in product, marketing innovation, organisational innovation, new to market product innovations and in house R\&D are significant and robust to controlling for size, age, sector and region.

Innovative firms engaged in procurement contracts also appear to have a greater propensity to be active in foreign public markets than their non-innovative counterparts, as shown in Figure $\mathbf{1 0}$ for Portugal. Again, the direction of the causal effects cannot be determined. Additional efforts are required to establish whether innovation allows firms to serve public markets, or the experience of procurement enables firm to introduce new products to the market and allows them to improve their processes. 
Figure 10. Firms with procurement contracts by type of public sector organisation, Portugal 2010-12

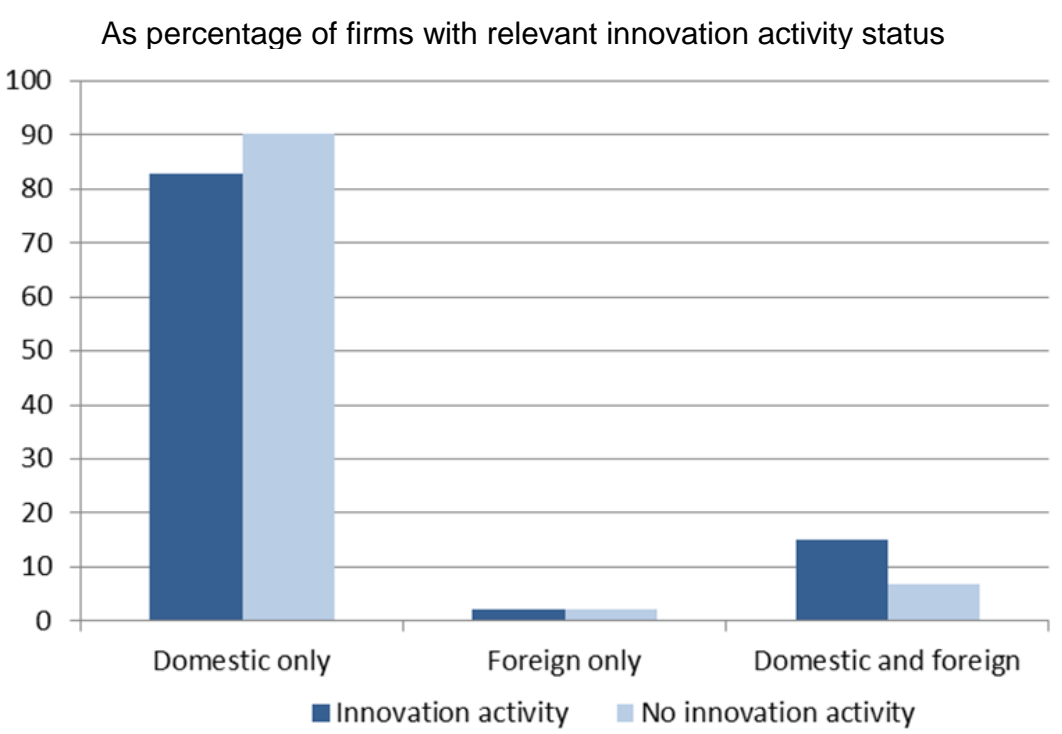

Source: OECD analysis, based on preliminary results from CIS2012 for Portugal. Enterprises with innovation activities (enterprises that implemented any type of innovation, including enterprises with abandoned, suspended or ongoing innovation activities).

Turning now to the analysis of responses to questions aiming to capture the link between public procurement and innovation, 14 to $36 \%$ of companies (contractors) in the 17 EU OECD countries involved in procurement activities over the reference period 2010-2012 reported to have undertaken some innovation activity as part of their procurement engagements with public sector organisations. Figure 11 displays, for the firms with procurement contracts, the share who reported to have undertaken an innovation activity as part of the procurement contract.

There is some significant variation as to whether companies undertaking innovation activities as part of procurement actions are required to innovate in their contracts. In the case of the Netherlands, Italy, Germany and Turkey, between $47 \%$ and $70 \%$ of firms that undertake innovation activities as part of public contracts indicate that they were required to innovate while in the case of Austria, Finland, France, Portugal and Sweden, this requirement tends to be reported as the exception: the percentages varies between $17-21 \%$. It is important to attempt to understand whether this is due to different interpretations of the terms required or actual differences in rules applied in countries. It is possible that public contracts in Germany are more likely to specify an innovation requirement if that is the intention or expected outcome. 
Figure 11. Innovation activity as part of a public procurement contract by type of requirement As percentage of contracting firms

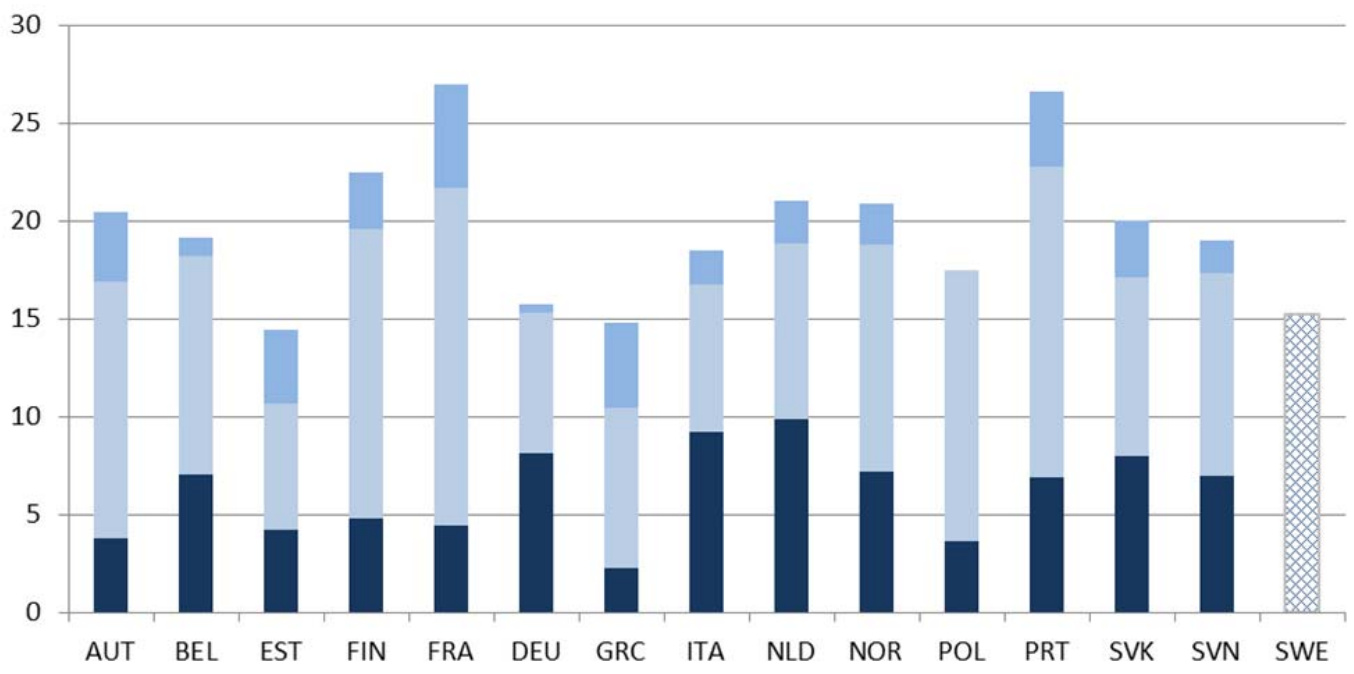

- Innovation always required $=$ Innovation never required $\|$ Innovation required and not required $\otimes$ No details on requirement

Source: OECD analysis, based on the final CIS2012 results. Estimates for Hungary and Turkey are pending confirmation.

Data shared by Portugal allows for a more detailed analysis within the group of firms that introduced product innovations (Figure 12). Firms that introduced both new goods and services are more likely to have undertaken an innovation activity as part of a public procurement contract. Formal requirements are relatively less important for these firms, which are probably more diversified than firms that only innovate in goods or services.

Figure 12. Innovation activity as part of procurement contract by type of requirement, Portugal 201012

As percentage of product innovators supplying goods and/or services to domestic or foreign PSOs

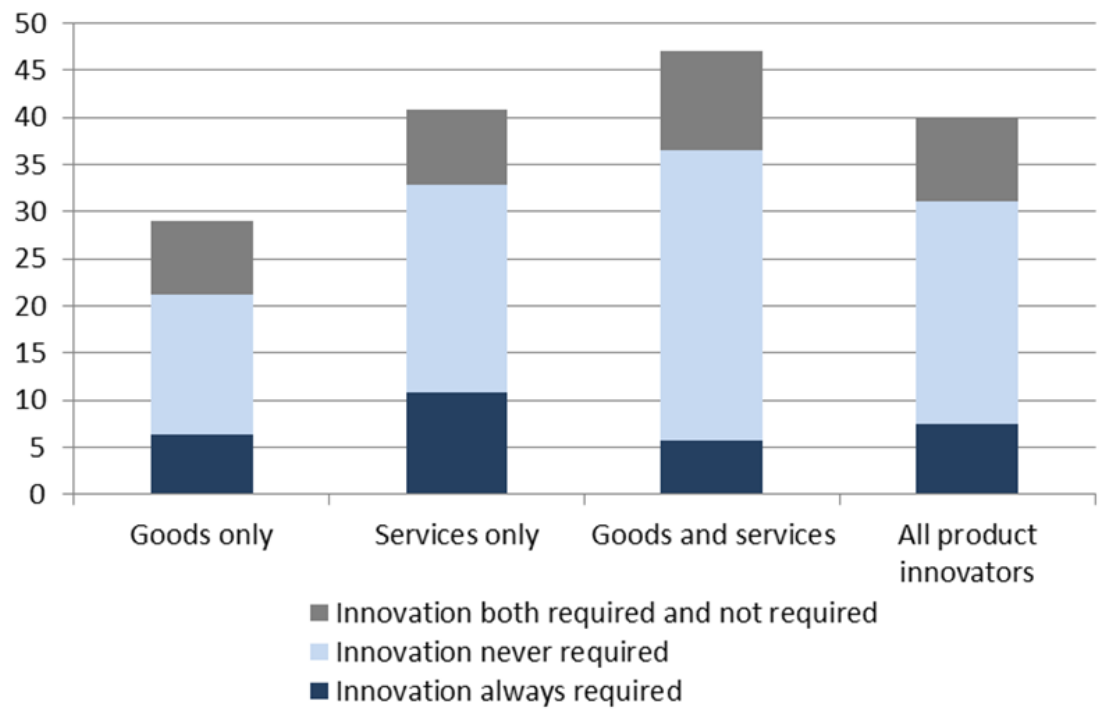

Source: OECD analysis, based on preliminary results from CIS2012 for Portugal. 
As noted in Section 1, there are significant sectoral differences in the relative importance of public procurement. This information is plotted for Germany against the proportion of firms in the sector with public contracts which are formally required to innovate as part of their contracts (Figure 13).

Figure 13. Public procurement contracts and innovation requirement by industry sector, Germany 2010-12

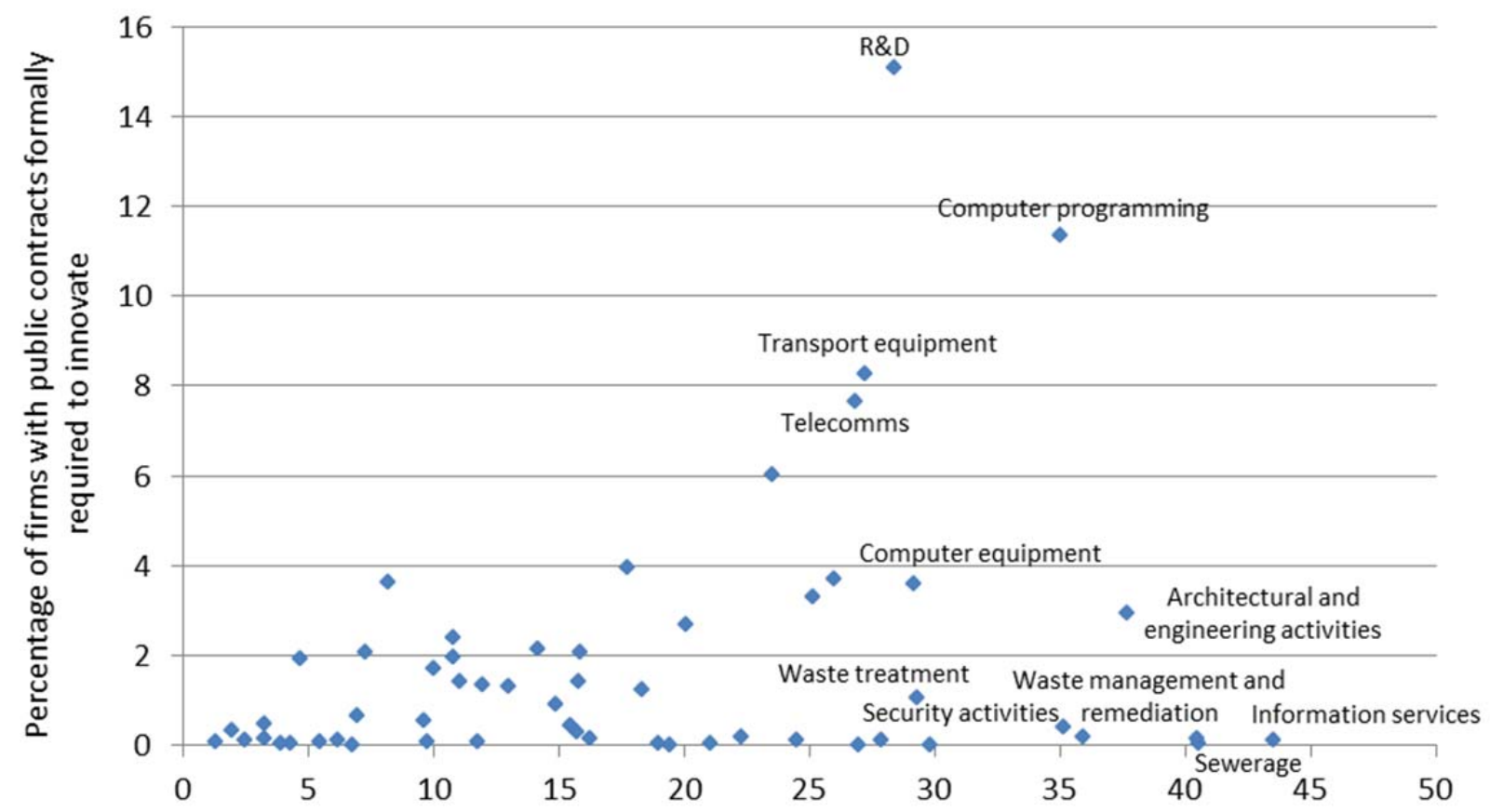

Percentage of firms with public procurement contracts

Source: OECD analysis, based on final results from CIS2012 for Germany (ISIC Rev. 4 industry sector classification).

Computer programming and architectural and engineering activities are two sectors that combine high procurement intensity with high expectations of innovation. Innovation requirements in other large procurement sectors such as those related to waste management and remediation are fairly low.

In the case of Belgium, the incidence of innovation as part of public contracts appears to be highest in knowledge intensive activities related to business services (Figure 14). 
Figure 14. Innovation activity as part of a procurement contract by industry sector and region, Belgium 2010-12

As a percentage of firms in relevant industry sector and region

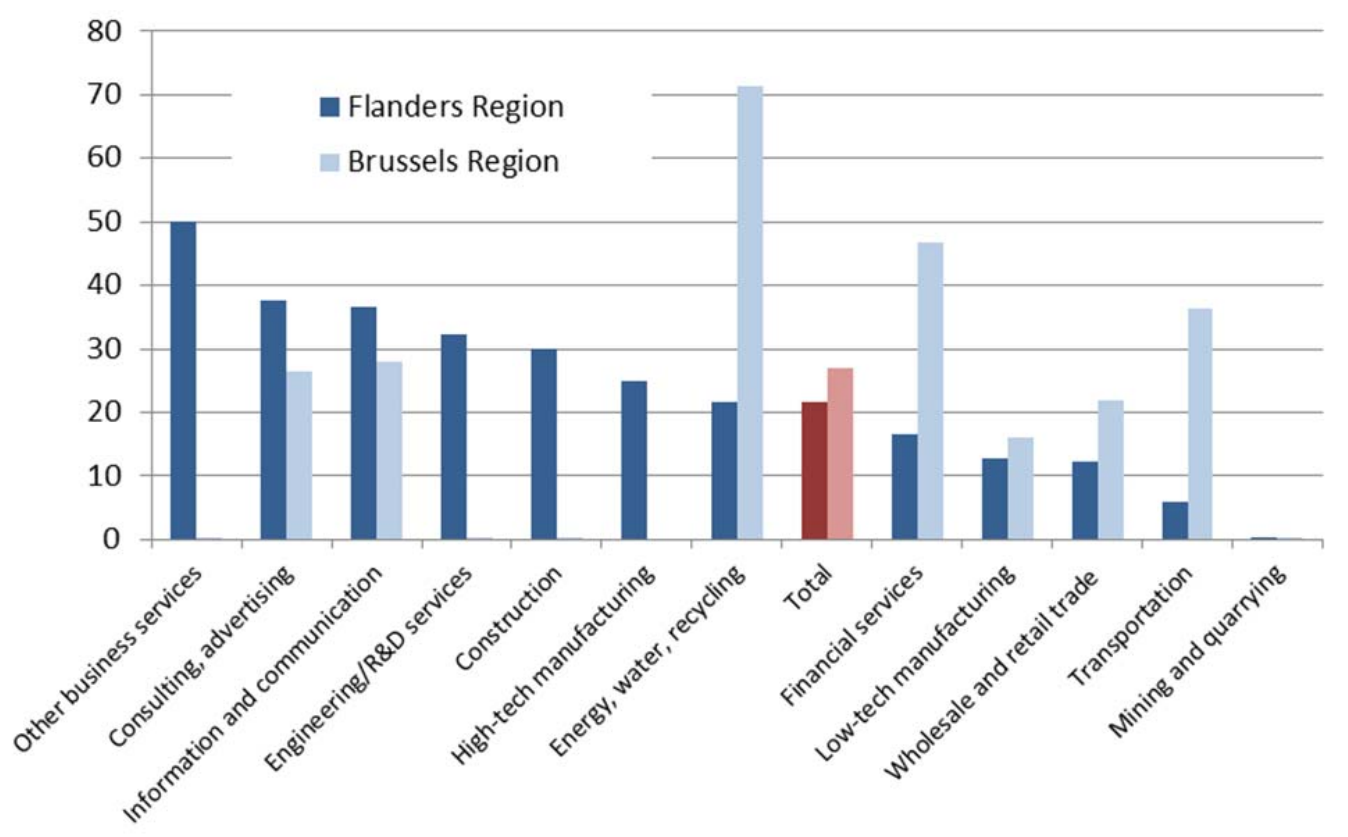

Source: OECD analysis, based on preliminary results from CIS2012 for Belgium (ISIC Rev. 4 industry sector classification).

Another set of changes introduced in CIS2012 relating to public procurement has to do with the roles played by public sector organisations as customers, information sources, collaboration partners or funders of innovation activities. Evidence from Germany's CIS shows that firms without public contracts rarely exhibit any of these types of relations with public sector organisations as customers (Figure 15). This provides a robustness check of the consistency of the response data. On average, collaboration with public customers on innovation is fairly low (around $10 \%$ of firms) unless procurement contracts require some form of innovation. In those cases, collaboration rates with public customers are the norm (nearly $60 \%$ of cases), although the importance of information from public sources is still somehow limited (nearly $30 \%$ ). Among these firms that engage in public contracts and are required to innovate as a part of them, more than $40 \%$ do not report receiving public funding for product or process innovation. This seems to suggest that not all firms recognise procurement as public funding of innovation. This may be related to the formulation of the question, which may be interpreted as asking firms whether they have received some form of subsidy for innovation. 
Figure 15. Engagement with public sector organisations (PSOs) by procurement status, Germany, 2010-12

As percentage of firms, by procurement status

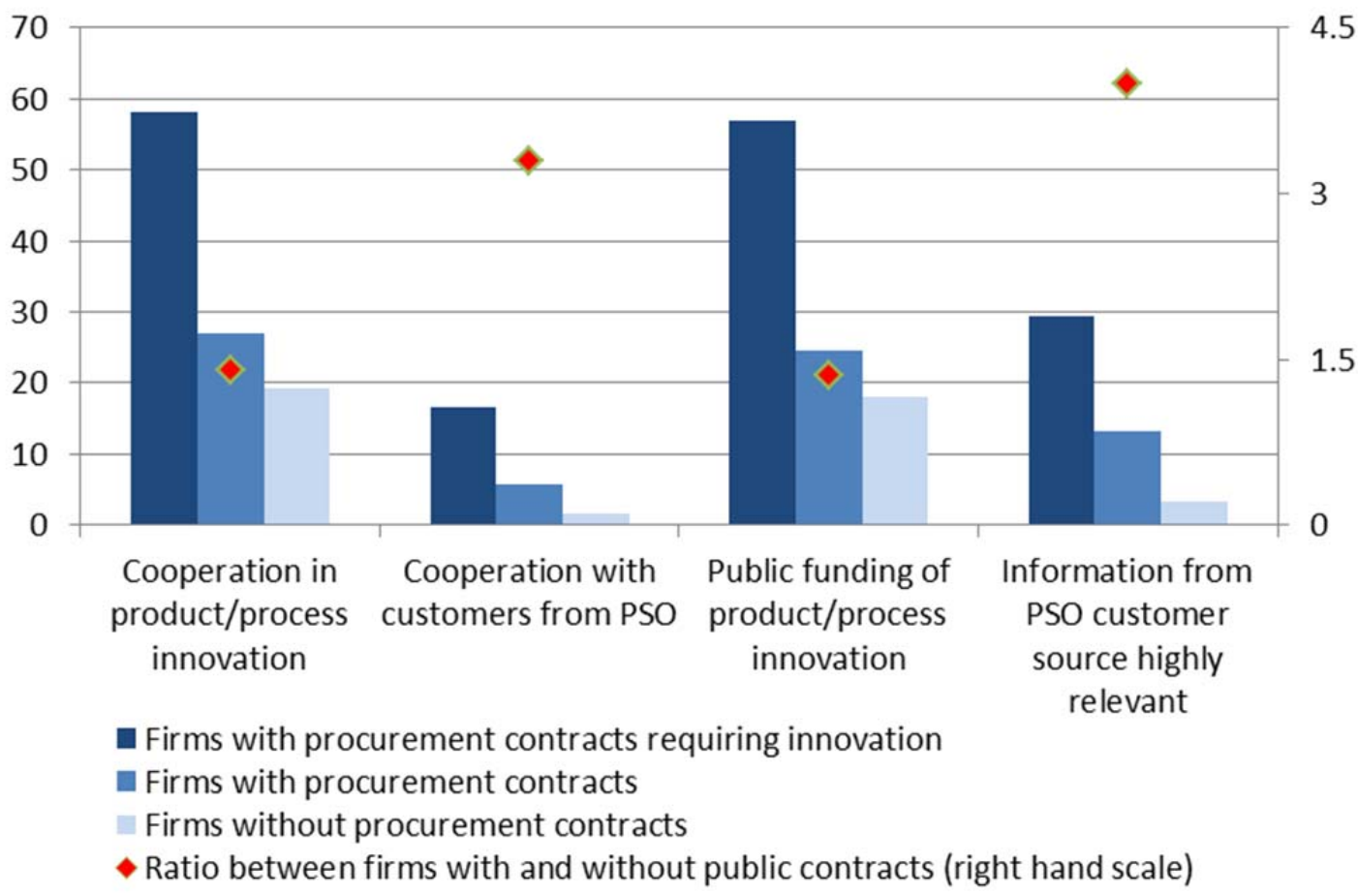

Source: OECD analysis, based on preliminary (unweighted) results from CIS2012 for Germany.

\subsection{Limitations}

There are obviously other policy-relevant dimensions of public procurement of innovation. For example, the catalytic role of public procurement in driving innovation is recognised to be an important aspect to consider. In this approach, government plays a role in strengthening demand for products and services that are still in an early stage of development or diffusion. Government purchases may provide firms with early market support and may act as a signalling device. ${ }^{24}$

Another aspect of potential interest is whether procurement drives radical, disruptive and transformational innovations. These concepts are still insufficiently tested in the context of innovation surveys, although a first approach would be to examine the link between procurement and market novelty of innovations, for which information is readily available from surveys. It is unclear to what extent innovation surveys can help identify these various concepts through simple questions. This requires a long- term perspective which typically exceeds the recall periods used in innovation surveys, and carries the added complexity of considering different products and their specific experience. Object-based measurement approaches - i.e. those focused on specific innovations rather than the entire firm's innovation activity - seem to be more suited for the study of catalytic and radical dimensions of innovation procurement. Longitudinal innovation data can be used as additional evidence to track over time the source of demand for a company's products, particularly young firms for which public procurement might be a first source of revenue. 


\section{Measuring $R \& D$ procurement}

Research and experimental development (R\&D) is an important innovation activity but not a necessary or exclusive source of innovations. R\&D is clearly just one aspect of innovation, and not all companies that innovate necessarily carry out $R \& D$. R\&D can be required towards the delivery of new goods and services as part of procurement contracts, or can be the actual object of procurement. It therefore needs to be stressed that "procurement of R\&D" and "procurement of innovation" are not synonyms. Public authorities can pay for R\&D services to be carried out by firms or other organisations without the R\&D performer being the party that ultimately introduces an innovation possibly the government or another firm. It is useful to consider separately the measurement of public procurement of $R \& D$ ( $R \& D$ procurement, for economy of words). Investigating $R \& D$ procurement is relevant in its own right and can also provide valuable insights on the procurement of innovation and its measurement.

The OECD Frascati Manual (OECD, 2002), which was recently revised in 2015 (OECD, 2015c), has provided a set of statistical guidelines specifically aimed at the collection of policy-relevant and internationally comparable data and indicators on $R \& D$ efforts. The focus of $R \& D$ statistics is collecting data on human and financial resources dedicated to the performance of R\&D within the reporting organisation, aggregating up to the level of broad "institutional sectors" such as business enterprises, government and higher education. Information about the sources of funds for those efforts is of high relevance, as it indicates to what extent a company or organisation relies on external funds, particularly those from government, and whether the financial flows reflect a flow of knowledge across them. ${ }^{25}$

$\mathrm{R} \& \mathrm{D}$ procurement by public authorities is one of the possible mechanisms by which governments may not only attain their own objectives but also directly or indirectly support R\&D activities elsewhere in the economy, alongside other instruments such as R\&D grants, tax relief for R\&D, and various forms of capital support such as the provision of loans, loan guarantees and equity funding. The transfer of funds from the government to other sectors is indeed particularly important to all users of $R \& D$ data, not only those interested in policies for the procurement of $R \& D$ and innovation.

Two categories of such government funds may be identified (OECD, 2002):

- $\quad$ Those that are specifically for the procurement of $R \& D$, i.e. the results of the $R \& D$ belong to the recipient of the output or product of the R\&D, which may -but not necessarily be- the funder of the R\&D.

- Those that are provided to the performers of $R \& D$ in the form of grants or other financial incentives, with the results of the $R \& D$ becoming the property of the $R \& D$ performers. ${ }^{26}$

The 2002 Frascati Manual proposed that the measurement of flows of funds, as components of the measure of R\&D, should focus on funds directly transferred from one unit to another that are both intended and used for the performance of $R \& D .{ }^{27}$ In the context of R\&D activities carried out by firms or other organisations in the context of public procurement, two cases may arise:

- "Direct" public procurement of R\&D. Public authorities can directly pay for R\&D carried out by business or other parties and claim some rights to its (uncertain) outputs. This is effectively a purchase of R\&D services.

- "Indirect" public procurement of R\&D. Contractors may need to engage in R\&D activities in order to meet (or to be in a position to bid for) the requirements specified in procurement 
tenders and contracts. This can be thought of as a particular type of innovation activity linked to public procurement, and as such can be analysed using the CIS2012 type by looking at the relationship between $\mathrm{R} \& \mathrm{D}$, innovation and contracting activity. This type of $R \& D$ procurement is excluded from what is considered to be government funding of $R \& D$ in the Frascati Manual, because the funds provided are for the ultimate good or service, and not necessarily intended for R\&D. ${ }^{28}$

The OECD Frascati Manual places particular emphasis on the importance of documenting the flow of R\&D funds from government to other sectors and recognises that these flows may be measured in two ways. One is performer-based reporting of the sums which one unit, organisation or sector has received or will receive from another unit, organisation or sector for the performance of intramural R\&D during a specific period. The second is source-based reporting of extramural expenditures which are the sums a unit, organisation or sector reports having paid or committed to pay to another unit, organisation or sector for the performance of R\&D during a specific period. The former is preferred for $\mathrm{R} \& \mathrm{D}$ statistics compilation purposes, but the utility of the latter is often recognised and a number of countries use it in a selective way to provide a more complete picture.

\subsection{Performer-based estimates of $R \& D$ procurement}

The Frascati Manual gives priority to data collected from a performer perspective in order to ensure consistency across the intramural $R \& D$ figures from individual survey respondents that are aggregated to derive estimates of Gross domestic expenditures on R\&D (GERD). ${ }^{29}$ The 2002 edition already recommended that, where possible, both categories of transfer of government R\&D funds should be identified in the R\&D data of the business enterprise sector. If possible, a similar breakdown should be made for government funds to the higher education sector.

While a considerable number of countries include very detailed questions in their business and higher education $R \& D$ surveys about the sources of $R \& D$ funding, this level of detail is often restricted to the identification of the institution, e.g. the government ministry, agency and sometimes programme which originates or distributes the funds. Few countries have so far collected information and reported on the type of transaction underpinning funding sources in their business R\&D surveys. Some exceptions are worth noting. As part of the questions asked to firms on sources of R\&D funds, the Survey of R\&D in Canadian Industry (RDCI) separately recorded R\&D grants and R\&D contracts from the federal government, but no similar breakdown is available for provincial governments. Data published in 2013 reported provisional estimates of CAD67 million worth of R\&D contracts in 2011, compared with CAD 377 million for grants and contributions. ${ }^{30}$ More detailed trends are provided in Figure 16, which shows how the role of R\&D contracts declined in the early 1990s, accounting for a relatively small fraction of direct public support for business R\&D in Canada. ${ }^{31}$ 
Figure 16. Federal grants and contracts as sources of funds for R\&D, Canada 1989-2011

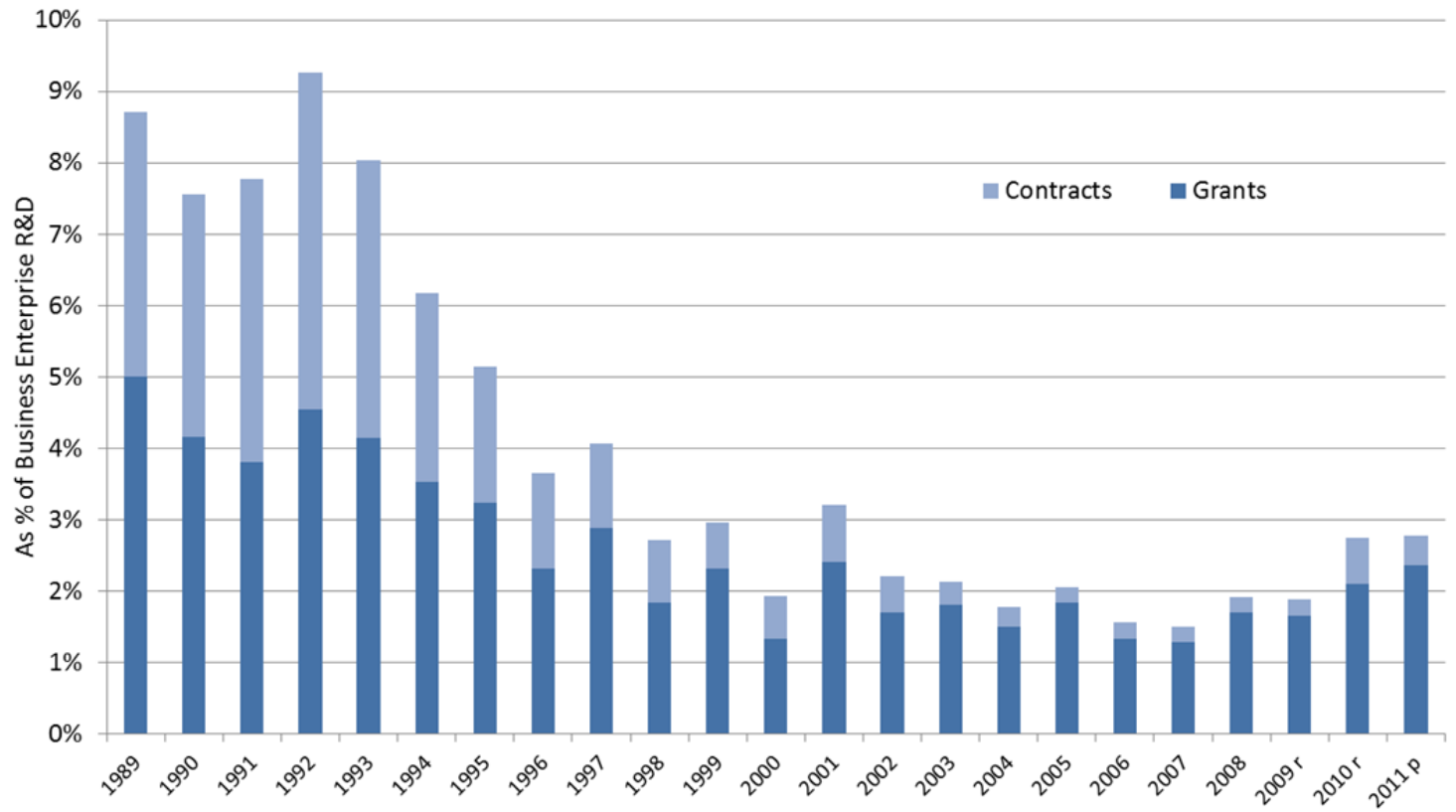

Source: OECD, based on data on sources of funds for intramural business enterprise R\&D from Statistics Canada. http://www.statcan.gc.ca/pub/88-202-x/2013000/t094-eng.htm

Spain's business R\&D and innovation survey asks companies about the value of R\&D contracts with central and local governments (separately from grants) within the sources of R\&D funds (Figure 17).

Figure 17. Grants and contracts as sources of funds for intramural business R\&D, Spain 2001-2012

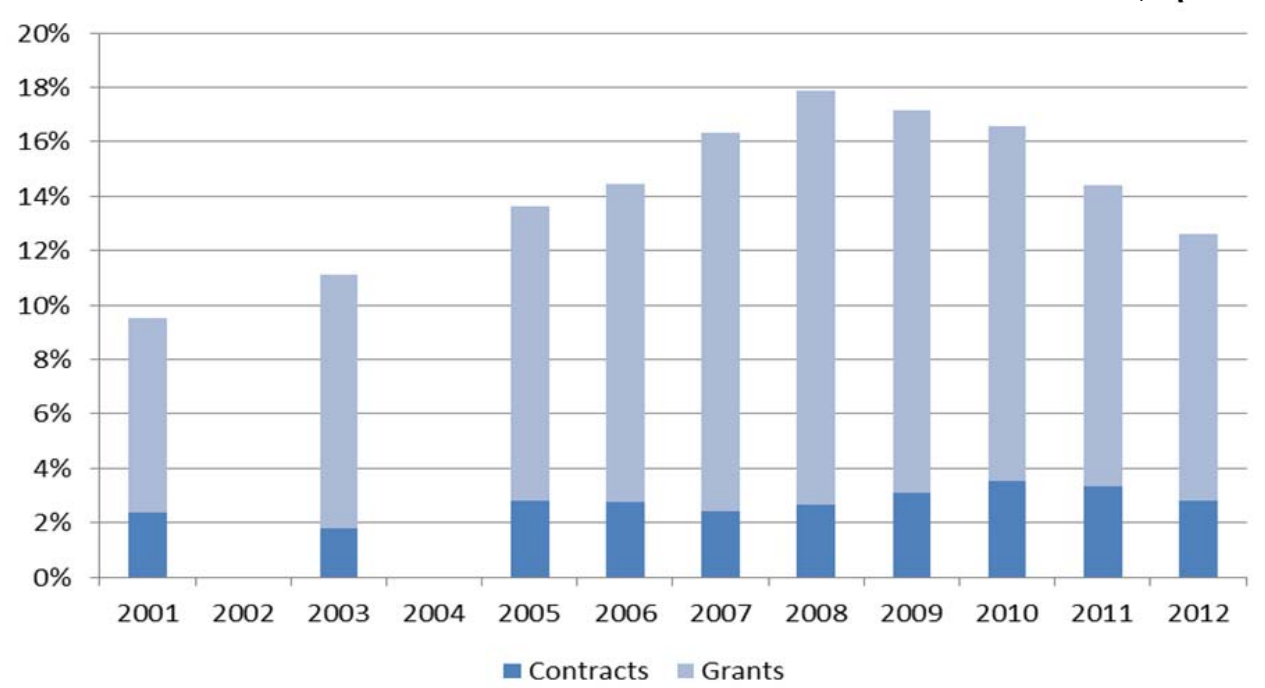

Source: OECD, based on data provided upon request by the Instituto Nacional de Estadística (INE). Results for each category combine estimates for central and regional government.

The UK Business R\&D survey included a new module in its 2012 questionnaire seeking to identify how much of business intramural R\&D was owned by government organisations, alongside domestic firms. ${ }^{32}$ This is a somewhat different concept, motivated by the national accountant's interest in $R \& D$ data for capitalisation purposes, which requires identification of economic ownership over R\&D (see Box 5). 


\section{Box 5. The capitalisation of R\&D in National Accounts - the treatment of R\&D procurement}

The decision to treat R\&D expenditures as leading to the formation of intellectual capital in the 2008 System of National Accounts (SNA 2008), the international standard for reporting economic and financial statistics, is another significant driver for the collection of data on R\&D procurement by the public sector. From the perspective of National Accounts, R\&D expenditures were traditionally treated as intermediate consumption when bought from another unit and payments to personnel devoted to R\&D fundamentally treated as overhead, resulting in no additional knowledge assets for the firm. From the perspective of governments, R\&D expenditures (purchases of R\&D services and in-house costs) contribute to final government consumption, as the measure of government output is constructed by adding up costs. R\&D grants, on the contrary, are transfers from government to other units.

In the new System of National Accounts, the distinction between procurement and grants becomes particularly important because it is necessary for identifying which sector owns the R\&D asset that public funds contribute to, and in what proportion. Collecting information on procurement of R\&D services helps adjust estimates of funds from government to industry that give business or other sectors full or partial ownership for the resulting knowledge-based capital. It is increasingly common in the context of R\&D procurement that contracting authorities relinquish ownership over the intellectual property arising from the R\&D services. At one extreme, this could be considered equivalent to grant funding. In practice, risk sharing arrangements are common. Governments may pay below the full economic cost of the R\&D and secure only partial rights to any new IP. The business in turn contributes its prior R\&D knowledge and effort in return for the right to the IP for use in other markets for example.

It is unclear whether the needs of National Accounts can be met through questions that ask explicitly about the ownership concepts, because of the practical challenges involved. In practice, the contract-grant distinction already used in some countries' R\&D surveys, as described below in Box 6 , is likely to suffice as a means of producing a reasonable approximation.

The U.S. Business R\&D and Innovation Survey (BRDIS) provides a much richer breakdown of sources of funds for intramural R\&D compared with its predecessor following its recent re-design. According to provisional estimates provided on request by the U.S. National Center for Science and Engineering Statistics and shared at the OECD expert workshop on measuring R\&D and innovation procurement, federal government funding accounted for $12.2 \%$ (USD 34 billion) of domestic business R\&D in 2010. Of that amount, between $84 \%$ (USD 28.8 billion) and 95\% (USD 32.6 billion) is funded through contracts, the remaining funds being allocated through grants, reimbursements and other measures of public funding. ${ }^{33}$ In the case of the United States, most contracts are related to defence procurement. A summary of the survey guidelines provided is available in Box 6.

\section{Box 6. Survey guidance on separating contracts and grants, BRDIS 2010}

\section{Contracts:}

A contract is a form of procurement where a good or service is provided by the recipient that benefits the funder; the funder specifies the expected outcomes and gains rights to the results

This category includes direct or prime contracts and subcontracts

The funder gains rights to results but does not necessarily own them nor have exclusive rights to them Grants:

A grant is a transfer of resources from one institution to another. Payments are received for which no current good or service is provided in exchange from the recipient.

Source: National Center for Science and Engineering Statistics, based on presentation at OECD expert workshop, February 2013. 
Contracts are identified with agreements for the delivery of services, with the funder gaining some partial or complete rights on the results of the R\&D. Grants are in contrast presented as unconditional payments in the sense of service being provided, although conditions can be present. The opposition between contracts and grants does not imply that there is no contractual basis to a grant agreement. In applying this type of guidance across other countries, it is important to take into account the usual terminology applied in the national context.

It is not possible at present to consider in detail the role of R\&D performers outside the business sector who provide R\&D services to governments. It is important to note that many R\&D contracts go to researchers in the higher education sector (not necessarily their commercial spinoffs which could be classified in the business sector) and many departments play a key role as subcontractors in R\&D procurement projects, carrying out research or providing access to research facilities. These statistics do not appear to be systematically captured by national statistical agencies at present.

Overall, the reporting of $R \& D$ procurement by performers has the advantage of ensuring consistency with total R\&D performance figures, and can be mainstreamed in the near future through the simple addition of a further breakdown within the existing survey question on government sources of funds. A main limitation is that firms may not recognise "direct" external funding for R\&D and under-report the government contribution as a result.

\section{2. $\quad$ Funder-based estimates of $R \& D$ procurement}

A funder-based approach for reporting R\&D procurement has some advantages of its own. This approach enables reporting on the R\&D procurement funds from the perspective of the public authority, which can also provide additional information on the policy or operational objectives being pursued. Few countries have surveys in place that cover the entire public administration and budgetary data rarely contain a relevant level of detail to separate between contracts and grants. However, these data also tend to include funds aimed at covering profit margins, funding for S\&T related activities which are not $\mathrm{R} \& \mathrm{D}$, or may in some cases include the entire value of a contract for a good or service instead of the sole $R \& D$ component. They are therefore less suitable for characterising $R \& D$ performance.

In contrast with the performer-based approach, government funder-based data are primarily based on governmental budgets and surveys of the administrators for those budgets. R\&D budget data are called "Government Budget Allocations for Research and Development" (GBARD), with OECD guidelines provided in Chapter 12 of the Frascati Manual 2015. Because of the issues noted above, the main rationale for collecting $R \& D$ data on this basis is to provide more timely estimates of $R \& D$ funding by governments and also to provide information on the socioeconomic objectives pursued by the funding of R\&D. The GBAORD data collections, as coordinated by the OECD, have not pursued the collection of more detailed information.

In recent years, users of statistics have called for more differentiated indicators on the public funding of $\mathrm{R} \& \mathrm{D}$ as captured by budget data, providing further insights on the process by which public funds are allocated across beneficiaries (e.g. the role of project-based or competitive funding) and its likely impact. Since 2008, an OECD/NESTI project has been assessing the feasibility of developing and collecting new indicators, based on such data. ${ }^{34} \mathrm{~A}$ revised methodology was proposed in 2012 to include in this exercise measure the value of government procurement contracts for R\&D alongside R\&D grants and other direct funds. The experience from the $2^{\text {nd }}$ pilot data collection launched in November 2012 indicated that few countries are currently able to provide information on this particular indicator ${ }^{35}$, with respondents indicating that they would have to use non budgetary data sources, administrative or survey-based, to attempt to provide information on public funding of R\&D 
by type of instrument. As a matter of fact, a number of countries use separate surveys of ministries, agencies and public bodies, to collect information on R\&D funding by governments. In a number of cases, this is the same data source used to report GBARD statistics (e.g. Canada, Switzerland and United Kingdom). ${ }^{36}$

For example, the Swiss Federal Statistical Office survey of government R\&D does not only include questions on intramural R\&D expenditures by government units but also includes questions on extramural R\&D funding. Figure 18 shows that $R \& D$ procurement contracts account for a relatively small amount of total direct public funding of $R \& D$ and that this share of $R \& D$ budget support has declined over the last decade, standing in 2010 at CHF 130 million out of a total of nearly CHF 4.6 billion.

Figure 18. The relative importance of R\&D procurement in Switzerland, 2000-2010

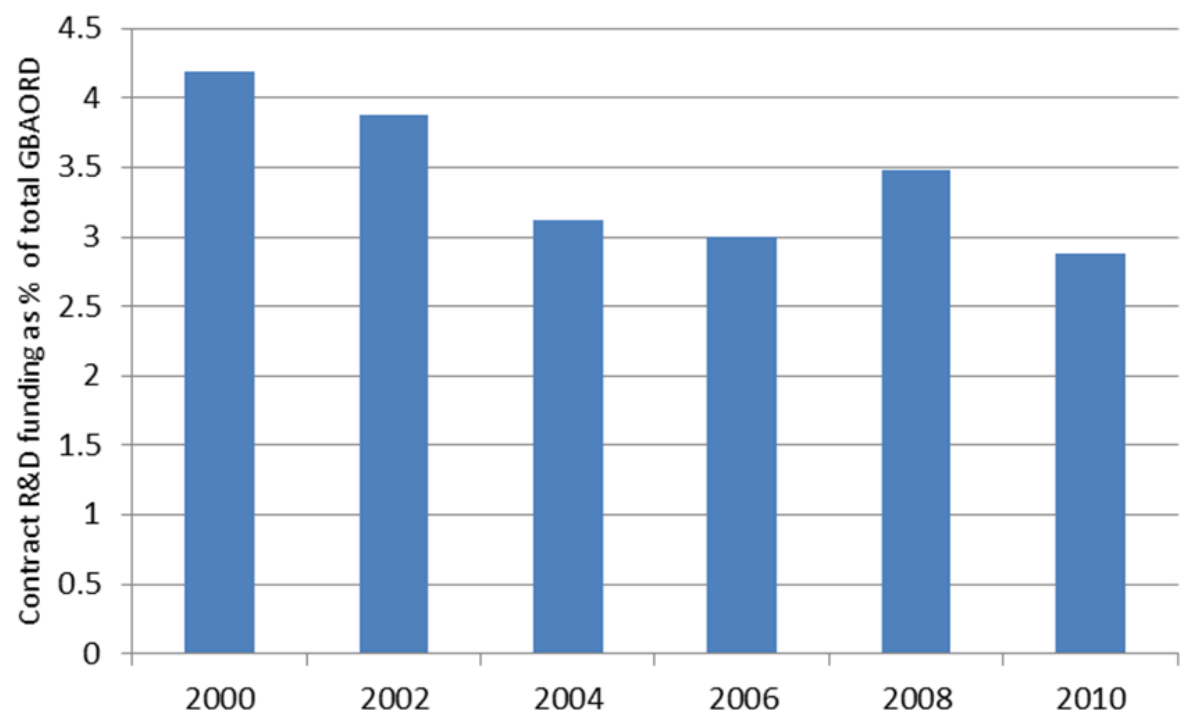

Note: Prior to the 2015 edition of the Frascati Manual, the acronym used for R\&D budget data and its main indicators was GBAORD (Government budget appropriations or outlays for R\&D).

Source: Swiss Federal Statistical Office (2012). Public Funding of Research in Switzerland $2000-2010$ http://www.bfs.admin.ch/bfs/portal/en/index/themen/15/22/publ.html?publicationID=4917

A breakdown of public support for R\&D by type of funding instrument is also available for Canada. According to the Statistics Canada publication on federal government expenditures on R\&D, about 40 percent (CAD 365 million) of funds devoted to domestic business was dedicated to R\&D contracts in financial year 2013/14, as opposed to grants and a small allocation to research fellowships. R\&D contracts with other institutions were significantly smaller, such as Canadian higher education institutions (CAD 23 million), Canadian non-profit organisations (CAD 10 million) and foreign performers (CAD 18 million). ${ }^{37}$

\subsection{Comparing performer and funder-based estimates of $R \& D$ procurement}

As highlighted in Statistics Canada's methodological notes, different interpretations of the definition of R\&D also result in discrepancies between government reporting of funds to industry or other sectors (such as the higher education sector) for R\&D and sectors' reporting of such funds. A government department may regard a contract to industry for the building of a prototype (e.g., communications satellite) as R\&D. The contractors and subcontractors, however, may only use a portion of the $R \& D$ contract and even that portion may not be reported because the contract is considered as part of the firm's "routine" contract work. Differences may also arise for contracts 
awarded to industry for services or equipment required for a government in-house project which are reported by the government sponsor as industrial R\&D contracts. Therefore, the totals for R\&D grants and contracts from government to industry shown in publications based on funder's reports are unlikely to agree with those reported by performers. Furthermore, payments in excess of the actual cost of the work performed (such as profit or fees) will be in principle excluded from performerreported R\&D funds.

Figure 19. Federal grants and contracts for business - funder vs. performer-based estimates, Canada, 2011-12

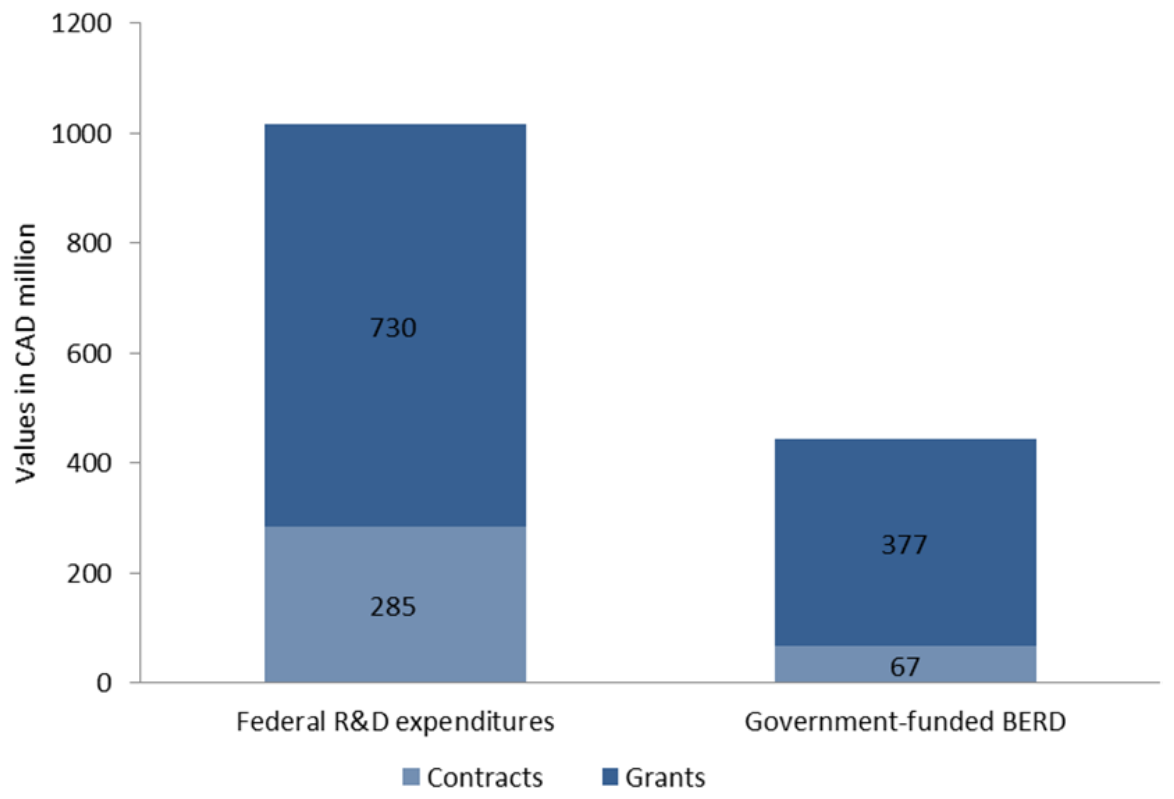

Source: OECD, based on data from Statistics Canada. http://www.statcan.gc.ca/pub/88-204-x/2011001/t011-eng.htm; http://www.statcan.gc.ca/pub/88-202-x/2013000/t094-eng.htm

This challenge is illustrated in Figure 19, which compares funder and performer-based estimates of the value of $R \& D$ contracts and grants allocated to businesses in Canada. Total federal R\&D expenditures received by domestic R\&D performers between 2011 and 2012, as reported by administrative sources in the Federal Government Survey on Federal Science Expenditures and Personnel, are more than four times as large as federal funds for domestic R\&D in Canada in 2011, as indicated by business in the Survey of R\&D in Canadian Industry. While government sources state that procurement accounts for approximately $28 \%$ of federally-funded R\&D performed domestically by Canadian business, business states that this share amounts to $15 \%$ only.

While it is desirable in principle to collect information on R\&D procurement from both funders and performers, this comes at a cost in terms of survey burden and requires a careful analysis and communication effort. Results are unlikely to coincide and the conflicting information, even when reasons are well understood to practitioners, may be difficult and challenging to explain. 


\subsection{Clarifying some concepts}

Through the discussions held in the workshops organised in the framework of the project, the need for a number of clarifications has become apparent because of the different perspectives that can be considered when governments fund $\mathrm{R} \& \mathrm{D}$ activities to be carried out by third parties:

- Key criteria for distinguishing between procurement contracts and grants relate to the extent the public authorities have a stake in the rights arising from the R\&D work and assume the risk that the R\&D project may not deliver the intended results. In the case of R\&D procurement, authorities pay for a service, as opposed to making an unconditional payment. $^{38}$

- In procuring $R \& D$ services, authorities can relinquish part of the IP rights arising from $R \& D$ contracts to the R\&D performer but never in their entirety, as this would imply there is no effective acquisition of goods or services.

- Many R\&D support programmes in areas of potential procurement interest by authorities are effectively grants, because authorities are not committed to the purchase of the goods or services arising from the sponsored $R \& D$ and companies retain full rights on the research outcomes. When that is the case, there is no commercial purchase of R\&D services. This applies for example to a substantial fraction of payments in the initial stages of some SBIRlike programmes. ${ }^{39}$

- It is important to distinguish between these grants, informally associated to policy procurement areas, with the concept of pre-competitive procurement (see Box 7).

\section{Box 7. R\&D procurement and related concepts - the case of pre-commercial procurement}

The concept of 'pre-commercial procurement' has been defined by the European Commission to refer to the purchase of research services where the contracting authority or contracting entity does not take all the risks, results and benefits for use in the conduct of its own affairs, but shares them with the providers under market conditions. The contract, the object of which falls within one or several categories of research and development defined in the EU State Aid framework, is of limited duration. With the exception of prototypes or a limited set of first test items, the purchase of products or services developed under a pre-commercial procurement contract must not be an object of that same contract.*

The purpose of this definition is to clarify which form of R\&D support for firms is not to be considered as state-aid but can simultaneously benefit from a range of exemptions relating for example to the need to use open tender procedures. While the EU State Aid Framework refers to the Frascati Manual to define the eligible categories of R\&D, practitioners should be careful in driving equivalences between PCP of R\&D and the statistical measurement of R\&D procurement. For example, it is noted that public purchasers may also procure research services from undertakings through commercial procurement where "the benefits accrue exclusively to the contracting authority for its use in the conduct of its own affairs."

Source: EU communication on Pre-commercial Procurement: Driving innovation to ensure sustainable high quality public services in Europe. SEC(2007) 1668; and Draft EU State Aid Framework for R\&D and innovation.19.12.2013

* Note: this features leads a number of observers to conclude that there is no innovation procurement, as no product has been effectively launched onto the market.

The OECD Frascati Manual has been recently revised. During its revision, the OECD considered how best to implement the existing recommendation to identify the proportion of government funds to business accounted for by contracts for the delivery of R\&D services or R\&D grants (unconditional payments to engage in $R \& D$ ), as currently reported by very few countries. As a result, a novelty in the 2015 edition of the Frascati Manual is the recommendation to separately identify R\&D funds between statistical units either with (exchange) or without (transfer) an actual or expected compensatory return 
flow of $R \& D$ from the performer to the provider of the funds. This has a direct application to the measurement of public procurement of R\&D services. R\&D exchange funds are funding flows from one statistical unit to another statistical unit in return for the performance of R\&D and the delivery of relevant $R \& D$ outcomes. The unit funding the work incurs a delivery risk associated with the uncertainty of the project. Examples of exchange funds activities include R\&D purchases (sales from the perspective of the performer), $R \& D$ outsourcing and contributions in the context of collaborative R\&D agreements.

Procurement of R\&D is one of the most common forms of the provision of R\&D exchange funds. It includes funds paid to research services firms or other units performing $R \& D$ under contract. From the perspective of the unit receiving the funds, they are part of the unit's intramural performance funded from external sources. It is possible that through a contract or procurement in some cases the unit funding the R\&D may forgo some of its rights to the outcomes of the research, e.g. on the condition that the government retains the right to use the $R \& D$ outcomes for its own internal purposes. This case should be considered as an instance of $R \& D$ exchange funds, even if there may be an implicit transfer element. A government agency funding an R\&D project through a procurement contract may at a later stage give away all rights on the outcome of the $R \& D$ that has been contracted. Since such a decision is the funder's prerogative, the transaction that funds the R\&D activity should still be treat as $R \& D$ exchange funds. There separate transfer of $R \& D$ knowledge and rights is outside the scope of classifying intramural $R \& D$.

The recommendations made in the Frascati Manual 2015 are currently in the process of being implemented in a new questionnaire for collecting data from countries. By combination of the exchange/transfer distinction with the identity of the funding and performing sectors the information that has been sought out by policy makers will be straightforward to compare across countries. The OECD is currently supporting the effort made by national statistical organisations to adapt their surveys to ensure that this information can be collected with the least reporting burden and highest possible accuracy. 


\section{Investigating the scope for using administrative procurement sources}

Procurement relationships span across two different institutional sectors, one of which, government, is not currently the subject of systematic measurement of innovation. As opposed to relying on information provided by firms, one possible mechanism for gauging the link between public procurement and innovation is to collect information from the public authorities on the extent to which they procure new goods and services, and not just R\&D. This information may be of a survey, administrative or mixed nature.

\subsection{Surveys of public sector agencies}

Surveys of public sector organisations can provide important insights into public procurement processes and how these processes relate to business or public sector innovation. For example, work by the Fraunhofer Institute for Open Communication Systems (Fokus 2013), based on a survey ${ }^{40}$ of German procurement agencies, shows that there is a positive correlation between the adoption of innovative procurement processes (e.g. use of functional requirements and acceptance of variants) and the procurement of goods and solutions that are innovative or new to the public organisation.

The results from the 2010 Innovation Barometer survey of European public administration organisations indicate that public sector innovation, as measured by the introduction of a new or significantly improved service provided by or for the organisation, may also result from public procurement activities. The practice among public administrations of putting out tenders to private business differs significantly across product categories and European countries. While the majority of public administration organisations reported consulting with potential suppliers/contractors or organisations conducting similar procurements prior to publishing tenders, only a small fraction (11\%) indicated that innovation is more important than low cost for winning a tender, $68 \%$ of public administrations declared that innovation and low cost are equally important for winning a tender.

Recent evidence on the relationship between enterprise innovation and public procurement has also been provided by Starzyńska and Borowicz (2012), carrying out a survey of 100 awarding entities and 685 participating enterprises (actual or potential contractors of public projects) in Poland. Only $5.3 \%$ of all enterprises stated to have been engaged in "innovative" contracts. A similar pattern emerges from the survey of public procurers. Only $7 \%$ of awarding entities stated to have been involved in innovation public procurement projects over the past three year time period, and only $3 \%$ to have used a multiple award criteria scheme that would include innovation as a criterion.

The results from Finland's VTT Technical Research Centre's survey of public procuring units in 2013 suggest that the capacity of procuring units influences the incidence of innovation procurement. Procuring units with 1000 or more employees are found to be more likely to make purchases as first users and award contracts requiring delivery work than smaller procuring units. Below the threshold of 1000 employees there is no distinctive size pattern in the propensity of public procurers to make purchases as first users or award contracts requiring delivery work (Valovirta, 2013)

The Korea Evaluation Institute of Industrial Technology (KEIT) evaluates the impact of Korea's public procurement policies based on the 2011 achievement utilization survey of project managers of "New Technology Purchasing Assurance" (NTPA). Respondents provided information on the labour and capital inputs and project performance across various dimensions for 298 NTPA projects supported from 2007 to 2009. Exploring which factors drive the likelihood with which NTPA projects generate sales, KEIT estimated a logistic regression model. The results of the empirical analysis suggest that the current level of the procured technology, the reduction in the technology gap (measured in years) and the number of other, non R\&D related staff in the R\&D project are associated 
with an increase in the likelihood of generating sales. By contrast, scientific publications and patent and design applications are found not to significantly affect the probability of achieving sales (Lee 2013a).

Related approaches are being considered in other countries. For example, the Spanish agency in charge of STI indicators (FECYT) recently carried out a feasibility study for tracking the innovation procurement objectives in the Spanish government's innovation strategy (e2i). Interviews carried out within this project revealed considerable problems in identifying innovation procurement actions by contracting authorities. A similar approach is being investigated in the case of Austria, where a pilot survey of public sector organisations engaged in procurement was launched in November $2014 .{ }^{41}$

\section{2. $\quad$ Administrative procurement databases}

Administrative procurement records provide a rich source of information that can be used in principle for purposes other than the originally-intended administrative uses. The OECD project on measuring the link between public procurement and innovation has evaluated the potential use of administrative public procurement micro-data to assess whether these can be used to construct meaningful and internationally comparable indicators of innovation procurement or closely related concepts, and whether it is possible to formulate research questions that the databases can help empirically test, using data linking and econometric tools.

Two major sources of procurement micro data were inspected in greater detail: the US Federal Procurement Data System New Generation (FPDS-NG) ${ }^{42}$ and the EU Tenders Electronic Daily (TED) database, which is the online version of the Supplement to the Official Journal of the European Union", dedicated to European public procurement. ${ }^{43}$ The two procurement databases are not the only examples of potentially usable datasets. Other administrative procurement databases include the Australian electronic tender system AusTender ${ }^{44}$ managed by the Department of Finance and Deregulation on behalf of the Australian government, the tender system $G E T S^{45}$ providing information on bidding opportunities and contracts awarded by federal and provincial governments in Canada, and the Brazilian federal procurement tender portal COMPRASNET ${ }^{46}$ managed by the Ministry of Planning, Budget and Management. It was beyond the scope of this project to make a complete assessment of administrative data availability across all OECD countries. Having these databases available in the public domain represents a major development compared to the traditional status quo. However, there are significant problems that need to be addressed before these can be considered as credible candidates for supporting the construction of reliable, internationally comparable indicators:

- The coverage of procurement administrative records is typically limited to a subpopulation of interest. The requirement to register procurement actions is constrained by monetary thresholds and excludes some types of actions outside the scope for which the administrative requirement applies such as confidential/classified actions.

- Compliance with the administrative requirement to file a record will be driven by enforcement efforts, creating the opportunity for adopting strategies designed to circumvent some of the administrative burdens. For example, some authorities may on purpose break down large contracts into small constituent parts in order to lie below formal reporting requirements, save time and effort and avoid scrutiny.

- Record completion can be subject to several sources of error, intentionally or by mistake of a reporting party. Contracting officials may mistakenly assign a product code or codes to a given procurement action. For example, borderline cases can be misclassified as R\&D if the official has no formal understanding of the technical boundaries beyond what is strictly required by procurement rules. In the absence of audit requirements, there are unlikely to be incentives to ensure the data are accurate and correct. 
- Even when accurate and representative of the population, the data contained in the records may not be or provide a sound basis for a "valid" indicator of the phenomenon of interest.

Notwithstanding these limitations, administrative databases can be useful complements ${ }^{47}$ to other methods and, in the worst case scenario, can be the only source of evidence available for many countries. It is therefore important to understand their strengths and weaknesses.

\subsection{Using public procurement databases to produce indicators}

Table 4 summarises the key features of the two administrative (EU and US) databases that have been investigated in the framework of the OECD/NESTI project. Significant differences between these databases imply that these are not suitable for straightforward international comparisons.

Table 4. Key features of procurement databases used for experimental OECD analysis

\begin{tabular}{|c|c|c|}
\hline & United States & European Union \\
\hline \multicolumn{3}{|l|}{ Key features } \\
\hline Name of database & $\begin{array}{l}\text { Federal Procurement Data System New } \\
\text { Generation FPDS-NG }\end{array}$ & Tenders Electronic Daily, TED \\
\hline Level of government & Central (Federal US government) & All levels, but variations in thresholds \\
\hline Public enterprises & No, only federal agencies & No, except utilities \\
\hline $\begin{array}{l}\text { Time horizon for data } \\
\text { availability }\end{array}$ & Fiscal years 2000-2011 & Calendar years 2006-2011 \\
\hline $\begin{array}{l}\text { Type of contract } \\
\text { actions recorded }\end{array}$ & $\begin{array}{l}\text { Contract awards, orders, agreements, } \\
\text { modifications, terminations }\end{array}$ & $\begin{array}{l}\text { Prior information notices, contract notices, } \\
\text { contract award notices, subcontract notices, } \\
\text { design contest notices, results of design contest }\end{array}$ \\
\hline $\begin{array}{l}\text { Monetary reporting } \\
\text { threshold }\end{array}$ & Above USD 3000 (micro purchase limit) & $\begin{array}{c}\text { Above EUR } 130000 \text { or higher depending on the } \\
\text { type of contract. Commission Regulation (EC) } \\
\text { No } 1177 / 2009\end{array}$ \\
\hline Known exemptions & $\begin{array}{l}\text { Classified procurement, US Postal. } \\
\text { Awards made to foreign vendors for work } \\
\text { performed outside the United States }\end{array}$ & $\begin{array}{c}\text { Contracts awarded as part of framework } \\
\text { contracts, research exemptions, fuel for energy } \\
\text { generation and warlike materials, purchase of } \\
\text { land or existing buildings }\end{array}$ \\
\hline \multicolumn{3}{|c|}{ Potential sources of innovation-relevant information } \\
\hline Product code & $\begin{array}{l}\text { Detailed Product and Service Code } \\
\text { (PSC) } \\
\text { 4-digit single code per action }\end{array}$ & $\begin{array}{l}\text { Common Procurement Vocabulary (CPV) 9-digit } \\
\text { code; Multiple codes per award } \\
\text { http://simap.eu.int }\end{array}$ \\
\hline Description of action & Very summary description & Title, extended description (abstract-like) \\
\hline Firm sector & NAICS classification, sector flags & No \\
\hline Vendor name/ code & Name and DUNS identifier code & Name only \\
\hline $\begin{array}{l}\text { Other relevant } \\
\text { indicators }\end{array}$ & $\begin{array}{l}\text { Indicator of commercial available for ICT } \\
\text { products and services } \\
\text { SME and other socioeconomic markers } \\
\text { Place of performance } \\
\text { Information on award criteria }\end{array}$ & $\begin{array}{l}\text { Information on procedure (i.e. open, restricted, } \\
\text { negotiated or competitive dialogue) } \\
\text { Information on award criteria (price, } \\
\text { economically advantageous, other) }\end{array}$ \\
\hline Language & English & $\begin{array}{l}\text { National. A summary of important elements of } \\
\text { each notice published in all official languages }\end{array}$ \\
\hline $\begin{array}{l}\text { Known issues with } \\
\text { data }\end{array}$ & Missing items & $\begin{array}{l}\text { Not all notices followed by reported awards, } \\
\text { awards published without contract notice, } \\
\text { missing award value information }\end{array}$ \\
\hline
\end{tabular}

Source: OECD, based on several US and EU sources. 


\section{US procurement data}

In the case of the U.S. procurement data, the number of actions registered in the database increases up to 2008 and then declines, down to nearly three million actions in 2011, mainly due to a drop in the number of supply and equipment award actions as shown in Figure 20. ${ }^{48}$ Contract award values experience a similar increase up to 2008 , but then remain stable in nominal terms, at approximately USD 550 billion, suggesting an increase in the average value per action in more recent years. Although not reported here, it is interesting to distinguish between initial awards and modifications, as approximately half of the awarded values are accounted for by modifications to existing contracts. "R\&D" codes (Box 8) account for nearly 10\% of the full value of actions and add up to an amount in excess of USD 54 billion in 2011.

Figure 20. U.S. federal government procurement estimates, 2000-11 Numbers of contract actions by 1-digit PSC classification

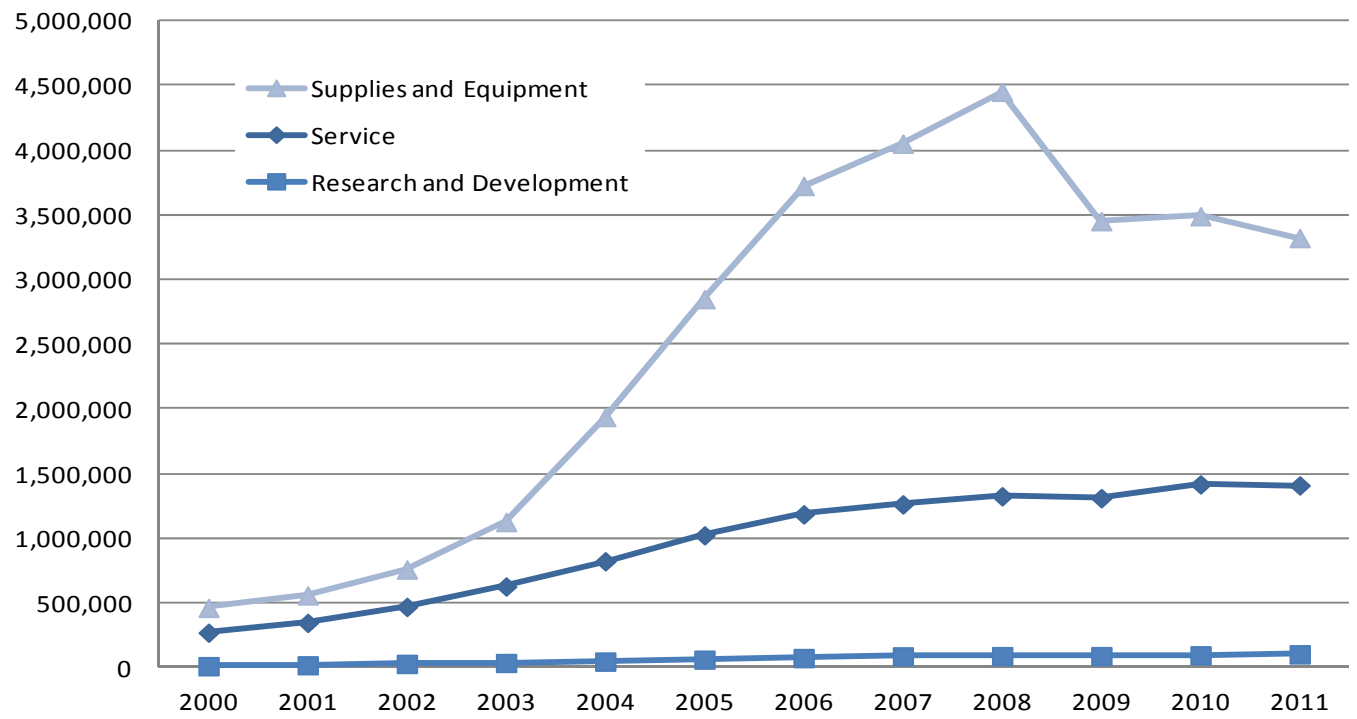

All contract actions by 1-digit PSC classification, USD billions

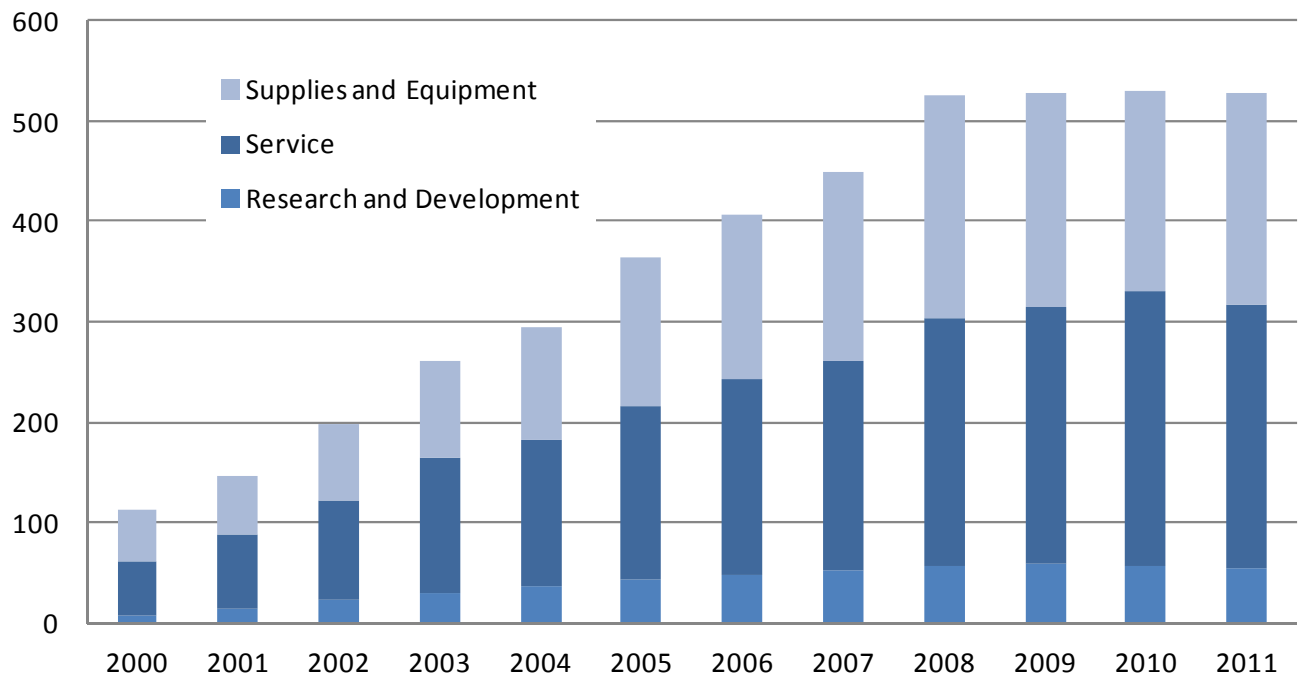

Source: OECD analysis of FDPS data. 


\section{Box 8. Definitions of R\&D used in the US Federal Procurement Database System}

The 2010 CNSTAT Report, "Data on Federal Research and Development Investments: A Pathway to Modernization" noted that "The FPDS data system aims to identify who buys what, from whom, for how much, when, [...], but appears to have little relevance to NSF because its reports and data focus on procurement actions, a category of federal spending mostly distinct from R\&D." There are seven categories of R\&D procurement in FPDS.

(1) Basic Research - includes all scientific effort and experimentation directed toward increasing knowledge and understanding in those fields of the physical, engineering, environmental, social, and life sciences related to long-term national needs. It provides fundamental knowledge ultimately required for the solution of social, economic, political, physical, or military problems. It forms a part of the base for subsequent applied research and exploratory and advanced development in the various disciplines, and new or improved functional capabilities.

(2) Applied Research and Exploratory Development - includes all effort directed toward the solution of specific problems, short of major development projects. This type of effort may vary from fairly fundamental applied research to quite sophisticated bread-board hardware, study, programming, and planning efforts. It would thus include investigations and minor development effort. The dominant characteristic of this category of effort is that it be pointed toward specific problem areas with a view toward developing and evaluating the feasibility and practicability of proposed solutions and determining their parameters.

(3) Advanced Development - includes all effort directed toward projects which have moved into, e.g., the development of hardware for test. The prime result of this type of effort is proof of design concept and/or prototype.

(4) Engineering Development - includes those projects in full-scale engineering development for government use but which have not yet received approval for production or had production funds included in the budget submission for the current or subsequent fiscal year. Thus are characterized by major line item projects.

(5) Operational Systems Development - includes those projects still in full-scale engineering development but which have received approval for production, or production funds have been included in the budget submission for the current or subsequent fiscal year.

(6) Management and Support - includes all effort directed toward support installations or operations required for general research and development. Included would be construction of a general nature, unrelated to specific programs, maintenance and support of laboratories, operation and maintenance of test ranges, and maintenance of test aircraft, equipment, or ships. Costs of laboratory personnel, either in house or contractor, would be assigned to appropriate projects or program areas above. sales.

(7) Commercialization-Includes efforts toward transition of a product from R\&D to commercial use and

Source: OECD; U.S. General Services Administration. Office of Government-wide Policy. FPDS Product and Service Codes Manual, August 2011 edition; and National Research Council http://www.nap.edu/catalog.php?record_id=12772

Figure 21 displays the value of R\&D procurement over the period 2000-11, as classified in the US federal procurement data system, providing a broad sectoral breakdown of total R\&D procurement and R\&D procurement attributed to the business sector. The broad sector breakdown, relying on the un-validated institutional flags provided in FPDS, suggests that the R\&D contract volume awarded by US federal agencies to business and non-business entities increased over the reference period 20002011, the share of R\&D procurement attributable to business being relatively constant (approximately $80 \%)$. The share of R\&D coded contracts in the total value of US federal procurement first increased from $6 \%$ in 2000 to $13 \%$ in 2004 and slightly dropped thereafter, amounting to 10\% in 2011. 
Figure 21. Federal government procurement estimates, United States, 2000-11

R\&D contract volume by sector, USD billions

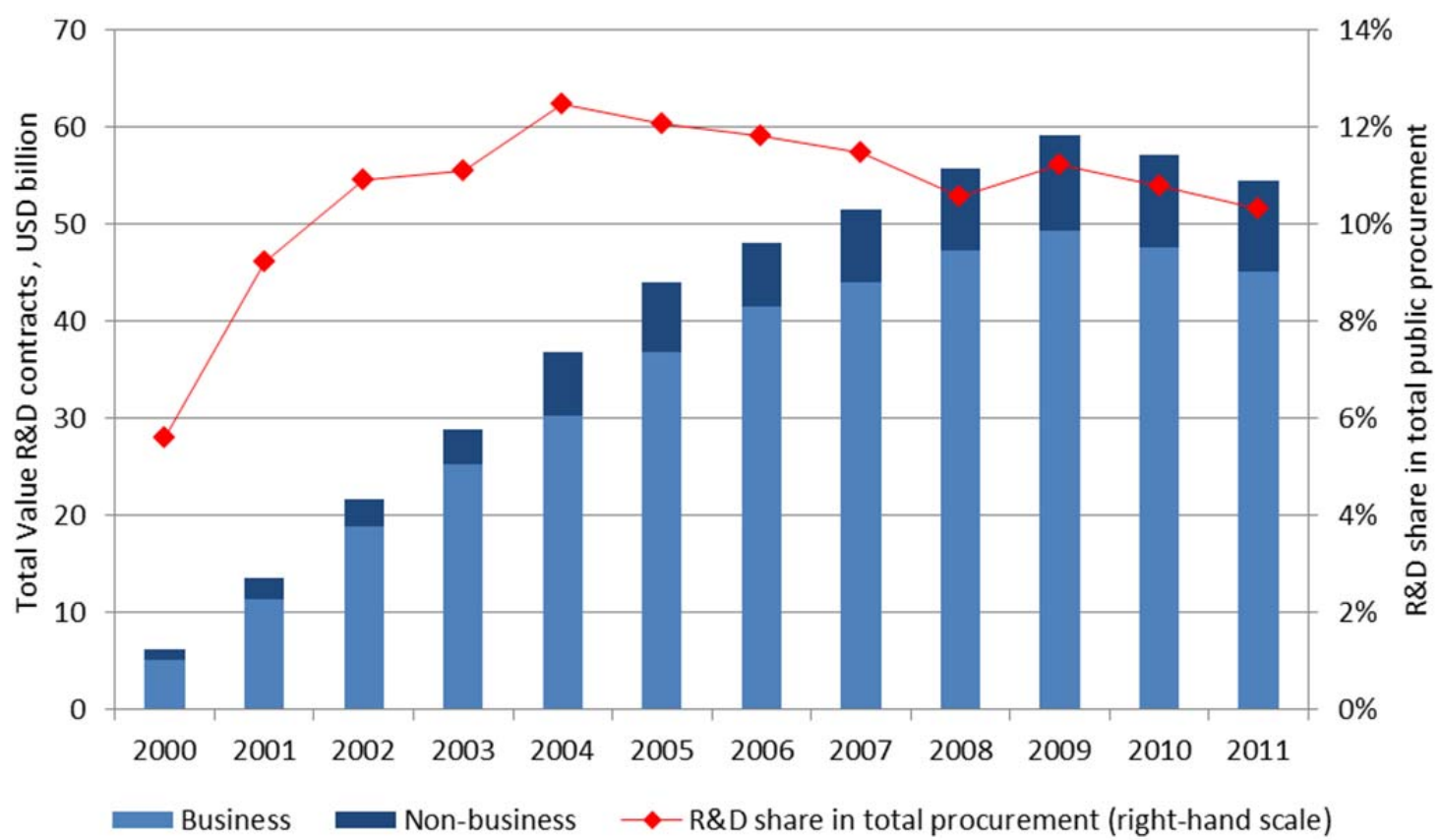

Source: OECD analysis of FPDS data.

In order to get a better sense for the administrative procurement data on $\mathrm{R} \& \mathrm{D}$ in relation to official R\&D statistics, the FPDS data have been analysed in the context of Federal R\&D expenditure statistics and compared with performer-based estimates of the value of R\&D public funding. ${ }^{49}$ Given the completely separate sources of data, FPDS being entirely focused on procurement, and the nondirectly comparable R\&D definitions being employed, such a comparison is rather exploratory in nature, not allowing for the drawing of policy conclusions. The comparison in Figure 22 suggests that total $R \& D$ procurement accounts for about $40 \%$ of total federal funds for R\&D. As expected, R\&D procurement is more business-oriented than total funds and nearly $85 \%$ of business funds seem to be procurement related, according to both performer and funder-based sources. 
Figure 22. Federal funds - funder vs. performer-based estimates, United States, 2010-11

Values in USD million

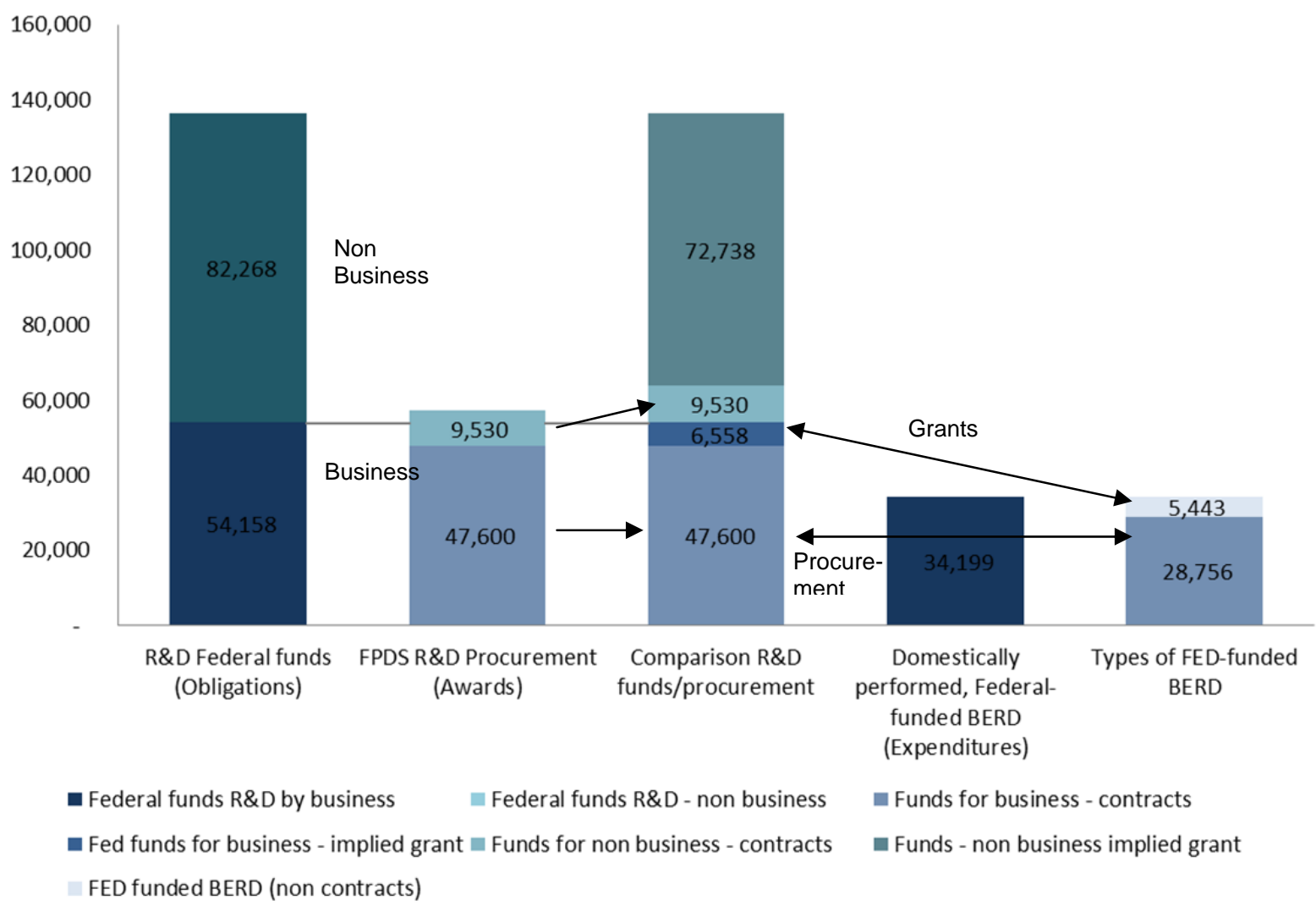

Source: OECD calculations based on FPDS data and NSF estimates of total federal funds for R\&D and of government-funded BERD.

\section{EU procurement data}

Statistics based on similar data for European Union countries are reported in Figure 23 and Figure 24. There is a reported increase in the number of actions over the 2006-2011 period. Award values are also observed to increase in nominal terms, although a decline is reported in 2011 with respect to the previous year. It is important to note that our estimates are based on raw award data and are not corrected for missing award information, which is the practice adopted by the EU (DG Internal Market) in reporting procurement statistics, given the large incidence of missing award information. ${ }^{50}$ The gap between our raw estimates and EU official figures is reported, including a projection of the gap for 2011. Procurement values reported in TED stand at approximately one quarter to one fifth of the best available national accounts-based estimate of total procurement, reflecting a broad range of coverage gaps described in Table 4 above. 
Figure 23. Procurement awards in the EU27, 2006-11

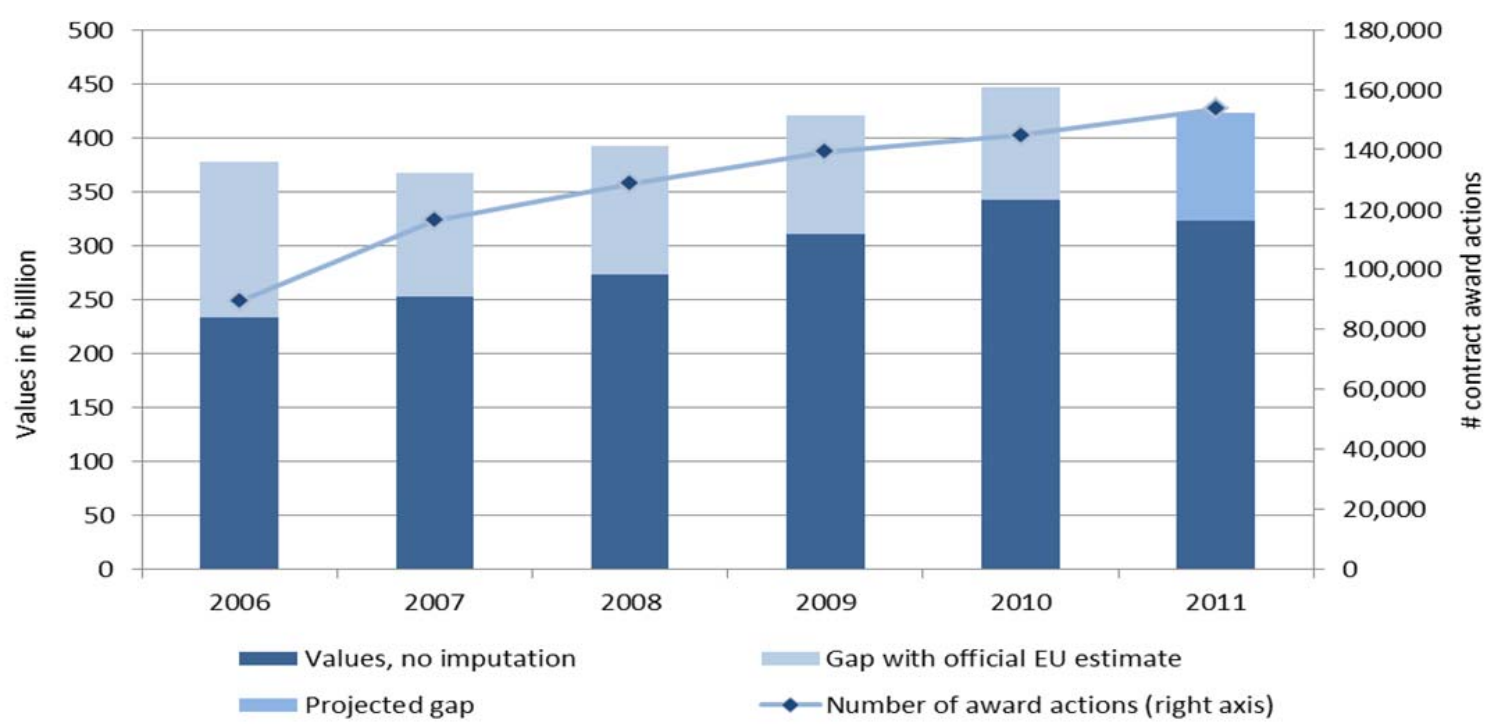

Note: The gap between OECD estimates and EU indicators is due to a lack of imputation of award values and compositional differences between the samples used, as EU figures are based on the value of procurement awards published in TED.

Source: OECD analysis of TED data and Public Procurement Indicators, 2011.

http://ec.europa.eu/internal market/publicprocurement/docs/indicators2010 en.pdf.

Figure 24. Values and numbers of contract award actions, EU countries, 2011

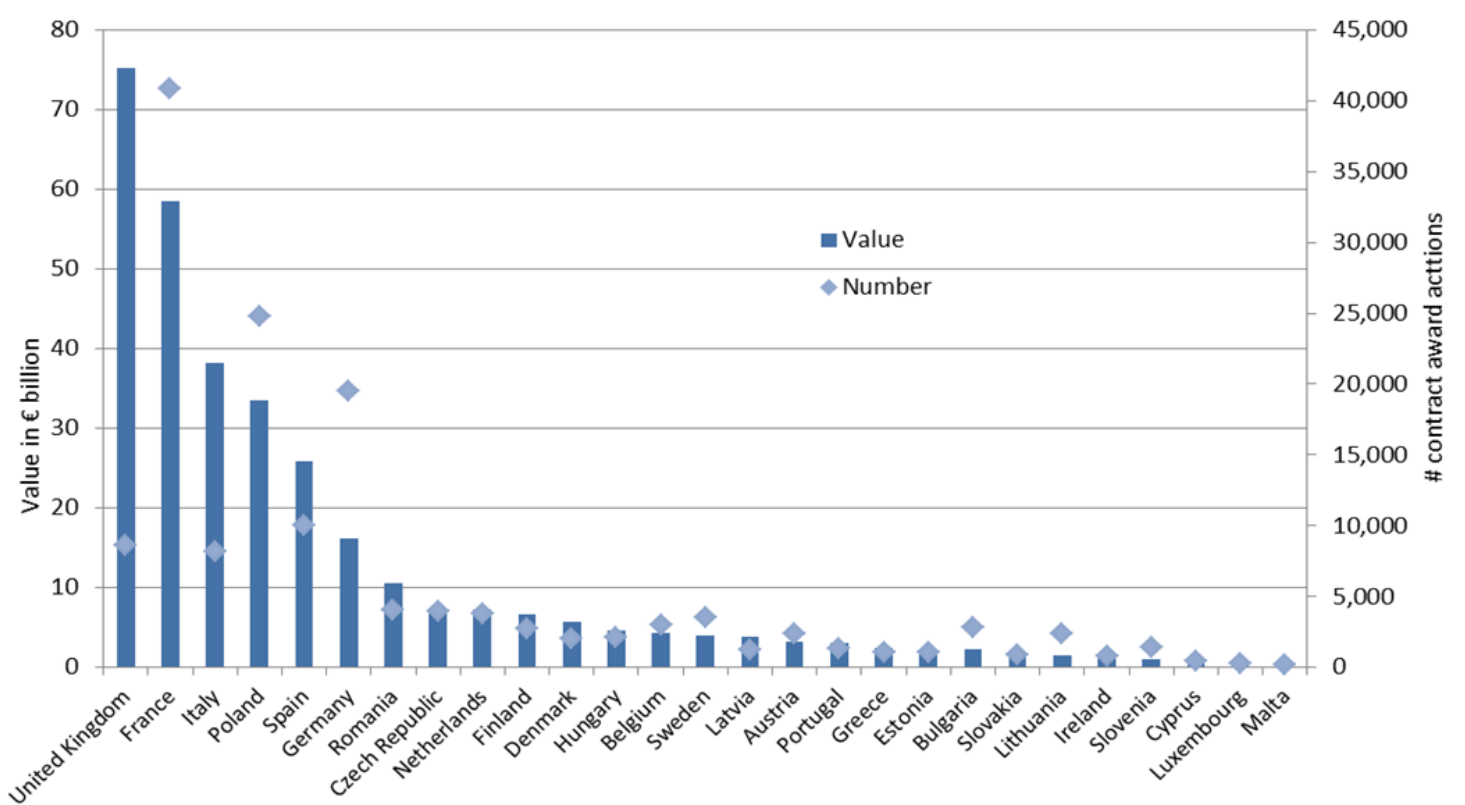

Note by Turkey: The information in this document with reference to "Cyprus" relates to the southern part of the Island. There is no single authority representing both Turkish and Greek Cypriot people on the Island. Turkey recognises the Turkish Republic of Northern Cyprus (TRNC). Until a lasting and equitable solution is found within the context of the United Nations, Turkey shall preserve its position concerning the "Cyprus issue".

Note by all the European Union Member States of the OECD and the European Union: The Republic of Cyprus is recognised by all members of the United Nations with the exception of Turkey. The information in this document relates to the area under the effective control of the Government of the Republic of Cyprus.

Source: OECD analysis of TED data. 
The results show that there are very large differences across countries in terms of reported actions and values in the TED database. France has the largest number of actions, followed by Poland, Germany, Spain and the United Kingdom. However, the largest values correspond to the United Kingdom, followed by France, Italy, Poland and Spain. This suggests the possible existence of systematic patterns of procurement and reporting across countries.

\section{Using product and sector classifications in procurement databases}

Sector or product-based approaches can be relatively easily implemented by associating all procurement actions for a given product code (or with firms in a given sector) to an innovation-related indicator which can be estimated for that product category. This approach broadly identifies all companies in a sector / or with actions in a given code as being equally "innovative", and implicitly makes no distinction between the innovation content of actions for that sector as it relates to public authorities or other types of customers. The usefulness of this type of indicator is thus limited to illustrative purposes but is nonetheless a significant advance on available statistics on the orientation of public procurement.

Figure 25. Top product and service codes in US Federal procurement, 2011

Top twenty-five 4-digit PSC codes by contract value (USD billion)

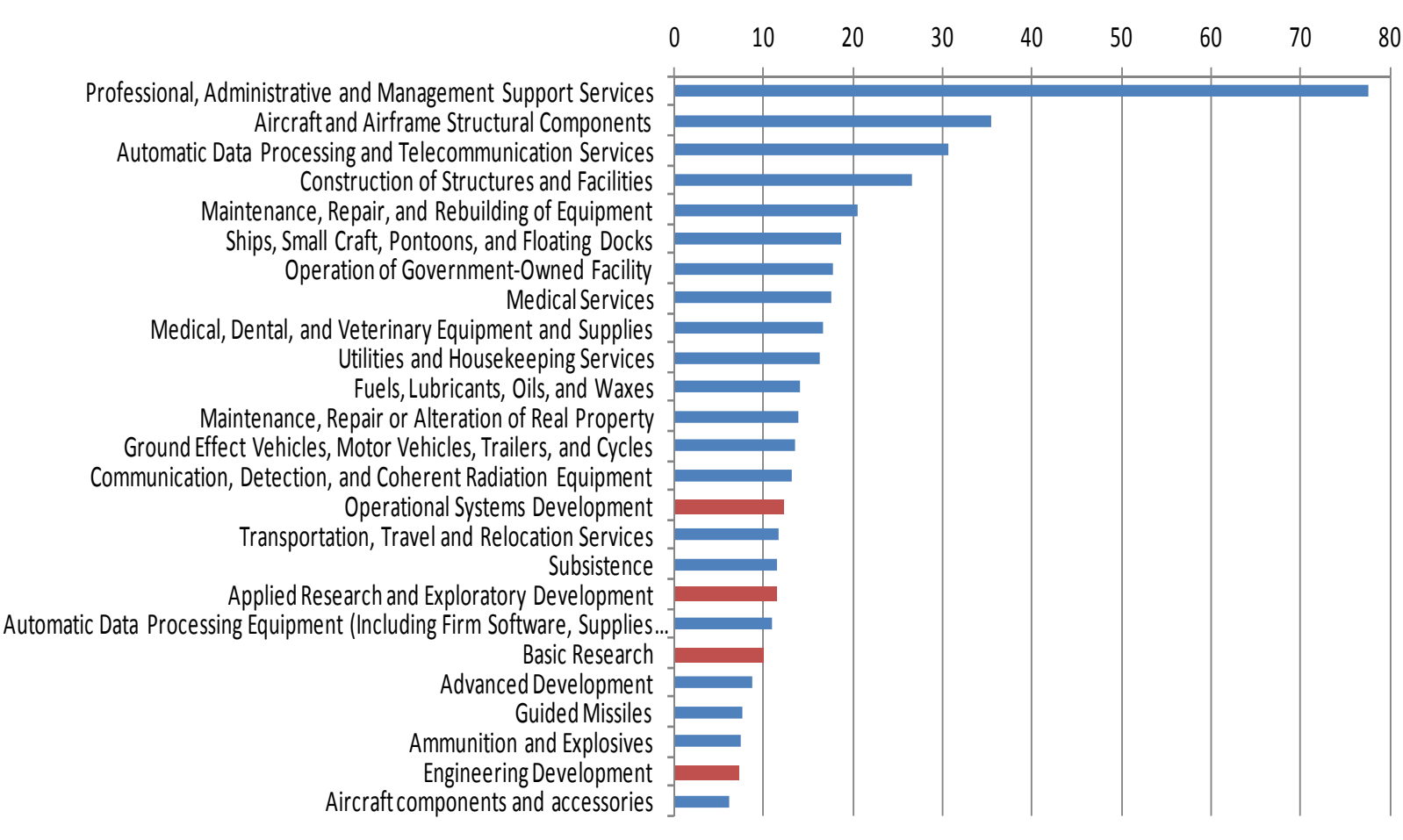

Source: OECD analysis of FPDS data.

The distribution of FPDS-reported procurement by Product and Service Code categories ${ }^{51}$ has the rather broad category of "professional services" at the top of the list and ICT services as third (Figure 25). The presence of defence and research-related components and services is a significant one. Both categories may be subject to different reporting requirements in other national databases, thus preventing international comparability. Several $R \& D$ codes are found in the list, with "operational systems development", "applied research and exploratory development" and even a category described as "basic research" among the top 25 codes. 
The detailed company information data available in FPDS also includes the company's NAICS classification code. Initial analysis shows that the manufacturing sector accounts for nearly $35 \%$ of all procurement reported in FPDS, with the aerospace, defence, transport equipment, ICT and pharmaceutical industries playing key roles within this category. The professional services sector is the second largest, with nearly $28 \%$ of total procurement value. ${ }^{52}$

Figure 26. The allocation of European procurement expenditures, by product code Top twenty 2-digit CPV product codes by contract value (EUR billion)

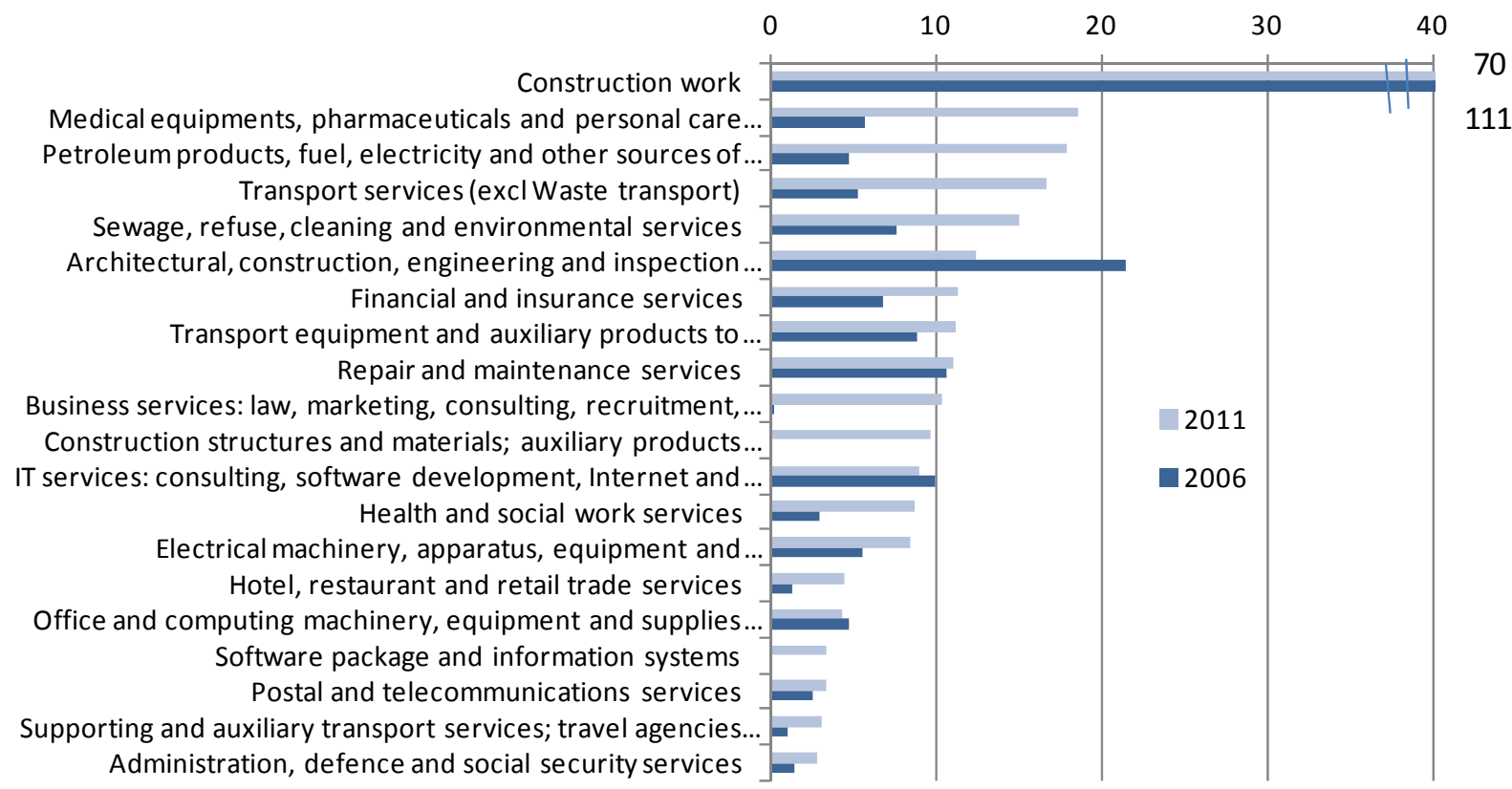

Source: OECD analysis of TED data. No imputation applied to missing award values.

Turning to the sector analysis of EU procurement as reported in the TED database, no industry codes for firms are directly available even though it is possible in principle to match company names to available business registers. Working on the product code information, based on the CPV classification $^{53}$, it is possible to note that construction work dominates procurement activities with nearly EUR 70 billion in 2011, in clear decline from 2006 when EUR111 billion were reported as shown in Figure 26. ${ }^{54}$ Medical equipment and pharmaceutical products are now the second code by size, at nearly EUR 20 billion. R\&D codes do not feature in the top list of products at only EUR387 million in 2011, which may be due to the different set of reporting rules -i.e. exemptions- that apply to pre-commercial procurement of R\&D. It would thus not be appropriate to compare this figure with the above mentioned U.S. estimate of USD 54 billion. ${ }^{55}$

\section{Using matched company information on their innovation activities}

Product and industry information are only general proxies for inferring the potential innovation content of actions. An approach based on this information will fail to reflect that not all companies in a given sector or delivering the same products are equally innovative. A more detailed approach can be based on the use of information about the extent of innovation activity by companies involved in procurement actions, independently of whether that activity bears any direct relation or not with the procurement. By linking information on companies awarded contracts with data on R\&D, innovation or other sources, it is possible to identify how much procurement goes to innovation-active companies. This approach requires (a) disambiguation of company names when company codes are not available, as it is the case of TED, (b) access to company level information and (c) a data matching 
infrastructure. Possible sources of company information are national R\&D and innovation surveys, where name/address or code-based matching is carried out confidentially by statistical offices. A key limitation of this type of measurement approach is that it is only useful for the purpose of identifying procurement relationships between public authorities and innovative companies, potentially on a very specific and narrow dimension of innovation, but does not provide any explicit evidence about whether the authority provided any form of innovative solution to public authorities.

\section{Identifying the innovation content of individual procurement actions}

The information contained in procurement records is typically rich and contains in many instances descriptions of the specific good or service being procured. Individual keywords and Ngrams (i.e. combinations of $\mathrm{N}$ terms) with a known strong association to innovation procurement can be in principle identified and searched within procurement records. This project has considered a number of potential experimental approaches to exploit such information at the level of individual actions. The content-based approach undertaken relies on a list of keyword tokens frequently associated with innovation. The list, reproduced below, was not drawn using any form of scientific method and was mainly intended for illustrative purposes. Using FPDS, a keyword search for instances of actions whose descriptions include any of the chosen "tokens" was carried out among 30 million records. Table 5 shows the frequencies of each token across the generic PSC categories.

Table 5. Innovation-related terms in new U.S. federal government contract awards and orders, 2000-11

Number of token occurrences in original contract requirement description, by type of product or service code

\begin{tabular}{|c|c|c|c|}
\hline Keyword & R\&D codes & Service codes & Supply \& Equipment \\
\hline RESEARCH & 40,387 & 35,995 & 17,693 \\
\hline DEVELOP & 41,691 & 66,254 & 19,565 \\
\hline R\&D & 9,135 & 2,270 & 730 \\
\hline SCIEN & 30,904 & 19,136 & 8,106 \\
\hline TECHNOLOG & 19,756 & 40,651 & 15,191 \\
\hline NOVEL & 1,282 & 315 & 540 \\
\hline NEW & 8,202 & 147,244 & 108,713 \\
\hline MODERN & 425 & 9,075 & 5,413 \\
\hline INNOVAT & 2,574 & 2,121 & 508 \\
\hline CHANG & 10,028 & 100,154 & 67,112 \\
\hline BREAKTHROUGH & 21 & 16 & 62 \\
\hline IMPROVE & 2,791 & 19,484 & 2,366 \\
\hline ADVANCE & 7,299 & 10,774 & 9,194 \\
\hline BETTER & 119 & 457 & 742 \\
\hline NONCOM & 30 & 87 & 39 \\
\hline PRECOM & 1 & 1,126 & 2 \\
\hline PROTOTYP & 1,329 & 1,431 & 1,268 \\
\hline Experimental PPI TAG (=1) & 114,780 & 427,788 & 244,503 \\
\hline Total number of actions with a description & 565,620 & $7,890,691$ & $15,364,167$ \\
\hline Proportion of "innovation"- tagged actions & $20.3 \%$ & $5.4 \%$ & $1.6 \%$ \\
\hline Total number of actions & 795,450 & $10,710,193$ & $18,692,690$ \\
\hline Proportion of actions with descriptions & $71.1 \%$ & $73.7 \%$ & $82.2 \%$ \\
\hline
\end{tabular}

Source: OECD analysis of FPDS data. 
It is possible to note some key shortcomings from using a basic list of tokens without an advanced type of semantic analysis. Examples of actions tagged with the "research" keywords have the following descriptions:

(1) THE CONTRACTOR SHALL PROVIDE THE US AIR FORCE STRATEGIC PLANNING DIRECTORATE AF/XPX MOBIS SUPPORT ON A LABOR HOUR BASIS TO ASSIST THE DIRECTORATE OF STRATEGIC PLANNING BY PERFORMING TECHNICAL RESEARCH AND ANALYSIS ACTIVITIES IN SUPPORT OF ...”;

(2) NATIONAL CORN-TO-ETHANOL RESEARCH CENTER, SOUTHERN ILLINOIS UNIVERSITY EDWARDSVILLE WILL PRODVIDE (sic) TRAINING IN ETHANOL PRODUCTION FOR 2 COCHRAN FELLOWS FROM 9/11-9/23/06.

Such descriptions are often missing or provide very little information, making the systematic tagging of innovation or research relevant concepts particularly difficult. The occurrence of "innovation"-related terms is very low, which is probably driven by the limited space available in the electronic records and the lack of comprehensive reporting. There are several examples of what a appear to be "false negatives", i.e. almost certain "innovation"-related activities which the keyword search failed to detect. Actions marked as having an R\&D product and service code that the keyword search did not tag as "research" $(80 \%)$ are found for example in the case of "DESIGN FOR REPAIR OF TAMPER SWITCH RENTAL (DEMURAGE) FOR NITROGEN", which could have been addressed by adding the token "DESIGN", while there are other descriptions such as "LIBRARY SERVICES" which do not seem to be necessarily R\&D-related but may be an integral part of an R\&D project. Using a broader range of innovation-related tags raises considerable challenges. For example, the use of the token "NEW" can result in picking up actions referring to "NEW York" and "NEWspapers" as in the example "NEWSPAPERS AND MAGAZINES SUBSCRIPTION", thus resulting in false positives. Contract modifications also tend to include the term "NEW". In other cases, the selected tokens appear to produce relevant results, as in "FLUID HEAT TRANSFER 150ML BTL ADVANCED INSTRUMENT". The results, however faulty as they may seem, appear to correlate with characteristics that indicate some innovation content of products or sectors, e.g. when considering sectoral value weighted shares of innovation-tagged actions (Figure 27).

Figure 27. Incidence of "innovation"-tagged actions across sectors, United States 2000-11 Proportion of identified actions (\%) by NAICS code, entire period

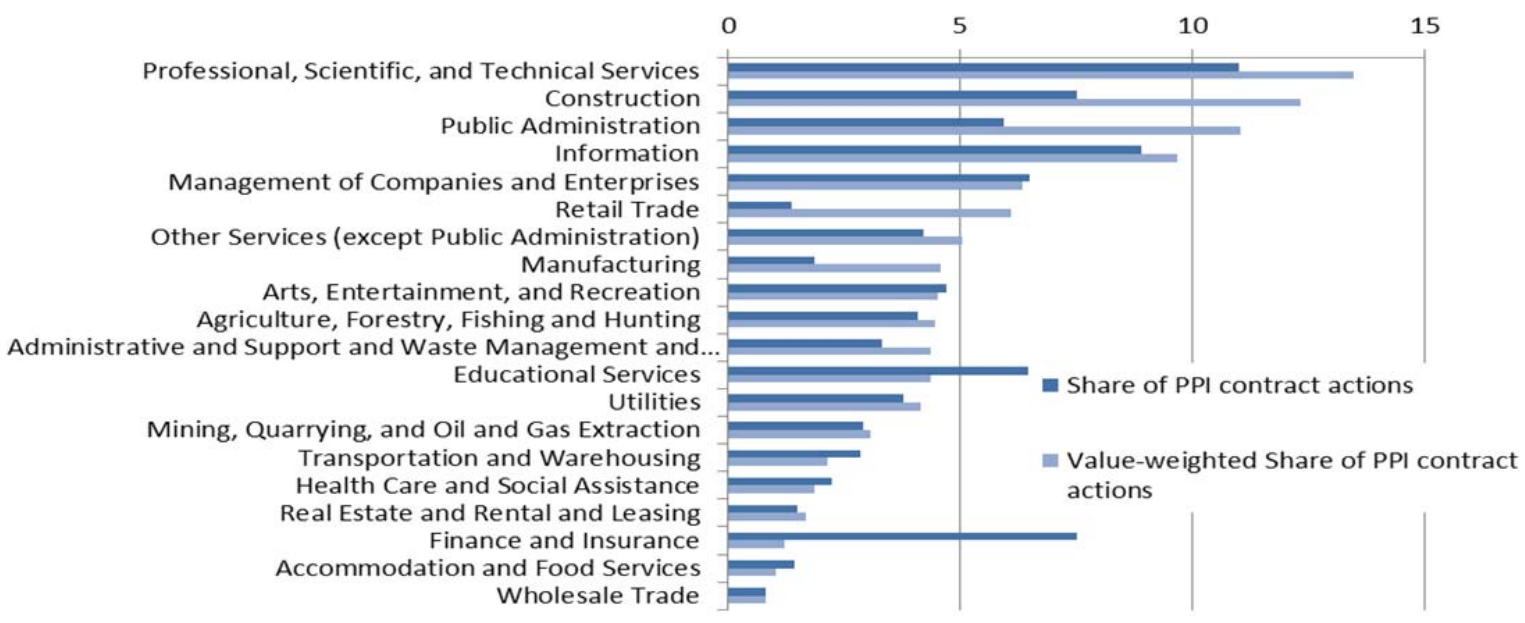

Source: OECD analysis of FDPS data.

A similar picture is obtained on a detailed product basis, in which the top 25 PSC codes by recurrence of innovation tags are listed, as seen in Figure 28. 
Figure 28. Proportion of U.S federal contract actions including innovation-related tokens, 2011 Proportion of identified actions (\%) by top-ranking 4-digit PSC codes

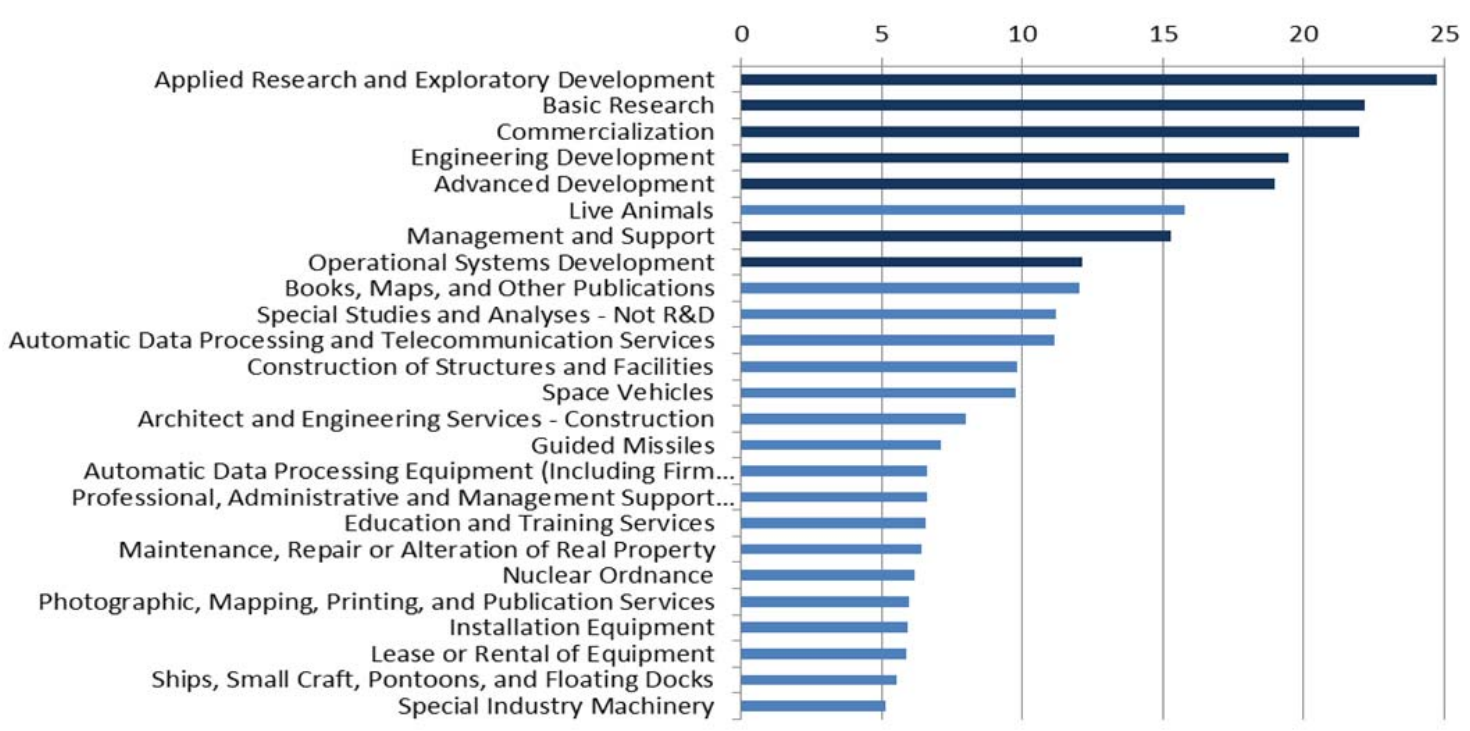

Source: OECD analysis of FPDS data. Data include modifications.

The experimental analysis of the text descriptions in EU-TED data (see Figure 29) has been limited to a number of countries as the process of data transmission from the EC could not be fully completed. Such analysis is therefore limited to countries and calendar years where contract award descriptions or translations thereof are available in English. Examples of "RESEARCH" tagged notices include "Feasibility study. Economic research services." and "Construction work for university buildings. Construction work for research buildings. library. Laboratory building."

Figure 29. The "innovation" content of European procurement actions, 2006-10(11) Proportion of identified awards (\%) by 2-digit CPV product code (top 20)

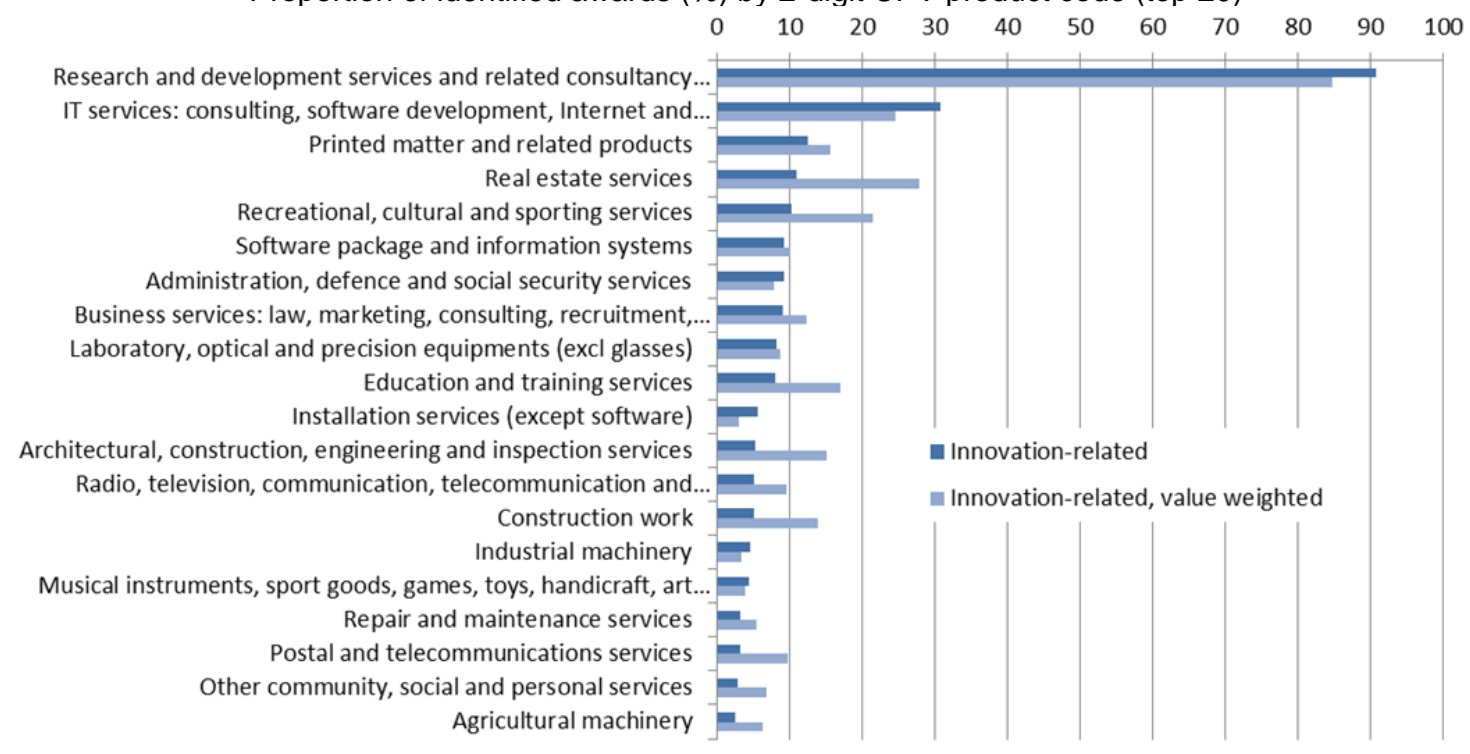

Source: OECD analysis of TED data. Sample with English contract descriptions are available for 2006-2010 for all non-English speaking countries but Italy. For Ireland, Great Britain and Malta, contract descriptions in English are available for 2006-11. 
A more comprehensive approach would entail looking at a "control" set of procurement actions that would have been previously assessed by procurement experts as a check on various possible choices of keywords and algorithms for allocating innovation scores to individual actions. Such an approach would be largely culture and language-dependent. The resource-intensity of such an exercise would be considerable. The keyword search activity undertaken has shown that keywords are largely context-dependent. Going beyond a pure probabilistic "detection" strategy would require the use of natural language processing (NLP) techniques, and for those to be applied on more comprehensive descriptions than available. The FPDS database appears to be rather limited in that respect, while the TED database still needs to be assessed in more detail. Internationally comparable statistics produced in such bases in the future are unlikely to be successful in the absence of a common reporting standard for procurement actions and their use for producing indicators cannot be recommended at this stage.

\section{Implementing a measurement system based on an administrative accreditation process?}

The previous discussion sheds some light on the difficulties of identifying innovation content in individual procurement actions from existing administrative databases. It has been suggested in a number of fora that public contracting authorities could be asked to identify which actions meet the requirements of an agreed and verifiable definition. New administrative records could eventually become available if authorities perceived the operational need to collect such information. That information could eventually be used to also meet statistical needs that fed in turn into policy. For example, procurement authorities might decide, as apparently implied by the Korean example, to confer special treatment to procurement actions securing the acquisition of goods and services which do not currently exist or are relatively new. In order to implement such a policy, some form of product accreditation process could give rise to a tagging of purchase action according to innovation. From an administrative perspective, one could argue, knowing whether a given public sector need requires innovation or can be addressed using minimally adapted goods and services should be a priori an evidence base that professional procurers should require in order to make optimal buying decisions. However, the procurement process is often one of knowledge discovery and it may not be apparent to procurement authorities whether an off-the-shelf solution exists.

Whether the implementation of an administrative standard of innovation procurement combined could provide the basis for statistical reporting and analysis is a more complicated question. This approach, while highly appealing in many respects, has a number of possible downsides:

- The implementation and enforcement of such a standard could be very resource-intensive, as it would impose reporting burdens on officials and applying companies. Such a system would potentially require some form of searchable product database enabling product searches on the basis of functionality. It would also require some system of third-party accreditation.

- The definition of innovation may differ from that used under other frameworks, and not lend itself easily to comparisons with other indicators.

- In order to provide a basis for international comparisons, a sufficiently large number of countries should adopt the standard. This is likely to be particularly complicated, given differing priorities for innovation policies across countries.

- To the extent that there are implicit incentives arising from the use, at a micro and macrolevel of the information contained in such an indicator, there is scope for the indicator to lose its informational content as key actors respond strategically to the likely uses of the information reported (i.e. Goodhart's law of indicators). 
Despite the limitations and challenges encountered, requiring efforts to establish to what extent they are fit for purpose, accurate and comprehensive ${ }^{56}$, administrative records are increasingly becoming publicly available and influencing analysis and discussion. Analytical and measurement uses will be better supported if there is a coordinated drive towards increased quality and easier access by experts and the public. A number of initiatives are currently in place to facilitate access to public payment databases using semantic web technologies and standards. For example, expenditure data for departmental and public sector organisations expenditure are being posted online. ${ }^{57}$ This has attracted an active research and IT community ${ }^{58}$ keen to demonstrate the potential of semantic web technologies to improve transparency of public expenditure by building tools and applications that improve access and analysis. These data openness initiatives require a significant degree of consistency and attention to the data that are being provided to ensure that records are comprehensive, timely and available in usable formats. This will certainly require in depth collaboration with procurement experts. ${ }^{59}$ 


\section{Linking data on public procurement and on innovation for analytical purposes}

Administrative procurement databases represent rich sources of information on contracting entities and the goods and services procured by public authorities. Institutional flags and product and service codes, for instance, provide some information about the destination and nature of contract funding and thus its link to R\&D and innovation. However, such flags and their associated classification schemes may not be perfectly comparable and standardized across national data recordings systems of $\mathrm{R} \& \mathrm{D}$ and business performance. Matching firm-level contract award data to company performance, intellectual property rights (IPR), R\&D and more general innovation data facilitates the analysis of a broader set of policy-relevant questions in way that cannot be accomplished by utilising those sources in an independent fashion.

Based on the combined use of business performance, R\&D and IPR data, a comparison of government suppliers and non-contractors according to their IP, R\&D and innovation activity becomes feasible. Such descriptive evidence may already point to important links between public procurement, $R \& D$ and other dimensions of business innovation. Evidence on the impact of public procurement on outcomes of interest can eventually be established through empirical analyses that help identify the effect of government contract awards on firm-level R\&D activity and turnover, while controlling for the size of the firm, its capital stock and other important influencing factors.

\subsection{Recent evidence on the link between procurement, innovation and economic outcomes}

Few empirical studies have systematically investigated the impact of public procurement on R\&D and innovation activity and broader economic outcomes, among those Lichtenberg (1988), Slavtchev, Wiederhold (2012), Draca (2012), Guerzoni and Raiteri (2013) and Simcoe and Toeffel (2013). The relative lack of quantitative evidence on the role of public procurement, in particular outside the United States in non-US economies, may be explained by existing definitional issues and data limitations. Furthermore, modelling both the direct and indirect effects of innovation procurement (Uyarra and Flanagan, 2010; Edler et al., 2011/2012; Draca, 2012) represents additional challenges. There are various methodological issues which need to be carefully addressed in order to obtain unbiased estimates of the intended indicators.

For instance, if the existence (and total value) of a procurement relationship is correlated with other factors that closely relate to innovation (e.g. the technological expertise of the procuring agency), it is difficult to conclude whether this implies a causal relationship from which policy recommendations can be drawn, e.g. to promote the use of procurement as an innovation policy tool. Put differently, if the procurement contract captures the positive effect of the procuring agency's expertise, its impact on innovation might be overstated. An upward or downward bias in estimates might also result due to selection or measurement error. More specifically, suppliers to governmental agencies may not represent a random sample of firms, exhibiting particular unobserved characteristics (e.g. a higher level of innovativeness) which influence the innovation outcome as well.

Various input or output measures of innovation of interest to policy makers may be subject to empirical scrutiny. Previous studies have sought to quantify the degree to which public procurement affects $R \& D$ expenditures, patenting, the occurrence of innovation and private sector demand. The seminal paper by Lichtenberg (1988) investigated how the value of procurement contracts affects private $\mathrm{R} \& \mathrm{D}$ investment, using a panel of 169 private firms who were awarded procurement contacts by the US Federal Government between 1979 and 1984 (as recorded in the Federal Procurement Data System FPDS). To account for the endogeneity of firm-level procurement receipts, Lichtenberg (1988) estimated an instrumental variable regression, instrumenting the value of contracts awarded to a firm in a given year with the value of competitive contracts potentially awardable to the firm (all contracts 
with two-digit product and service codes for which firm activity is observed between 1974 and 1985). The results suggested that non-R\&D related procurement stimulates private $R \& D$ whereas $R \& D$ related procurement crowds out private $\mathrm{R} \& \mathrm{D}$, the latter being attributable to the large and negative effect of non-competitive R\&D contracts which seem to outweigh the positive effect of competitive $\mathrm{R} \& \mathrm{D}$ contracts.

Slavtchev and Wiederhold (2012) have more recently explored how the technological content of government purchases affects private R\&D employment decisions in 50 US states from 1997 to 2009. Employing US federal procurement data from the US Federal Procurement Data System (FPDS) and restricting the analysis to non-R\&D-related procurement actions, they seek to capture the effect of government-induced demand rather than contract research. Technological content is constructed as a share of federal non-R\&D procurement in high-tech industries in total federal non-R\&D procurement in a state and year. R\&D employment denotes the number of weekly working hours in $R \& D$ occupations per state and year. The baseline estimates from a fixed effect regression indicate that a doubling of the high-tech share is associated with a 2.6 percent increase in weekly working hours of R\&D personnel. These results do not appear to be robust to the use of instrumental variable techniques that use information on political party affiliation to predict the value of contracts locally awarded.

Investigating the broader welfare effects of military procurement spending, Draca (2012) quantifies the impact of defence-related public procurement engagements on firm-level patenting activity and R\&D expenditures. His analysis is based on US defence-related procurement data from the National Archives and Records Administration (NARA) and covers the time period 1966-2003. Public procurement engagements denote the total annual value of contracts received by a firm. Draca (2012) exploits product-level spending shifts around the Reagan defence build-up of the 1980s as a source of exogenous variation to address the endogeneity of firm-level procurement receipts. The instrumental variable and baseline OLS regression estimates indicate that defence procurement has a positive and statistically significant impact on the two proxies for innovation activity. The latter reveal that a $10 \%$ increase in procurement contracts is associated with a $0.7 \%$ increase in patenting and company-sponsored $\mathrm{R} \& \mathrm{D}$, which is a twice as large as the effect of a $10 \%$ increase in civilian sales. Notably, the results also hold for citation-weighted patents, suggesting that patent quality has not been traded off against quantity.

To measure the simultaneous effect of innovation-related public procurement and R\&D subsidies on private R\&D investment and innovation, Guerzoni and Raiteri (2013) employ 2009 Innobarometer survey data. The latter provide information on whether firms received R\&D subsidies and at least one procurement contract between 2006 and 2008 with the possibility to sell new or significantly improved product or service to government (innovation-related procurement). Furthermore, the data indicate whether firms increased R\&D expenditures and whether most of their sales come from innovative products. Based on this information, Guerzoni and Raiteri (2013) construct binary R\&D and innovation outcome variables and binary treatment variables for the two policy instruments. Using propensity score matching, they identify firms that have similar characteristics (control group) like recipients of $R \& D$ subsidies or government contracts (treatment group) but did not receive support through subsidies or procurement. The estimated average treatment effects, computed as differences in the average $R \& D$ and innovation outcomes between treatment and control groups, suggest that innovation-related procurement is associated with a positive increase in firm-level R\&D and innovativeness, even if $\mathrm{R} \& \mathrm{D}$ subsidies are being controlled for.

Some evidence on the impact of procurement rules (as opposed to purchasing decisions) on private demand is brought forward by Simcoe and Toeffel (2013). Based on hand-collected panel data covering 144 US cities over the time period 2000-2008, they estimate the impact of municipal policies requiring governments to construct green buildings on private-sector adoption of the US Green 
Building Council's Leadership in Energy and Environmental Design (LEED) standard. Simcoe and Toeffel (2013) find that the LEED standard diffuses more quickly among private-sector developers in cities that adopt government-oriented green building procurement policies than among a matched sample of non-adopting cities of similar size, demographics, and environmental preferences. Moreover, they identify a spillover effect to cities bordering a city that adopted a green building policy. The LEED standard diffuses more quickly in such cities.

\subsection{Demonstrating the combined use of administrative data, company accounts and IP data}

Regardless of the data, measures for innovation and procurement and the econometric approach used, previous empirical studies tend to find a positive effect of public procurement on R\&D and innovation activity. Comprehensive evaluations of the impact of public procurement on R\&D and innovation activity generally rely on the combined use of available administrative procurement, business R\&D and innovation survey, intellectual property (IP) company accounts data, facilitating a link between government contract awards, $R \& D$ and innovation activity at firm-level and helping identify how public procurement actually spurs innovation and what factors prevent that from happening.

\section{A quantitative case study based on US procurement records and other micro data}

To showcase the use of matched firm-level contract, business performance and IP data, US federal contract award data from FPDS were matched for a subset of US companies to the commercial database ORBIS, developed by Bureau Van Dijk. ORBIS contains firm-level information on publicly reported R\&D expenses, turnover and employment, as of June 2011. The matched data were also linked to information on patent and trademark applications filed at USPTO within the OECD-STI Microdata lab. The data matching exercise was performed at consolidated firm-level, using the Dun \& Bradstreet numeric company identifier. Ensuring the comprehensiveness and consistency of the data linkage, a string-based matching ${ }^{60}$ and manual search routine were carried out subsequently to identifying the counterpart of unmatched $R \& D$ reporting firms and $R \& D$ contractors ${ }^{61}$ respectively. While the matched set of US firms accounts for about $87 \%$ of total R\&D expenditures reported by US firms from 2003 to 2011 , they account for $31 \%$ of the total R\&D procurement volume awarded to US and non-US contractors by the US federal government from 2000 to 2011 as reported in FPDS.

Annex 1 contains a list of selected manual firm name searches for demonstration purposes, highlighting successful and unsuccessful instances of manual firm name matching, the former leading to an update of the matched firm data sample. Examination of the list of unmatched R\&D contractors helps understand the comparatively small share of total US federal R\&D procurement volume (31\%) that is attributable to the matched set of US companies. The top 100 unmatched R\&D contractors to the US federal government, accounting for $50 \%$ of the total R\&D coded procurement volume from 2000 to 2011, oftentimes represent US-based higher education or government institutions or non-US headquartered enterprises.

The final data set consists of 2374 US companies reporting company-sponsored $R \& \mathrm{D}^{62}$ between 2003 and 2011, out of which 1179 firms supplied to the US federal government from 2000 to 2011. A more complete data description, contrasting firms supplying to government and non-contractors, is also provided in Annex 1. On average, contractors have larger employment and capital stock levels than non-contractors as measured in the last year of reporting. Moreover, they achieve higher turnover, report a larger amount of company-sponsored R\&D and file more patent and trademark applications at USPTO over the given time period. 
The exploratory analyses, which control for a number of firm characteristics such as employment and capital stock, as well as firm fixed-effects, yield new findings about the relationship (correlation) between public procurement and the outcome variables of interest, as highlighted in Box 9. Regression tables and information on the econometric modelling are also available in Annex 1.

\section{Box 9. Key findings of OECD analysis}

\section{The link between US federal procurement and company-sponsored R\&D}

- There is a positive correlation between reporting any R\&D expenses in a given year and having received a contract award from US federal government in the previous period. Firms that previously obtained a contract award are twice as likely to report R\&D expenses compared with firms that were not awarded government contracts. This effect on R\&D mainly stems from non-R\&D related contracts. Among the population, R\&D service contracts seem to neither induce nor prevent firms from reporting R\&D expenses.

- The value of government contracts in a year is positively related to the value of a company's volume of R\&D expenses in the following year. The effect, observable for the full sample of contractors, implies that R\&D expenses increase by $0.2 \%$ as the value of past obligations increases by $10 \%$. There is no evidence that changes in the value of government R\&D contracts result in additional R\&D expenses by firms, but do not either lead to crowding out (i.e. offsetting reductions in firm-sponsored $\mathrm{R} \& \mathrm{D})$.

2. The link between US federal procurement and IP filings (patent and trademark applications)

- $\quad$ The number of patent applications firms file at USPTO in a given year is positively correlated with past R\&D expenditures and the size of the firm as measured by the number of employees in the previous year. After controlling for past R\&D expenditures and labour and capital inputs, past contract obligations have no effect on firms' patent filing behaviour.

- Contractors that regularly supply to the US federal government are however more likely to seek trademark protection for goods and services at the USPTO. As the value of past obligations increases by $10 \%$, the number of trademarks firms file in a given year rises by $0.5 \%$. This effect suggests that firms introduce new goods and services as part of or as a result of their fulfilment of government contracts. It remains to be investigated whether this is followed by filings in other jurisdictions.

\section{The link between US federal procurement and firm turnover}

- Public procurement seems to stimulate demand. Firm turnover is positively correlated with past contract obligations, rising by $0.3-0.4 \%$ as the value of past contract obligations increases by $10 \%$. The results suggest that this effect is attributable to non-R\&D related contracts.

- This effect also applies for turnover net of government awards in that particular year. Business turnover net of government awards rises by $0.2 \%$ as the value of past contract obligations increases by $10 \%$.

- Overall, these findings appear to be supportive of the view that public procurement's dominant impact on innovation occurs from a goods and services demand perspective, rather through the actual procurement of R\&D services.

Source: OECD data linkage and analysis of FPDS-NG contract award data (2000-2011) matched to company R\&D, performance and USPTO patent and trademark filing data. FPDS-NG data include modifications.

It is important to bear in mind that the sets of firms supplying to government, performing R\&D and filing IP are selected samples of the firm population whereby overlaps between these sets of firms may exist. Inferences drawn upon the matched sample of firms may, as a consequence, not fully apply to the whole population of firms. Further insights into the effect of public procurement on R\&D and innovation may be gained through an extension of the scope of the empirical analysis to a broader, less 
R\&D intensive population of firms or to other countries. Evidence can also be gained through the use of outcome indicators reflecting the value of $R \& D$ and innovation outputs.

While a range of important correlations between public procurement, reported R\&D, IP activity and firm turnover have been uncovered, further empirical work is necessary to establish the causal links between public procurement and the outcome variables of interest. The allocation of government contracts is likely to be correlated with unobservable firm characteristics (e.g. entrepreneurial leadership) which also influence firm-level outcomes such as turnover and R\&D activity. If a selected subset of firms, e.g. ex-ante more innovative firms, are more likely to obtain government contracts, the innovation impact of procurement, capturing the positive effect of firms' unobserved innovativeness, may be overstated. Different empirical approaches, such as difference-in-difference or instrumental variable regression techniques can help mitigate the endogeneity and selection issues that are likely to arise in this setting.

\subsection{Linking innovation surveys and procurement data}

Since publicly available innovation-related measures focus at best on R\&D expenses and IPrelated activities, it is of particular relevance to attempt to link public procurement information with micro-data from statistical surveys of $R \& D$ and innovation. The Centre for European Economic Research (ZEW) kindly agreed to collaborate with the OECD secretariat to investigate the feasibility of linking EU administrative procurement data and business level information from the German Innovation Panel for analytical purposes. The results were as follows:

\section{Box 10. ZEW data linking of 2012 CIS and TED data (German enterprises)}

- A substantial percentage of TED awards (only going up to 2011) cannot be matched to company innovation data because some procurement intensive sectors like construction and wholesale and retail trade/ repair of motor vehicles and motor cycles are only partially covered in the innovation survey. These are often sectors with large firms and high contraction volumes. TED does not capture innovations introduced by other enterprises than the contractor or sub-contractor innovations, while CIS does not cover innovations introduced prior to the reference period 2010-2012.

- $\quad 13.9 \%$ of German enterprises who reported a procurement contract in the German 2012 CIS survey were found in TED. While 5.5\% of firms were found in TED that obtained contracts between 2006 and 2009, $80.9 \%$ of enterprises were not found in TED at all.

- $\quad$ Among the German CIS enterprises with a TED contract linked to them, $43.9 \%$ actually reported not having been involved in public contracts. This result points to the possibility of awareness or recall biases that need to be further investigated.

- The analysis of the link between procurement and innovation using TED administrative data provides somewhat less clear results than those obtained by using self-reported procurement information from the surveys. Some specifications do show some effect of introducing a product innovation on the probability of being awarded a procurement contract in the following year. Further analysis of the preliminary results is currently taking place.

Source: Rammer (2013). "Linking EU Procurement and CIS Data: Results from Germany"; presentation Christian Rammer, Centre for European Economic Research (ZEW), Germany, at OECD expert workshop on "Measuring the link between public procurement, R\&D and innovation", 4-5 December 2013, Paris.

As detailed innovation survey data with information on procurement becomes available from CIS2012, national statistical offices will have the option to undertake similar linking and analytical exercises. Such linking need not be constrained by procurement data only, but could include information on grants and other incentives, including tax-related, so that the comparative effectiveness and efficiency of these policy instruments can be compared. 


\section{Concluding remarks}

The project underlying this report has sought to contribute to the exchange of experiences among experts and policy makers on the measurement of research and innovation activities and their relationship with procurement, with the review of OECD measurement frameworks for science, technology and innovation in mind. It has played a significant role in the discussions supported the revision of the Frascati Manual. It has also been possible to promote the discussion on the appropriate methods to investigate the link between demand and innovation. This debate resulted in the experimental introduction by Eurostat of selected modifications in the CIS model survey which several countries adopted in their 2012 surveys and the publication of results in the 2015 edition of the OECD Science, Technology and Industry Scoreboard (OECD, 2015e). Furthermore, in the case of France, this also led to the formulation of a similar approach for investigating the role of private demand on business innovation which might enable the comparison of public and private demand effects. It is indeed through trial and error and analysis of the relevance and validity of the resulting data that specific recommendations may be made in the future for including measurement guidelines in the Oslo Manual or potential separate guidelines on measuring government engagement in innovation, as suggested by some participants at the project final workshop.

In the project workshop discussions, most participants fundamentally agreed with a conceptualisation of public procurement of innovation (PPI) as describing the action by which a public authority places an external order and commits to pay for the delivery of a new solution (in the form of a good, services, intellectual product, systems or multiple combinations) with specifications aiming to support its own or another authority's delivery of public services. The solution may not exist in the market or it may need additional development and testing work to meet the specific needs of the contracting authority.

This type of definition, however sensible, is not particularly conducive for measurement from the perspective of firms delivering a solution or possible components of it. Such a definition may describe situations ranging from announcing the intention to buy, through to its final use by authorities, which may require additional work, possibly by other companies. While firms can potentially assess the novelty of their product offering in relation to themselves, or at best the market in which they operate, they may not know about the uses intended by the customer and the final application. The definition, as such, involves a large number of conceptual linkages and actors' perspectives. For this reason, it cannot be recommended that such a definition is used for business surveys, as is the primary object of the Oslo Manual, at least until there is testing evidence that supports the opposite view.

Nonetheless, this report shows that it has proved possible to ask questions that identify whether firms have innovated in the context of delivering goods and services to public authorities, and whether in their view the tenders or the agreed contracts formally required them to do so. Such an approach appears to have been understood by firms, but there are potential concerns that this is viewed differentially in different contexts and countries, so the information may not be entirely comparable. Some degree of caution is therefore recommended.

While the concept of "innovation procurement" may appear to be more feasible to implement in surveys that collect information from the perspective of the public authority, there are implementation aspects such as the specification of novelty requirements and respondent's knowledge of the marketplace that require very careful analysis. Based on recent information, it appears that some countries are interested in testing this approach - Austria is taking some steps in this direction - but there are some concerns that respondents may not have the required knowledge or incentives to assess 
and report correctly the innovativeness of their purchasing decisions and the impact of their procurement processes.

It is also important to note that PPI as commonly understood is a very distinct notion from that of what is typically meant by "innovative procurement", which could potentially refer to new or improved procurement processes by public sector organisations. Innovative procurement falls outside the current Oslo Manual framework as it concerns measurement of innovation by business, and could be described as part of what might be defined as innovation within/by the public sector. In that regard, efforts aimed at standardising measurement of innovation in the government sector should pay particular attention to procurement activities as a source of innovations and as processes bound to be themselves the object of improvement.

This report has also demonstrated the value and importance of being able to link longitudinal survey data and administrative information in order to understand the dynamics associated with innovation procurement and its economic impacts. Although administrative sources are unlikely to be reliable sources of indicators in the short to medium term, some micro-data based analytical uses can be justified and deliver relatively robust results. Countries should pay increased attention to improving the quality of administrative databases, ensuring their accessibility by adhering to basic data sharing standards which enable data linking to other administrative and survey data sources. Without the appropriate data and analytical infrastructure, it is unlikely that policy makers will be able to evaluate the impact of procurement on innovation and the potential scope for policies to achieve their desired objectives. 


\section{NOTES}

1. This definition is sometimes extended to the notion of "works", e.g. in EU directives. A work is defined as "the outcome of building or civil engineering works taken as a whole" - e.g. a hospital, theatre or bridge - "that is sufficient of itself to fulfil an economic and technical function", i.e. fully equipped and and completed. http://ec.europa.eu/internal_market/publicprocurement/docs/guidelines/works_en.pdf)

2. See for example, the OECD flagship publication, "Government at a Glance". The 2013 and 2015 editions include a dedicated section to procurement.

3. Social transfers in kind supplied to households via market producers; (D.6311 + D63121 + D. 63131) consist of reimbursements by social security funds of approved expenditures made by households on specified goods or services, of social transfers in kind, except reimbursements, made by social security funds to households and of transfers in kind provided to households by government units or non-profit institutions serving households (NPISHs) that are similar in nature to social security benefits in kind but are not provided in the context of a social insurance scheme. The goods and services are produced by market producers.

4. Canada, Greece, Iceland, Israel, Mexico, the United Kingdom and the United States do not report separate data on social transfers in kind via market producers in their National Accounts.

5. The government sector may include non-profit units such as public higher education institutions. This is the case for the majority of EU countries, with the exception of Ireland and the United Kingdom, whose public universities are deemed to be independent enough to be classified into the Non Profit Institutions Serving Households sector.

6. Institutional sector statistics typically include breakdowns of capital investment according to broad categories, including dwellings, other buildings and structures, transport equipment, other machinery and equipment, cultivated assets and intangible fixed assets, according to the SNA1993 for which data are currently available on the OECD databases.

7. Information on this measurement framework and indicators collected by national authorities based on it are available at www.oecd.org/sti/inno-stats.htm.

8. For example, many innovative and greener products and services may initially have higher costs or longer payback periods. Government procurement rules usually require assessment against "value for money" (VFM). However, VFM does not always require choosing the cheapest bids. For example, the EU Procurement Directives define VFM as "the optimum combination of whole-life cost and quality to meet the user's requirement". VFM could therefore include the consideration of environmental performance along with cost, performance, availability and quality.

9. These agreements can also be a source of international statistics. The World Trade Organisation's monitoring system is based on Article XIX:5 of the General Procurement Agreement (GPA), whereby parties are obliged to collect and provide to the GPA Committee, on an annual basis, statistics in relation to procurements covered by the Agreement, include statistics on the number and estimated value of contracts awarded. Such statistics must be broken down by entity and categories of products 
and services, and also by country of origin of products and services. These requirements, to be revised as part of the GPA renegotiation, are reported by WTO as not having worked well. See http:/www.wto.org/english/tratop e/gproc e/gpstat e.htm

10. Examples of other European countries with dedicated innovation policy support to public procurement of innovation include Denmark, Norway and Sweden. European regions and cities developing dedicated actions to support innovation procurement include the Flanders region in Belgium (OECD, 2011a), Piedmont in Italy, the Rhône-Alpes region in France, the North Rhine-Westphalia region in Germany, Vienna in Austria, and Helsinki in Finland (information based on personal communication with DG ENTR officials and http://cordis.europa.eu/fp $7 /$ ict/pcp/msinitiatives en.html).

11. Descriptions of national experiences with innovation procurement are available for the United States, Korea, China and other countries (Mowery, 2013; Lee 2013a; Lemper et al., 2013; OECD, 2014a/2014b).

12. This stands in contrast with 23 countries having specific policies for SMEs. See http://dx.doi.org/10.1787/gov_glance-2013-46-en.

13. Edquist et al. (2014) describe the potential benefits to public and private actors from the selective use of this policy instrument, outlining the requirements and constraints for its operationalization.

14. As noted in the SNA, market production must be aimed at selling products at economically significant prices. Prices are said to be economically significant if they have a significant effect on the amount that producers are willing to supply and the amounts purchasers wish to buy. These prices normally result when the producer has an incentive to adjust supply either with the goal of making a profit in the long run (or at a minimum, covering capital and other costs) and consumers have the freedom to purchase or not purchase and make the choice on the basis of the prices charged.

15. Public corporations are within the scope of the Oslo Manual because, regardless of the ultimate control exercised by government, these are units that operate in the market.

16. This is largely because the measurement of innovation in the public (government) sector presents other conceptual and practical features. For this reason, there is no formal standard on how innovation should be measured in the public sector, although a number of studies have already worked on transposing the Oslo definition.

17. It allows, on the contrary, for innovations to be developed by public research institutes or the like as long as they are implemented by firms.

18. Other business surveys have been conducted outside the framework of official innovation statistics. The 2005 CBI/QinetiQ innovation survey, targeting 94 enterprises in the United Kingdom which had either tendered for contracts or supplied to central or local governmental bodies, provided preliminary insights into how procurement practices affect innovation. $70 \%$ of respondents stated that government procurement practices fail to foster innovation. Public agencies are rarely considered to be apt to support innovation, acting as an early-adopter of new ideas (79\% disagree with the statement). Key issues raised include the lack of firm engagement in defining the problem and developing novel solutions (62\%) and deficient skills within public agencies involved the procurement process $(69 \%)$. Notably, there are few statistically significant differences in responses obtained for central or local governmental bodies.

Edler et al. (2011/2012) obtain results supportive of the view that public procurement promotes innovation based on the 2011 Manchester University CATI (Computer Aided Telephone Interviewing) survey of 800 suppliers to central government, local authorities and the English National Health System carried out in the United Kingdom. Out of all innovating firms in the sample 
(94\% of respondents), $67 \%$ state that bidding for or delivering contracts to public agencies has had some impact on their innovation activity. $25 \%$ of innovators ascertain that all innovations realised over the previous three year time period can be attributed to public procurement. Self-reported innovation effects are most prevalent among large firms, central government suppliers and suppliers of professional services. Importantly, the most innovation-friendly rated procurement practices, including innovation requirements in tenders, early-interactions with procuring agencies, outcomespecifications in tenders and advanced communications of future procurement needs, are shown to occur only very infrequently. Furthermore, public procurers appear to have little expertise about the technology or market in which the product (good or service) operates. Georghiou et al. (2013) develop a taxonomy of procurement policies and instruments in OECD countries in response to perceived deficiencies in public procurement and compare the latter with the responses collected in the 2011 UNDERPINN survey. The authors conclude that the barriers encountered by firms correspond to the deficiencies addressed by policies but do not address them sufficiently.

19. This can also include the role of contracting authorities as standard setters.

20. When asking a respondent whether event $\mathrm{B}$ is due to event $\mathrm{A}$, the respondent may be confused about whether (s)he is being asked whether A is true, whether B is true, or whether B would have been different if $\mathrm{A}$ had been different. In attempting to provide an answer to the latter, respondents may consider different scenarios for A, based on alternative heuristics (e.g. comparing against the past, against other companies, etc...), which also renders answers hard to compare within a given study and limits the validity and usefulness of the results.

21. For example, in the case of France, the question asks whether the firm "had innovation activities to deliver goods or services (for public sector markets)" ["Si oui, votre entreprise a-t-elle eu des activités d'innovation pour fournir ces biens ou prestations de services?: a - oui et l'innovation était exigée dans le contrat; b - oui mais l'innovation n'était pas exigée dans le contrat ; c - non”].

22. As firm size increases, the probability of serving only foreign public sector organisations declines as companies also serve their domestic markets.

23. Estimates for Germany are based on the final results from the CIS2012 survey except for Figure 8, 9a and 16 which refer to the initial, non-revised sample-based estimates reported to the OECD.

24. In different policy contexts the term "catalytic" has been used with a somewhat different meaning to that employed here. For instance, in Sweden, Finland and Norway 'catalytic procurement' refers to government actions aimed at bringing private buyers together to encourage them to purchase a particular innovation (OECD, 2014b).

25. To be reported as such, R\&D funds have to be intended for and used for R\&D.

26. Some limitations may apply, for example in the case of requirements, to disclose some of the intellectual outputs in the form of scientific publications, enabling access to data, etc.

27. This excludes funds provided for unspecified uses for the recipient to decide upon, or funds such as various types of tax relief which are provided as a result of having carried out R\&D but are not necessarily used for R\&D.

28. More challenging, hybrid cases arise, particularly in the case of the procurement of complex systems, where contracts may envisage milestones which allow firms to recoup through indirect charges on government contracts.

29. The intention of this approach is to minimise the risk of double-counting $R \& D$ expenditures. 
30. See http://www.statcan.gc.ca/pub/88-202-x/2013000/t094-eng.htm

31. The decline in direct federal support for R\&D during the 1990s was offset by rising R\&D tax support, which is excluded from the figure as they correspond to a form of indirect support. Tax incentives are currently the prevalent form of R\&D support in Canada (www.oecd.org/sti/rd-tax-stats.htm).

32. The approach adopted by the UK Office for National Statistics is part of its redesign of R\&D surveys intended to meet the needs of national accounts to identify the user of the $R \& D$, as will be explained below.

33. BRDIS also provides some information on the size of what might be described as "indirect" R\&D procurement", namely internal business R\&D funding that firms expect to be recouped through federal government contracts. This was estimated to be worth USD 13.9 billion in the 2010 survey.

34. See for example Van Steen (2012).

35. Data on public R\&D contracts were only collected from Belgium, Switzerland, Ireland, Israel and New Zealand.

36. The United Kingdom reported that in order to provide the requested breakdown, a specific question would have to be included in its government R\&D survey.

37. See http://www.statcan.gc.ca/pub/88-204-x/2013001/t004-eng.htm

38. Grants are typically subject to specific conditions and can sometimes be clawed back if these are not met.

39. In the U.S. Small Business Research Initiative, small businesses that receive awards begin a threephase programme, in which the funds support the exploration of the technical merit or feasibility of an idea or technology (phase 1) and R\&D work is performed and the developer evaluates commercialisation potential (phase 2). In the case of the first two phases, the project is entirely funded by the programme and the IP stays with the company, with some limitations, and grants are the main funding instrument. In the third phase, SMEs pursue commercialisation objectives resulting from the previous phase activities. This phase is not supported by SBIR funds, so SMEs must find funding in the private sector or other non-SBIR federal agency funding. While the purchase and testing of precommercial goods and services are exempt from provisions within international agreements such as the WTO's General Procurement Agreement, follow-on purchases should be subject to open bidding. In the case of the United States, an SME exception applies which allows SBIR-participating SMEs to proceed with phase-3 activities, possibly in partnership with the same agency that had initially sponsored the R\&D.

40. The survey of German public organisations was carried out by the Berlin Institute of Technology and cooperation partners in the course of the research project "procuring state" ("Einkäufer Staat"), funded by the German Federal Ministry of Education and Research. A summary of the results is available in German. http://www.vergabe24.de/fileadmin/dateien/Dokumente/Downloads/Studie_Staat_als_Innovationstrei $\underline{\text { ber.pdf }}$

41. Information on Austria's survey of public sector organisations, including the questionnaire, is available at: http://www.statistik.gv.at/web_de/frageboegen/oeffentliche_einrichtungen/innovations_foerdernde_be schaffung/index.html 
42. FPDS-NG (https://www.fpds.gov/fpdsng cms) is a congressional database established to collect historical and statistical information about the government's procurements to understand how and where tax dollars are spent, used to provide data on Freedom of Information Act requests and other inquiries and used to provide the data for the www.USASpending.gov website, a result of the Federal Funding Accountability and Transparency Act of 2006.

43. See http://ted.europa.eu/TED/main/HomePage.do and http://simap.europa.eu/supplier/opportunitiesin-europe/index en.htm. In addition to TED there exist several national repositories of procurement information: http://simap.europa.eu/supplier/national-procurement-databases/index_en.htm.

44. Both current tender opportunities and contract awards can be found on AusTender (https://www.tenders.gov.au/) which generally specifies the contract value and uses the acronym ATM (Approach to Market) to refer to business opportunities advertised by Australian public agencies.

45. GETS (https://buyandsell.gc.ca/opportunities) is hosted by MERX (http://www.merx.com/), which also offers tender information on US federal, state and local government procurement opportunities.

46. http://www.comprasnet.gov.br/; In Brazil, state or municipal tenders are published in the state's official gazette and in a major state or municipality newspaper.

47. For example, administrative procurement data can be used to draw targeted sample frames for investigating specific aspects of policy interest on innovation procurement. Statistical agencies can also potentially investigate the predictive (or now-casting) power of procurement data indicators to build more timely estimates of R\&D investments.

48. When it comes to administrative databases, it is important to be mindful of potential changes in reporting rules which may impact on the interpretation of time trends.

49. As in the case of Canada (Section 4), these figures indicate that federal funds for domestic R\&D received and reported by performers in the business sector only account for a fraction (roughly 65\%) of R\&D federal funds for business as reported in the Federal Funds survey. Various factors, including different interpretations of R\&D, may explain the gap between what firms report and what budget data indicate. A fraction of federally-funded R\&D may be performed abroad by US and non-US firms. Moreover, a share of federal funds for R\&D budgeted in a given fiscal year might be distributed to and subsequently redistributed by governmental agencies at state or local level to recipients, sometimes in a different fiscal year. Aside from administrative or survey errors which may consciously or unintentionally arise, different timings of funding and appropriation/expenditure of $\mathrm{R} \& \mathrm{D}$ funds could also cause the notable divergence in estimates obtained from funder and performerbased R\&D surveys.

50. Official estimates are typically based on the estimation of an "average" award per action within a relevant product code and applying this value to those actions with missing award information.

51. $\quad$ http://www.acquisition.gov/PSC\%20Manual\%20-\%20Final\%20-\%2011\%20August\%202011.pdf

52. Our initial analysis confirms results in the U.S. GSA Top 100 Contractors Report, which lists companies like Lockheed Martin, Boeing, Northrop Grumman, General Dynamics and Raytheon at the very top of contract award recipients.

53. $\quad$ http://simap.europa.eu/codes-and-nomenclatures/codes-cpv/codes-cpv_en.htm

54. The procurement of architectural, construction and engineering services is equally down. 
55. For an example, an exhaustive analysis of procurement databases (TED and other national sources) by Deloitte on behalf of DG Connect identified approximately EUR 2.5 billion worth of R\&D procurement in 2011 for 29 countries (compared with the FPDS figure of USD 55 billion of which USD 45 billion are attributable to business). Some factors point to this being a significant underestimate. In the case of Spain, survey data provided by the National Statistical Institute indicated a total EUR 245 million worth of R\&D contracts received from central and local government. In a recent declaration to the Cour des Comptes, the French Ministry of Defence for the former's 2013 Report on Public Financing of R\&D indicated a total value of EUR 2.4 billion in R\&D contracts. (http://www.dgdr.cnrs.fr/daj/archivactus/2013/juin13/Docs/rapport thematique_financement_public_recherche.pdf)

56. See the US Government Accountability Office discussion of under-reporting and inconsistencies in the federal award website used in this study.

57. For example, all spending transactions over GBP $25 \mathrm{~K}$ made by the UK central government are published monthly by departments on http://data.gov.uk/data.

58. E.g. https://openspending.org/ It includes 673 databases from 66 countries, incl. the UK $25 \mathrm{~K}$ database.

59. The OECD Working Party of the Leading Practitioners on Public Procurement ${ }^{59}$ provides a forum to discuss concerns and ensure continuous improvement in public procurement. To achieve its objectives, it works to develop analytical tools, comparative data and indicators on the performance of public procurement systems and conducting benchmarking and peer reviews of public procurement systems.

60. The string-based matching was carried out using the MTB Merge ToolBox (Version 0.73, German Record Linkage Center; https://www.uni-due.de/soziologie/schnell_forschung_safelink_mtb.php).

61. R\&D contracts are classified based on the first-digit product and service code in FPDS-NG (first-digit PSC code "A" for R\&D).

62. In line with accounting standards, $R \& D$ expenses exclude the value of $R \& D$ paid for by third parties through contracts, but include payments to third parties to carry out R\&D on the company's behalf. 


\section{REFERENCES}

Aschoff, B. and W. Sofka (2009), "Innovation on Demand - Can Public Procurement drive Market Success of Innovations?", Research Policy, Vol.38, 1235-1247.

Audet, D. (2002), "The Size of Government Procurement Markets", OECD Journal on Budgeting, Vol. 2. No. 3, OECD Publishing, Paris.

Bound, K. and R. Puttick (2010), "Buying Power ? Is the Small Business Research Initiative for procuring R\&D driving innovation in the UK ?", NESTA Research report, National Endowment for Science, Technology and the Arts, United Kingdom.

CBI/QinetiQ (2006), "Innovation and Public Procurement - A New Approach to Stimulating Innovation", CBI, London.

CNBS (2007), "Statistics of National Industrial Enterprise Innovation 2007”, China National Bureau of Statistics.

Draca, M. (2012), "Reagan's Innovation Dividend? Technological Impacts of the 1980s US Defence Build-up”, Working Paper, London School of Economics, London.

Edler, J. (2007), "Demand-based Innovation Policy”, Manchester Business School Working Paper, No. 529, Manchester Business School, Manchester.

Edler, J. (2009), "Demand Policies for Innovation in EU CEE Countries", Manchester Business School Working Paper, No. 579, Manchester Business School, Manchester.

Edler, J. and L. Georghiou (2007), "Public Procurement and Innovation - Resurrecting the Demand Side", Research Policy, Vol. 36, 949-963.

Edler, J. et.al. (2011), "Procurement and Innovation: Underpinning the debate", Background Paper, UNDERPINN project, Manchester.

Edler, J. et.al. (2012), "Public procurement and innovation in an evolutionary framework: evidence from public sector suppliers", presentation delivered at the Demand, Innovation and Policy Underpinning Policy Trends with Academic Analysis conference, Manchester Institute for Innovation Research, MBS, University of Manchester, March 22-23, 2012.

Edquist, C. and L. Hommen (2000), "Public Technology Procurement and Innovation Theory." in C., Edquist, L., Hommen and L., Tsipouri (Eds.), Public Technology Procurement and Innovation, Kluwer Academic Publishers, Boston, MA / Dordrecht / London, UK.

Edquist, C. and J.M. Zabala-Iturriagagoitia (2012), "Public Procurement for Innovation as Missionoriented Innovation”, Research Policy, Vol. 41, Issue 10, pp. 1757-1769.

Edquist, C. et.al. (2014), Public Procurement for Innovation, Edward Elgar Publishing, Cheltenham.

Edquist, C. (2015), “Innovation-related Public Procurement as a Demand-oriented Innovation Policy Instrument”. CIRCLE Working Paper 2015/28, Lund University, Sweden: Centre for Innovation, Research and Competence in the Learning Economy.

European Commission (2003), Research Investment Action Plan, European Commission, Brussels.

European Commission (2007), Public Procurement for the Promotion of R\&D and Innovation in ICT, Institute for Prospective Technological Studies, European Commission, Spain. 
European Commission (2011a), "Compilation of Results of the Survey on the Status of Implementation of Pre-Commercial Procurement across Europe", Working document, European Commission, Brussels.

European Commission (2011b), "Public Procurement Indicators 2010", Working document, European Commission, Brussels.

EC, IMF, OECD and World Bank. (2008), The System of National Accounts, 2008 (2008 SNA), European Commission, International Monetary Fund, OECD, United Nations and World Bank, 2009, http://unstats.un.org/unsd/nationalaccount/docs/SNA2008.pdf

Fokus (2013), "Experiences with innovation-related procurement", presentation by the Fraunhofer Institute for Open Communication Systems at the OECD expert workshop on Measuring the link between public procurement, R\&D and innovation, Paris, 4-5 December 2013.

Georghiou, L. et. al. (2013), "Policy instruments for public procurement of innovation: choice, design and assessment", Technological Forecasting and Social Change, Volume 86, July 2014, pp. 112.

Geroski, P.A. (1990), "Procurement policy as a tool of industrial policy", International Review of Applied Economics, Vol. 4 (2), pp. 182-198.

Guerzoni, M. and E. Raiteri (2013), "Innovative public procurement and R\&D subsidies: hidden treatment and new empirical evidence on the technology policy mix", Working Paper, University of Turin, Turin.

Hommen, L. and M. Rolfstam (2009), "Public Procurement and Innovation: Towards a Taxonomy", Journal of Public Procurement, Vol. 9, Issue 1.

Kraan, D., A. Lupi and E. Job (2012), "Manual: Public Finance and Employment Database", OECD Working Papers on Public Governance, No. 20, OECD Publishing, Paris.

Ko, Y. and H. Choe (2011), "Mini Country Report/ South Korea", Thematic Report 2011 under Specific Contract for the Integration of INNO Policy TrendChart with ERAWATCH (20112012).

Lee, W. (2013a), "Impact of Korean innovative procurement policies", report prepared for the OECD expert workshop on Measuring the link between public procurement, R\&D and innovation, 4-5 December 2013, Paris.

Lee, W. (2013b), "Impact of Korean innovative procurement policies", presentation held at the OECD expert workshop on Measuring the link between public procurement, R\&D and innovation, 4-5 December 2013, Paris.

Lember, V., R. Kattel and T. Kalvet (2014), Public Procurement, Innovation and Policy International Perspectives, Springer-Verlag Berlin Heidelberg.

Lerner, J. (1999), "The government as venture capitalist: the long-run impact of the SBIR program", Journal of Business, Vol. 72.

Lichtenberg, F. R. (1988), "The Private R and D Investment Response to Federal Design and Technical Competitions”, American Economic Review, Vol. 78, No. 3, pp. 550-559.

MBS/ICLEI (2012), "Feasibility Study on Future EU Support to Public Procurement of Innovative Solutions: Obtaining Evidence for a Full Scheme", Final Report, Manchester Business School, Manchester.

Mowery, D. C. (2013), "Public Procurement and Innovation in the post-1945 U.S. Economy", Report prepared for the Expert Group on Innovation and Growth, European Commission. 
OECD (2015a), Government at a Glance 2015, OECD Publishing, Paris, DOI: http://dx.doi.org/10.1787/gov_glance-2015-en.

OECD (2015b), The Innovation Imperative: Contributing to Productivity, Growth and Well-Being, OECD Publishing, Paris, DOI: http://dx.doi.org/10.1787/9789264239814-en.

OECD (2015c), Frascati Manual 2015: Guidelines for Collecting and Reporting Data on Research and Experimental Development, The Measurement of Scientific, Technological and Innovation Activities, OECD Publishing, Paris, DOI: http://dx.doi.org/10.1787/9789264239012-en.

OECD (2015d), Recommendation of the Council on Public Procurement. www.oecd.org/gov/ethics/OECD-Recommendation-on-Public-Procurement.pdf

OECD (2015e). "Demand and support for innovation", in OECD Science, Technology and Industry Scoreboard 2015: Innovation for growth and society, OECD Publishing, Paris.

DOI: http://dx.doi.org/10.1787/sti_scoreboard-2015-35-en.

OECD (2014a), Industry and Technology Policies in Korea, OECD Publishing, Paris.

DOI: http://dx.doi.org/10.1787/9789264213227-en.

OECD (2014b), "Intelligent Demand: Policy Rationale, Design and Potential Benefits", OECD Science, Technology and Industry Policy Papers, No. 13, OECD Publishing, Paris. DOI: http://dx.doi.org/10.1787/5jz8p4rk3944-en

OECD (2013), "Strategic public procurement", in Government at a Glance 2013, OECD Publishing, DOI: http://dx.doi.org/10.1787/gov_glance-2013-46-en.

OECD (2012), "Evaluation of STI policies", in OECD. OECD Science, Technology and Industry Outlook 2012, OECD Publishing, Paris. DOI: http://dx.doi.org/10.1787/sti outlook-2012-10-en

OECD (2011a), Demand-side Innovation Policies, OECD Publishing, Paris.

DOI: http://dx.doi.org/10.1787/9789264098886-en

OECD (2011b). Government at a Glance, OECD Publishing, Paris.

DOI: http://dx.doi.org/10.1787/gov_glance-2011-en

OECD (2002), Frascati Manual: Proposed Standard Practice for Surveys on Research and Experimental Development, The Measurement of Scientific and Technological Activities, OECD Publishing, Paris. DOI: http://dx.doi.org/10.1787/9789264199040-en

OECD and Eurostat (2005), Oslo Manual: Guidelines for Collecting and Interpreting Innovation Data, 3rd Edition, The Measurement of Scientific and Technological Activities, OECD Publishing, Paris. DOI: http://dx.doi.org/10.1787/9789264013100-en

Simcoe, T. and M. W. Toffel, M. W.(2013), "Government Green Procurement Spillovers: Evidence from Municipal Building Policies in California", Harvard Business School Working Papers, No. 13-030.

Slavtchev, V. and S. Wiederhold (2012), "Technological Intensity of Government Demand and Innovation", Ifo Working Paper, No. 135.

Starzyńska, W. and A. Borowicz, (2012), "The pro-innovative effect of Poland's public procurement system on the country's economy", paper presented at the Demand, Innovation and Policy. Underpinning Policy Trends with Academic Analysis conference, Manchester Institute of Innovation Research, MBS, University of Manchester, 22-23 March 2012.

Uyarra, E. and K. Flanagan (2010), "Understanding the Innovation Impacts of Public Procurement", European Planning Studies, Vol. 18, No. 1, pp. 123-143. 
Uyarra, E. (2013), "Review of Measures in Support of Public Procurement of Innovation". Nesta Working Papers, 13/17, November 2013, www.nesta.org.uk/wp13-17.

Wallsten, S. (2000), "The effects of government-industry R\&D programmes on private R\&D: the case of the Small Business Innovation Research Program", RAND Journal of Economics, Vol. 31, No. 1.

Young, A. (2001), "Improving Measures of Government Support to Industrial Technology", STI Review No. 27. OECD Publishing, Paris. 


\section{ANNEX}

\section{Description and results from the quantitative case study on data liking and analysing administrative procurement records}

Table 6. Validation of data matching quality: selected examples

A. Top 100 unmatched R\&D reporting firms, USA, 2003-2011

\begin{tabular}{|c|c|c|c|c|}
\hline Ranking & R\&D reporting firms & Searched word & Words found in FPDS-NG & Manual match \\
\hline 1 & ADVANCED MICRO DEVICES INC & MICRO DEVICES, AMD & - & no \\
\hline 2 & BROADCOM CORP & BROADCOM & - & no \\
\hline 3 & GENENTECH INC & GENENTECH & - & no \\
\hline 4 & ELECTRONIC ARTS INC & ELECTRONIC ARTS & ELECTRONIC ARTS INTERMIX IN & no \\
\hline 5 & FREESCALE SEMICONDUCTOR, INC. & FREESCALE & FREESCALE SEMICONDUCTOR INC. & yes \\
\hline 6 & NVIDIA CORP & NVIDIA & - & no \\
\hline 7 & WESTERN DIGITAL CORP & WESTERN DIGITAL & WESTERN DIGITAL VIDEO CORPORATION & no \\
\hline 8 & ACTIVISION BLIZZARD, INC. & ACTIVISION & - & no \\
\hline 9 & SANDISK CORP & SANDISK & - & no \\
\hline 10 & VMWARE, INC. & VMWARE & - & no \\
\hline 30 & FACET BIOTECH CORP & FACET & FACET DECISION SYSTEMS INC, FACET INDUSTRIAL U K LTD & no \\
\hline 31 & SYBASE INC & SYBASE & SYBASE INC & yes \\
\hline 32 & THERAVANCE, INC & THERAVANCE & - & no \\
\hline 33 & MEDAREXINC & MEDAREX & - & no \\
\hline 34 & ZYNGA INC. & ZYNGA & - & no \\
\hline 35 & FAIRCHILD SEMICONDUCTOR INTERNATIONAL INC & FAIRCHILD & FAIRCHILD SEMICONDUCTOR CORPO & yes \\
\hline
\end{tabular}

B. Top 100 unmatched R\&D contractors, USA, 2000-2011

\begin{tabular}{|c|c|c|c|c|}
\hline Ranking & R\&D contractors & Searched word & Words found in company accounts database [comment] & Manual match \\
\hline 1 & LOCKHEED MARTIN CORPORATION & LOCKHEED & - & no \\
\hline 4 & BATTELLE MEMORIAL INSTITUTE INC & MEMORIAL & MEMORIAL PRODUCTION PARTNERS LP & no \\
\hline 6 & MASSACHUSETTS INSTITUTE OF TECHNOLOGY & - & [university] & no \\
\hline 11 & BAE SYSTEMS PLC & BAE & BAE SYSTEMS PLC [GBR is country of headquarter] & no \\
\hline 12 & THE MITRE CORPORATION & MITRE & - & no \\
\hline 13 & GENERAL ELECTRIC COMPANY & ELECTRIC, GE & [several non-matching hits for "ELECTRIC"] & no \\
\hline 31 & STATE OF CALIFORNIA & - & [government] & no \\
\hline 32 & MISCELLANEOUS FOREIGN CONTRACTORS & - & - & no \\
\hline 39 & CARNEGIE MELLON UNIVERSITY & - & [university] & no \\
\hline 43 & ROLLS-ROYCE GROUP PLC & ROLLS & ROLLS-ROYCE GROUP PLC [GBR is country of headquarter] & no \\
\hline 52 & QINETIQ GROUP PLC & QINETIQ & QINETIQ GROUP PLC [GBR is country of headquarter] & no \\
\hline 64 & GOVERNMENT OF THE UNITED STATES & - & [government] & no \\
\hline 68 & UNIVERSITY OF SOUTHERN CALIFORNIA & - & [university] & no \\
\hline 78 & UNIVERSITY OF ARIZONA & - & [university] & no \\
\hline 80 & UTAH STATE UNIVERSITY & - & [university] & no \\
\hline 94 & UNIVERSITY OF WASHINGTON INC & - & [university] & no \\
\hline
\end{tabular}

Notes: The names of the top 100 unmatched R\&D reporting firms (R\&D contractors) in terms of total R\&D expenditures reported by US firms from 2003 to 2011 (total R\&D contract volume awarded from 2000 to 2011) were manually searched in the administrative public contract award (company account) data set to ensure the comprehensiveness and consistency of the company ID and string-based data matching. The top 100 unmatched R\&D reporting firms account for $8.96 \%$ of R\&D reported by US companies between 2003 and 2011 (12.96\% of total R\&D expenditures reported in this period is attributable to unmatched R\&D reporting firms). The top 100 unmatched R\&D contractors account for $50.05 \%$ of the R\&D coded contract volume awarded to US firms between 2000 and 2011 (69.14\% of the R\&D coded procurement volume is attributable to unmatched US and non-US contractors). Contractors received contract awards from US federal government from 2000 to 2011. R\&D contracts are classified based on the first-digit product and service code in FPDS-NG (first-digit PSC code "A" for R\&D).

Source: OECD data linkage and analysis of FPDS-NG contract award data (2000-2011) matched to ORBIS firm-level R\&D and performance and USPTO patent and trademark filing data. FPDS-NG data include modifications. 
Table 7. Description of matched US firm panel data

A. R\&D reported, IP activity, contracting and business performance, 2000-2011

\begin{tabular}{|c|c|c|c|c|c|c|}
\hline & \multicolumn{3}{|c|}{ Contractors } & \multicolumn{3}{|c|}{ Non-contractors } \\
\hline & $\mathrm{N}$ & Mean & Median & $\bar{N}$ & Mean & Median \\
\hline R\&D expenditures (Total value 2003-2011) & 1179 & 1240 & 118 & 1555 & 124 & 8 \\
\hline Turnover (Total value $2000-2011$ ) & 1179 & 25800 & 1070 & 1555 & 1,530 & 25 \\
\hline USPTO patent applications (Total 2000-2011) & 1179 & 215 & 7 & 1555 & 20 & 0 \\
\hline USPTO trademark applications (Total 2000-2010) & 1179 & 36 & 7 & 1555 & 9 & 0 \\
\hline Employees (Number of staff last year reported) & 1020 & 6515 & 567 & 1212 & 643 & 48 \\
\hline Capital assets (Value last year reported) & 1003 & 4460 & 146 & 1555 & 480 & 10 \\
\hline Contract obligations (Total value $2000-2011$ ) & 1179 & 730 & 2 & 1555 & 0 & 0 \\
\hline
\end{tabular}

B. Non-R\&D vs. R\&D coded contract obligations, 2000-2011

\begin{tabular}{|c|c|c|c|c|c|c|c|c|c|c|c|c|}
\hline & \multicolumn{4}{|c|}{ Contract obligations } & \multicolumn{4}{|c|}{ non-R\&D related obligations } & \multicolumn{4}{|c|}{ R\&D related obligations } \\
\hline & $\bar{N}$ & Mean & Median & Total & $\overline{\mathrm{N}}$ & Mean & Median & Total & $\overline{\mathrm{N}}$ & Mean & Median & Total \\
\hline 2000 & 444 & 30.1 & 0.59 & 13400 & 416 & 29.2 & 0.55 & 12100 & 116 & 10.5 & 0.58 & 1300 \\
\hline 2001 & 481 & 45.6 & 0.69 & 21900 & 452 & 40.0 & 0.58 & 18100 & 126 & 30.5 & 0.58 & 3800 \\
\hline 2002 & 538 & 58.7 & 0.61 & 31600 & 499 & 49.0 & 0.45 & 24500 & 138 & 51.6 & 0.71 & 7100 \\
\hline 2003 & 606 & 70.2 & 0.59 & 42600 & 568 & 60.1 & 0.44 & 34100 & 176 & 47.9 & 0.59 & 8500 \\
\hline 2004 & 686 & 82.5 & 0.50 & 56600 & 646 & 71.2 & 0.38 & 4600 & 189 & 56.0 & 0.62 & 52000 \\
\hline 2005 & 755 & 89.8 & 0.49 & 67800 & 723 & 75.4 & 0.33 & 54500 & 236 & 56.2 & 0.46 & 13300 \\
\hline 2006 & 801 & 98.2 & 0.50 & 78700 & 762 & 83.1 & 0.33 & 63300 & 219 & 70.1 & 1.04 & 15400 \\
\hline 2007 & 831 & 118 & 0.58 & 97700 & 795 & 99.8 & 0.37 & 79300 & 243 & 75.8 & 0.92 & 18400 \\
\hline 2008 & 843 & 137 & 0.57 & 116100 & 799 & 119 & 0.42 & 94900 & 229 & 90.8 & 0.85 & 21200 \\
\hline 2009 & 810 & 141 & 0.62 & 114000 & 770 & 121 & 0.49 & 93500 & 237 & 85.7 & 0.63 & 20500 \\
\hline 2010 & 812 & 138 & 0.56 & 112000 & 773 & 120 & 0.44 & 93000 & 232 & 80.8 & 0.54 & 19000 \\
\hline 2011 & 797 & 142 & 0.50 & 113100 & 763 & 126 & 0.42 & 96400 & 207 & 81.1 & 0.43 & 16700 \\
\hline
\end{tabular}

Notes: Contractors received contract awards from the US federal government between 2000 and 2011. R\&D expenditures reported, turnover, capital assets and contract obligations denote USD2005 million. Panel (B): R\&D contracts are classified based on the first-digit product and service code in FPDS-NG (first-digit PSC code "A" for R\&D).

Source: OECD data linkage and analysis of FPDS-NG contract award data (2000-2011) matched to ORBIS firm-level R\&D and performance and USPTO patent and trademark filing data. FPDS-NG data include modifications. 
Table 8. The link between US federal procurement and company-sponsored R\&D

A. Probability of conducting R\&D, 2003-2011

\begin{tabular}{|c|c|c|c|c|c|c|}
\hline & \multicolumn{6}{|c|}{ Conditional FE Logistic regression: $\operatorname{Pr}\left(R \& D_{t}\right)$} \\
\hline & \multicolumn{3}{|c|}{ Coeffients (Odds Ratio) } & \multicolumn{3}{|c|}{ Coeffients (Odds Ratio) } \\
\hline & $(1)$ & $(2)$ & $(3)$ & (1) & (2) & (3) \\
\hline \multirow{2}{*}{ Contract $\operatorname{award}_{\mathrm{t}-1}(0 / 1)$} & 0.962 & 2.152 & & 2.207 & 2.152 & \\
\hline & $(0.489)^{\star \star}$ & $(0.724)^{\star \star \star}$ & & $(0.714)^{\star \star \star}$ & $(0.724)^{\star \star \star}$ & \\
\hline \multirow[t]{2}{*}{$R \& D$ contract award ${ }_{t-1}(0 / 1)$} & & & -1.052 & & & -1.052 \\
\hline & & & $(1.400)$ & & & $(1.400)$ \\
\hline \multirow[t]{2}{*}{ Non $R \& D$ contract award $t-1(0 / 1)$} & & & 2.238 & & & 2.238 \\
\hline & & & $(0.754)^{\star \star \star}$ & & & $(0.754)^{\star \star \star}$ \\
\hline \multirow[t]{2}{*}{ Log(employees $\left.{ }_{\mathrm{t}-1}\right)$} & & 0.496 & 0.501 & & 0.496 & 0.501 \\
\hline & & $(0.158)^{\star \star \star}$ & $(0.158)^{\star \star \star}$ & & $(0.158)^{\star \star \star}$ & $(0.158)^{\star \star \star}$ \\
\hline \multirow[t]{2}{*}{ Log(capital assets $\left.{ }_{t-1}\right)$} & & 0.086 & 0.084 & & 0.086 & 0.084 \\
\hline & & $(0.078)$ & $(0.078)$ & & $(0.078)$ & $(0.078)$ \\
\hline Year trends & Yes & Yes & Yes & Yes & Yes & Yes \\
\hline Number of observations $(\mathrm{N})$ & 1937 & 704 & 704 & 704 & 704 & 704 \\
\hline Number of firms (G) & 393 & 137 & 137 & 137 & 137 & 137 \\
\hline Prob > chi2 & $<0.001$ & $<0.001$ & $<0.001$ & $<0.001$ & $<0.001$ & $<0.001$ \\
\hline
\end{tabular}

Notes: Standard errors clustered by firm in parentheses. The dummy variable R\&D denotes 1 if the amount of company-sponsored $R \& D$ expenditures reported by firm i in year $t$ is positive and 0 otherwise. The analysis is confined to contractors and non-contractors for which a switch in R\&D activity can be observed.

B. R\&D expenditures conditional on having contract awards, 2003-2011

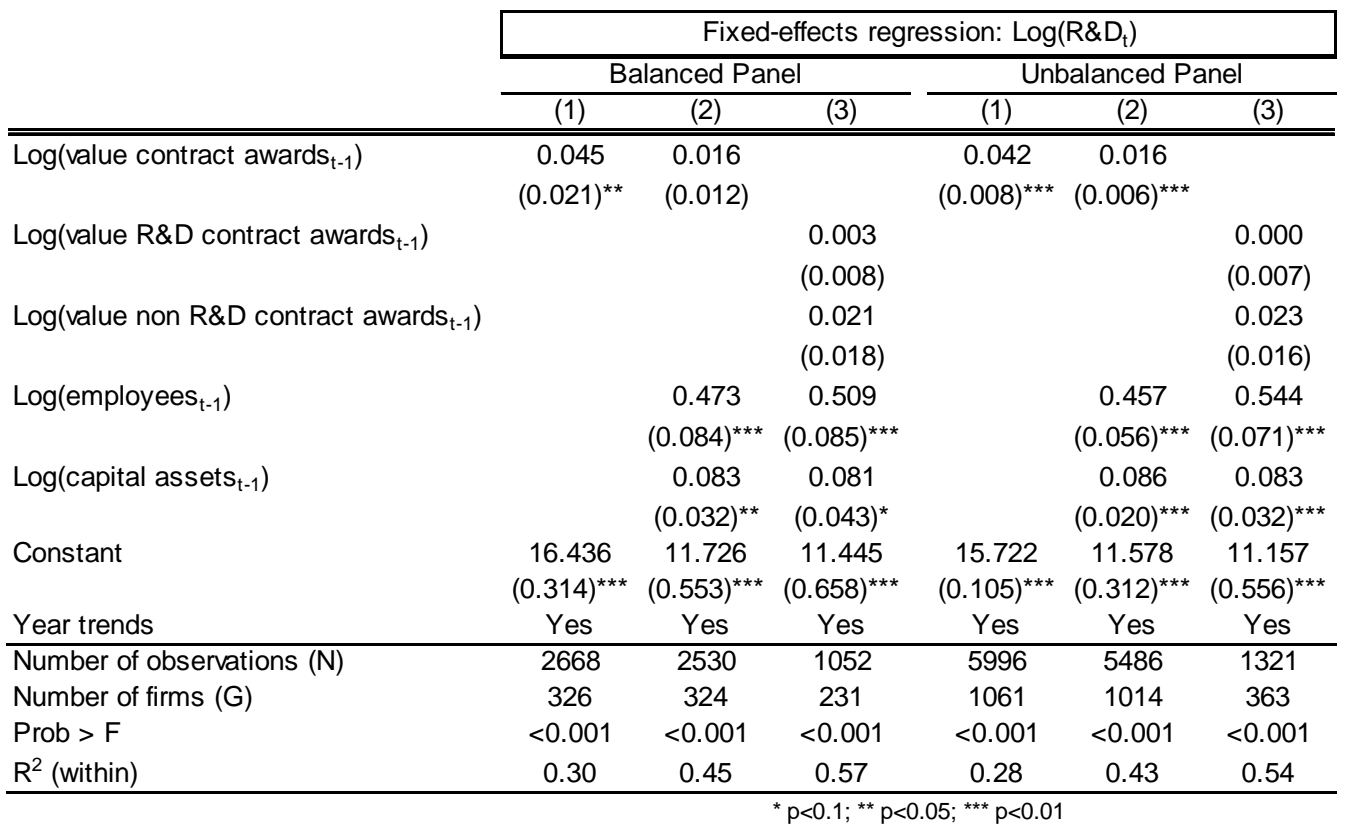

Notes: Standard errors robust to heteroskedasticity and clustered by firm in parentheses. The dependent variable represents the log of company-sponsored R\&D expenditures reported by firm $i$ in year t. The analysis is confined to firms that received contract awards from the US federal government. The balanced panel consists of firms that supplied to the US federal government in every year from 2000 to 2011 (326 firms), while the unbalanced panel includes all contractors that obtained contract awards between 2000 and 2011, independent of the award frequency.

Source: OECD data linkage and analysis of FPDS-NG contract award data (2000-2011) matched to ORBIS firm-level R\&D and performance and USPTO patent and trademark filing data. FPDS-NG data include modifications. 
Table 9. The link between US federal procurement and IP filings

A. Patent applications USPTO conditional on having contract awards, 2000-2011

\begin{tabular}{|c|c|c|c|c|c|c|}
\hline & \multicolumn{6}{|c|}{ Conditional FE negative binomial regression: Count $\left(\mathrm{PAT}_{\mathrm{t}}\right)$} \\
\hline & \multicolumn{3}{|c|}{ Balanced Panel } & \multicolumn{3}{|c|}{ Unbalanced Panel } \\
\hline & $(1)$ & (2) & (3) & $(1)$ & $(2)$ & (3) \\
\hline \multirow{2}{*}{ Log(value contract awards $\mathrm{t}_{\mathrm{t}-1}$ ) } & 0.033 & -0.011 & -0.014 & 0.028 & 0.004 & 0.002 \\
\hline & $(0.011)^{\star \star \star}$ & $(0.013)$ & $(0.014)$ & $(0.007)^{\star \star \star}$ & $(0.008)$ & $(0.009)$ \\
\hline \multirow[t]{2}{*}{ Log(employees $\left.\mathrm{t}_{\mathrm{t}-1}\right)$} & & 0.179 & 0.123 & & 0.122 & 0.104 \\
\hline & & $(0.043)^{\star \star \star}$ & $(0.055)^{\star \star}$ & & $(0.032)^{\star \star \star}$ & $(0.040)^{\star \star \star}$ \\
\hline \multirow[t]{2}{*}{$\log \left(\right.$ capital assets $\left._{\mathrm{t}-1}\right)$} & & -0.003 & -0.014 & & 0.024 & 0.001 \\
\hline & & $(0.030)$ & $(0.033)$ & & $(0.022)$ & $(0.024)$ \\
\hline \multirow[t]{2}{*}{$\log \left(R \& D\right.$ expenditures $\left.t_{t-1}\right)$} & & & 0.118 & & & 0.109 \\
\hline & & & $(0.043)^{\star \star \star}$ & & & $(0.032)^{\star \star *}$ \\
\hline \multirow[t]{2}{*}{ Constant } & 0.713 & 0.718 & -1.755 & 0.779 & -0.075 & -1.867 \\
\hline & $(0.176)^{\star \star \star}$ & (0.528) & $(0.675)^{\star \star \star}$ & $(0.114)^{\star \star \star}$ & (0.381) & $(0.484)^{\star \star \star}$ \\
\hline Year trends & Yes & Yes & Yes & Yes & Yes & Yes \\
\hline Number of observations (N) & 2771 & 2109 & 1729 & 5145 & 4075 & 3456 \\
\hline Number of firms (G) & 254 & 248 & 237 & 638 & 602 & 571 \\
\hline Prob > chi2 & $<0.001$ & $<0.001$ & $<0.001$ & $<0.001$ & $<0.001$ & $<0.001$ \\
\hline
\end{tabular}

Notes: Standard errors clustered by firm in parentheses. The dependent variable is the count of patent applications filed by firm $i$ in year $t$ at the US patent and trademark office (USPTO). The analysis is confined to firms that obtained contract awards from US federal government and changed their patenting activity over time. The balanced panel consists of firms that supplied to US federal government in every year from 2000 to 2011, while the unbalanced panel includes all contractors that obtained contract awards between 2000 and 201,1 independent of the award frequency.

B. Trademark applications USPTO conditional on having contract awards, 2000-2010

\begin{tabular}{|c|c|c|c|c|c|c|}
\hline & \multicolumn{6}{|c|}{ Conditional FE negative binomial regression: Count $\left(\mathrm{TM}_{\mathrm{t}}\right)$} \\
\hline & \multicolumn{3}{|c|}{ Balanced Panel } & \multicolumn{3}{|c|}{ Unbalanced Panel } \\
\hline & $(1)$ & $(2)$ & $(3)$ & $(1)$ & $(2)$ & (3) \\
\hline \multirow[t]{2}{*}{ Log(value contract awards $t_{t-1}$ ) } & 0.096 & 0.049 & & 0.088 & 0.021 & \\
\hline & $(0.015)^{\star \star \star}$ & $(0.022)^{\star \star}$ & & $(0.010)^{\star \star \star}$ & $(0.014)$ & \\
\hline \multirow[t]{2}{*}{ Log(value R\&D contract awards $\mathrm{t}_{\mathrm{t}-1}$ ) } & & & -0.011 & & & -0.003 \\
\hline & & & (0.021) & & & $(0.020)$ \\
\hline \multirow[t]{2}{*}{ Log(value non $R \& D$ contract awards $\left.t_{t-1}\right)$} & & & 0.078 & & & 0.060 \\
\hline & & & $(0.039)^{\star \star}$ & & & $(0.037)$ \\
\hline \multirow[t]{2}{*}{ Log(employees $\left.{ }_{\mathrm{t}-1}\right)$} & & 0.177 & -0.069 & & 0.176 & 0.013 \\
\hline & & $(0.087)^{\star \star}$ & $(0.141)$ & & $(0.057)^{\star \star \star}$ & $(0.124)$ \\
\hline \multirow[t]{2}{*}{ Log(capital assets $\left.\mathrm{t}_{-1}\right)$} & & 0.077 & 0.223 & & 0.044 & 0.196 \\
\hline & & $(0.057)$ & $(0.095)^{\star \star}$ & & $(0.038)$ & $(0.087)^{\star \star}$ \\
\hline \multirow[t]{2}{*}{$\log \left(R \& D\right.$ expenditures $\left.t_{t-1}\right)$} & & 0.014 & 0.014 & & 0.028 & 0.021 \\
\hline & & $(0.089)$ & (0.089) & & (0.041) & $(0.084)$ \\
\hline \multirow[t]{2}{*}{ Constant } & -1.234 & -3.873 & -4.896 & -1.213 & -2.876 & -5.080 \\
\hline & $(0.263)^{\star \star \star}$ & $(0.870)^{\star \star \star}$ & $(1.471)^{\star \star \star}$ & $(0.166)^{\star \star \star}$ & $(0.594)^{\star \star \star}$ & $(1.386)^{\star \star \star}$ \\
\hline Year trends & Yes & Yes & Yes & Yes & Yes & Yes \\
\hline Number of observations $(\mathrm{N})$ & 2525 & 1502 & 634 & 4440 & 2811 & 711 \\
\hline Number of firms (G) & 254 & 231 & 133 & 588 & 506 & 156 \\
\hline Prob > chi2 & $<0.001$ & $<0.001$ & $<0.001$ & $<0.001$ & $<0.001$ & $<0.001$ \\
\hline
\end{tabular}

Notes: Standard errors clustered by firm in parentheses. The dependent variable is the count of trademark applications filed by firm $i$ in year $t$ at the USPTO. The analysis is confined to firms that received contract awards from the US federal government and changed their trademarking activity over time. The balanced panel consists of firms that supplied to the US federal government in every year from 2000 to 2011, while the unbalanced panel includes all contractors that obtained contract awards between 2000 and 2011, independent of the award frequency.

Source: OECD data linkage and analysis of FPDS-NG contract award data (2000-2011) matched to ORBIS firmlevel R\&D and performance and USPTO patent and trademark filing data. FPDS-NG data include modifications. 
Table 10. The link between US federal procurement and firm turnover

Turnover conditional on having contract awards, 2000-2011

\begin{tabular}{|c|c|c|c|c|c|c|}
\hline & \multicolumn{6}{|c|}{ Fixed-effects regression: Log(Turnover ${ }_{t}$ ) } \\
\hline & \multicolumn{3}{|c|}{ Balanced Panel } & \multicolumn{3}{|c|}{ Unbalanced Panel } \\
\hline & (1) & $(2)$ & (3) & (1) & $(2)$ & (3) \\
\hline \multirow[t]{2}{*}{ Log(value contract awards $\left.\mathrm{t}_{\mathrm{t}-1}\right)$} & 0.077 & 0.036 & & 0.056 & 0.027 & \\
\hline & $(0.026)^{\star \star \star}$ & $(0.018)^{\star}$ & & $(0.009)^{\star \star \star}$ & $(0.007)^{\star \star \star}$ & \\
\hline \multirow[t]{2}{*}{ Log(value R\&D contract awards $\mathrm{t}_{\mathrm{t}-1}$ ) } & & & 0.005 & & & -0.004 \\
\hline & & & $(0.007)$ & & & $(0.007)$ \\
\hline \multirow[t]{2}{*}{ Log(value non R\&D contract awards $\mathrm{t}_{\mathrm{t}-1}$ ) } & & & 0.016 & & & 0.023 \\
\hline & & & $(0.010)$ & & & $(0.013)^{\star}$ \\
\hline \multirow[t]{2}{*}{ Log(employees $\left.{ }_{t-1}\right)$} & & 0.567 & 0.494 & & 0.535 & 0.605 \\
\hline & & $(0.088)^{\star \star \star}$ & $(0.066)^{\star \star \star}$ & & $(0.059)^{\star \star \star}$ & $(0.152)^{\star \star \star}$ \\
\hline \multirow[t]{2}{*}{ Log(capital assets $\left.\mathrm{t}_{-1}\right)$} & & 0.104 & 0.128 & & 0.077 & 0.097 \\
\hline & & $(0.029)^{\star \star \star}$ & $(0.039)^{\star \star \star}$ & & $(0.021)^{\star \star \star}$ & $(0.033)^{\star \star \star}$ \\
\hline \multirow[t]{2}{*}{ Constant } & 18.576 & 13.247 & 14.129 & 17.949 & 13.634 & 13.021 \\
\hline & $(0.470)^{\star \star \star}$ & $(0.647)^{\star \star *}$ & $(0.585)^{\star \star \star}$ & $(0.208)^{\star \star \star}$ & $(0.369)^{\star \star \star}$ & $(1.056)^{\star \star \star}$ \\
\hline Year trends & Yes & Yes & Yes & Yes & Yes & Yes \\
\hline Number of observations $(\mathrm{N})$ & 3133 & 2711 & 1102 & 6745 & 5838 & 1390 \\
\hline Number of firms (G) & 326 & 324 & 234 & 1080 & 1029 & 373 \\
\hline Prob > F & $<0.001$ & $<0.001$ & $<0.001$ & $<0.001$ & $<0.001$ & $<0.001$ \\
\hline $\mathrm{R}^{2}$ (within) & 0.45 & 0.62 & 0.73 & 0.36 & 0.52 & 0.63 \\
\hline
\end{tabular}

Turnover net of contract obligations conditional on having contract awards, 2000-2011

\begin{tabular}{|c|c|c|c|c|c|c|}
\hline & \multicolumn{6}{|c|}{ Fixed-effects regression: Log(Private sector turnover $_{t}$ ) } \\
\hline & \multicolumn{3}{|c|}{ Balanced Panel } & \multicolumn{3}{|c|}{ Unbalanced Panel } \\
\hline & (1) & $(2)$ & (3) & (1) & (2) & (3) \\
\hline \multirow[t]{2}{*}{ Log(value contract awards $\left.\mathrm{t}_{\mathrm{t}-1}\right)$} & 0.048 & 0.013 & & 0.043 & 0.015 & \\
\hline & $(0.019)^{\star \star}$ & $(0.013)$ & & $(0.008)^{\star \star \star}$ & $(0.006)^{\star \star}$ & \\
\hline \multirow[t]{2}{*}{ Log(value R\&D contract awards $s_{t-1}$ ) } & & & -0.000 & & & -0.007 \\
\hline & & & $(0.007)$ & & & $(0.007)$ \\
\hline \multirow[t]{2}{*}{ Log(value non R\&D contract awards $t_{t-1}$ ) } & & & 0.011 & & & 0.026 \\
\hline & & & $(0.017)$ & & & (0.019) \\
\hline \multirow[t]{2}{*}{ Log(employees $\left.\mathrm{t}_{-1}\right)$} & & 0.516 & 0.516 & & 0.515 & 0.618 \\
\hline & & $(0.052)^{\star \star \star}$ & $(0.077)^{\star \star \star}$ & & $(0.042)^{\star \star \star}$ & $(0.122)^{\star \star \star}$ \\
\hline \multirow[t]{2}{*}{$\log \left(\right.$ capital assets $\left._{\mathrm{t}-1}\right)$} & & 0.109 & 0.148 & & 0.087 & 0.076 \\
\hline & & $(0.022)^{\star \star \star}$ & $(0.041)^{\star \star \star}$ & & $(0.017)^{\star \star \star}$ & $(0.040)^{\star}$ \\
\hline \multirow[t]{2}{*}{ Constant } & 18.913 & 13.827 & 13.604 & 18.073 & 13.731 & 13.203 \\
\hline & $(0.325)^{\star \star \star}$ & $(0.485)^{\star \star \star}$ & $(0.606)^{\star \star \star}$ & $(0.163)^{\star \star \star}$ & $(0.294)^{\star \star \star}$ & $(0.954)^{\star \star \star}$ \\
\hline Year trends & Yes & Yes & Yes & Yes & Yes & Yes \\
\hline Number of observations $(\mathrm{N})$ & 3099 & 2689 & 1091 & 6660 & 5777 & 1369 \\
\hline Number of firms (G) & 326 & 324 & 232 & 1081 & 1028 & 369 \\
\hline Prob $>$ F & $<0.001$ & $<0.001$ & $<0.001$ & $<0.001$ & $<0.001$ & $<0.001$ \\
\hline $\mathrm{R}^{2}$ (within) & 0.44 & 0.60 & 0.66 & 0.37 & 0.52 & 0.60 \\
\hline
\end{tabular}

Notes: Standard errors robust to heteroskedasticity and clustered by firm in parentheses. The dependent variable represents the log of firm l's turnover net of government contract obligations in year t. The analysis is confined to firms that obtained contract awards from the US federal government. The balanced panel consists of firms that supplied to the US federal government in every year from 2000 to 2011 (326 firms), while the unbalanced panel includes all contractors that obtained contract awards between 2000 and 2011, independent of the award frequency.

Source: OECD data linkage and analysis of FPDS-NG contract award data (2000-2011) matched to ORBIS firm-level R\&D and performance and USPTO patent and trademark filing data. FPDS-NG data include modifications. 